UNIVERSIDADE DE SÃO PAULO

FACULDADE DE MEDICINA DE RIBEIRÃO PRETO

DEPARTAMENTO DE FISIOLOGIA

PROGRAMA DE PÓS-GRADUAÇÃO EM FISIOLOGIA

ADRIELI OLIVEIRA RAMINELLI

Modelos experimentais para o estudo do transtorno obsessivo compulsivo: perspectivas e limitações 


\author{
UNIVERSIDADE DE SÃO PAULO \\ FACULDADE DE MEDICINA DE RIBEIRÃO PRETO \\ DEPARTAMENTO DE FISIOLOGIA \\ PROGRAMA DE PÓS-GRADUAÇÃO EM FISIOLOGIA
}

\title{
Modelos experimentais para o estudo do transtorno obsessivo compulsivo: perspectivas e limitações
}

\author{
Dissertação apresentada como requisito à obtenção do \\ título de Mestre em Ciências com enfâse em \\ Fisiologia, no Programa de Pós-Graduação em \\ Fisiologia, Faculdade de Medicina de Ribeirão Preto, \\ Universidade de São Paulo.
}

Orientador: Prof. Dr. Norberto Garcia Cairasco

Ribeirão Preto

2020 
Autorizo a reprodução e divulgação total ou parcial deste trabalho, por qualquer meio convencional ou eletrônico, para fins de estudo e pesquisa, desde que citada a fonte.

\section{FICHA CATALOGRÁFICA}

Raminelli, Adrieli Oliveira

Modelos experimentais para o estudo do transtorno obsessivo compulsivo: perspectivas e limitações. Ribeirão Preto, 2020.

94 p. : il. ; $30 \mathrm{~cm}$

Dissertação de Mestrado, apresentada à Faculdade de Medicina de Ribeirão Preto/USP. Área de concentração: Fisiologia.

Orientador: Garcia-Cairasco, Norberto.

1. Transtorno Obsessivo Compulsivo. 2. Modelos animais. 3.

Grooming. 4. Ocitocina. 


\title{
FOLHA DE APROVAÇÃO
}

\author{
Adrieli Oliveira Raminelli
}

\section{Modelos experimentais para o estudo do transtorno obsessivo compulsivo: perspectivas e limitações}

Dissertação apresentada como requisito à obtenção do título de Mestre em Ciências com enfâse em Fisiologia, no Programa de Pós-Graduação em Fisiologia, Faculdade de Medicina de Ribeirão Preto, Universidade de São Paulo.

Orientador: Prof. Dr. Norberto Garcia Cairasco

Aprovado em:

Banca Examinadora

Prof. (a) Dr. (a):

Instituição:

Julgamento:

Prof. (a) Dr. (a):

Instituição:

Julgamento:

Prof. (a) Dr. (a):

Instituição:

Julgamento: 
Dedico este trabalho À MINHA FAMÍLIA, e a todos que sofrem por causa de algum transtorno psiquiátrico. 


\section{AGRADECIMENTOS}

A Deus, que sempre me deu forças em todos os momentos desta minha jornada. Obrigada por ser meu amparo.

À minha amada família, Valter Luiz, Ivani e Luiz Fernando, que sempre estiveram ao meu lado, incentivando todos os meus sonhos e acreditando na minha capacidade. Obrigada por tanto amor, respeito e sobretudo pela compreensão.

Aos meus padrinhos, Edson e Lourdes, e aos meus primos, Larissa e Felipe, que me acompanharam nesta jornada, com boas conversas, sorrisos. Obrigada pela paciência, carinho, e por dividirem o lar comigo.

Ao Professor Norberto Garcia-Cairasco, meu orientador, e grande incentivador, que me auxiliou durante a realização deste trabalho, sempre com muito entusiasmo e alegria. Seus ensinamentos me fizeram uma profissional melhor. Obrigada por ter aberto as portas do LNNE a mim, possibilitando a realização deste sonho.

Às amigas Polianna Delfino e Ana Luiza Donatti, por terem me recebido com tanto carinho. Obrigada pela paciência, ensinamentos e amizade.

Aos amigos Suélen e Jordan, por terem contribuído para o meu crescimento acadêmico. Obrigada pela paciência, amizade, palavras de incentivo e pelo carinho para comigo e com meu trabalho.

Aos membros do meu querido LNNE e amigos de outros laboratórios, obrigada pela amizade, vocês se tornaram parte da minha família. Sou imensamente grata por todas as conversas, abraços, e por todo o apoio, que foi essencial! A vocês toda minha admiração e amor.

Aos Técnicos José Antônio, Flavio Del Vecchio e Rubens Melo, que se tornaram grandes amigos. Obrigada pelas conversas, amizade, paciência e por contribuírem com este trabalho. Minha eterna gratidão!

Ao Professor Claudio M. Costa-Neto, e a os membros do seu laboratório por todo apoio e conhecimento compartilhado. 
Ao Professor José Antunes Rodrigues, e a os membros do seu laboratório pelo suporte e contribuições científicas.

Ao Professor Edson Z. Martinez, pela colaboração e orientação de nossas análises estatísticas.

À Professora Rosangela Chriguer, que sempre me incentivou a realizar meus sonhos. Obrigada pelo carinho, paciência e amizade.

Aos amigos, Adriana Fortunato e Julio César Pascoalotti que sempre me acolheram com doces palavras que acalmavam meu coração e o enchiam de ânimo e esperança.

Às amigas, Bruna Loria Garcia, Bianca Ligabó e Luiza Ferreira, obrigada pelas palavras de incentivo, carinho e pela amizade que só se fortalece ao longo dos anos.

À Universidade de São Paulo, pela oportunidade de aprimorar meu conhecimento e realizar este trabalho.

À Coordenação de Aperfeiçoamento de Pessoal de Nível Superior - CAPES e ao Conselho Nacional de Desenvolvimento Científico e Tecnológico - CNPq, pelo apoio financeiro que possibilitou a realização deste estudo. 
“Todo grande sonho começa com um sonhador. Lembre-se sempre que você tem consigo a força, a paciência e a paixão para alcançar as estrelas e mudar o mundo."

Harriet Tubman 
Apoio financeiro:

- Coordenação de Aperfeiçoamento de Pessoal de Nível Superior (CAPES) - O presente trabalho foi realizado com apoio da Coordenação de Aperfeiçoamento de Pessoal de Nível Superior - Brasil (CAPES) - Código de Financiamento 001.

- Conselho Nacional de Desenvolvimento Científico e Tecnológico (CNPq) - O presente trabalho foi realizado com apoio do Conselho Nacional de Desenvolvimento Científico e Tecnológico - Brasil (CNPq).

- Fundação de Assistência ao Ensino e Pesquisa (FAEPA) do Hospital das Clínicas da Faculdade de Medicina de Ribeirão Preto da Universidade de São Paulo.

- Pró-Reitoria de Pós-Graduação da Universidade de São Paulo. 


\section{RESUMO}

RAMINELLI, Adrieli Oliveira 2020. Modelos experimentais para o estudo do transtorno obsessivo compulsivo: perspectivas e limitações. Dissertação (Mestrado em Fisiologia) Faculdade de Medicina de Ribeirão Preto, Universidade de São Paulo, Ribeirão Preto, 2020.

O transtorno obsessivo compulsivo (TOC) é caracterizado por obsessões e/ou compulsões, que acometem cerca de 2 a $3 \%$ da população geral. Apesar do TOC ser um transtorno bastante conhecido, sua etiologia continua a ser questionada. Dentre as obsessões e comportamentos compulsivos mais comuns estão o medo excessivo de contaminação e a limpeza excessiva. $\mathrm{O}$ indivíduo com TOC realiza rituais a fim de minimizar a ansiedade que as obsessões causam. Contudo, na maioria dos casos, isso torna-se um ciclo difícil de ser interrompido. Além disso, foi descrito que eventos estressantes podem estar relacionados à gravidade dos sintomas obsessivos-compulsivos, e inclusive anteceder o TOC. Neste contexto, na tentativa de compreender o que influencia e causa os sintomas obsessivos-compulsivos, o uso de modelos animais com o objetivo de mimetizar doenças observadas em humanos, tem se tornado cada vez mais comuns. Estudos demonstraram que a autolimpeza (grooming), comportamento inato dos animais, está envolvido na manutenção de processos fisiológicos. Entretanto, o mesmo pode ser modificado a ponto de tornar-se patológico. Este comportamento pode ser alterado através de drogas e neuropeptídios como a ocitocina (OT). A OT é sintetizada nos núcleos paraventriculares (PVN) e supraópticos do hipotálamo (SON) e pode estar envolvida em funções neuroendócrinas como a lactação e a contração uterina. Estudos apontaram que a microinjeção de OT no núcleo central da amígdala (CeA) de ratos machos Wistar e aqueles da linhagem Wistar Audiogenic Rat (WAR), modelo genético de epilepsia, induziu o comportamento de limpeza exacerbada ou hypergrooming em roedores. Além da OT, existem outros modelos farmacológicos e genéticos que também induzem comportamentos repetitivos com a finalidade de compreender os comportamentos observados em pacientes com TOC. Os modelos animais têm sido utilizados a fim de verificar semelhanças entre estruturas cerebrais, neurotransmissores, e aspectos moleculares que sejam comuns a animais de experimentação e humanos, o que possibilitem a descoberta de possíveis causas para a fisiopatologia do TOC. Contudo, o desafio está em produzir um modelo animal que atenda a três requisitos: validade de face, validade de constructo e validade preditiva. Logo, estudos consideram que ainda não exista modelo animal capaz de modelar completamente patologias humanas, porém, pesquisas pré-clínicas são indispensáveis para o conhecimento de doenças e de seus tratamentos. Logo, o objetivo desse estudo é analisar diferentes modelos animais utilizados no estudo do TOC, e verificar quais são as vantagens e as limitações que eles apresentam.

Palavras-Chave: Transtorno Obsessivo Compulsivo, Modelos Animais, Grooming, Ocitocina 


\begin{abstract}
RAMINELLI, Adrieli Oliveira. 2020. Experimental models for the study of obsessive compulsive disorder: perspectives and limitations. Dissertação (Mestrado em Fisiologia) Faculdade de Medicina de Ribeirão Preto, Universidade de São Paulo, Ribeirão Preto, 2020.

Obsessive compulsive disorder (OCD) is characterized by obsessions and / or compulsions, which affect about 2 - 3\% of the general population. Although OCD is a well-known disorder, its etiology remains to be questioned. Among the most common obsessions and compulsive behaviors are excessive fear of contamination and excessive cleaning. The individual with OCD performs rituals in order to minimize the anxiety that obsessions cause. However, in mostly cases, this becomes a difficult cycle to disrupt. In addition, has been described that stressful events may be related to the severity of obsessive-compulsive symptoms, and even precede OCD. In this context, in an attempt to understand what influences and causes obsessive-compulsive symptoms, the use of animal models in order to mimic diseases observed in humans, has become increasingly common. Studies have shown that selfcleaning, the innate behavior of animals, is involved in the maintenance of physiological processes. However, it can be modified becoming pathological. This behavior can be administration drugs and neuropeptides such as oxytocin (OXT). OXT is synthesized in the paraventricular (PVN) and supraoptic nuclei of the hypothalamus (SON) and may be involved in neuroendocrine functions such as lactation and uterine contraction. Studies elucidates that microinjection of OT in the central amygdala nucleus $(\mathrm{CeA})$ of male Wistar rats and Wistar Audiogenic Rat (WAR) strain, a genetic model of epilepsy, induced exacerbated cleaning or hypergrooming behavior. In addition to OT, there are other pharmacological and genetic models that also induce repetitive behaviors in order to understand the behaviors observed in patients with OCD. Animal models have been used in order to verify similarities between brain structures, neurotransmitters, and molecular aspects that are common to experimental animals and humans, which help the discovery of possible causes for the pathophysiology of OCD. However, the challenge is to produce an animal model that meets three requirements: face validity, construct validity and predictive validity. Therefore, studies consider the absence of animal model able to completely modeling human pathologies, however, preclinical research is indispensable for the knowledge of diseases and their treatments. Therefore, the objective of this study is to analyze different animal models used in the study of OCD, and to verify what are the advantages and limitations that they present.
\end{abstract}

Key-Words: Obsessive Compulsive Disorder, Animals Model, Groooming, Oxytocin 


\section{LISTA DE FIGURAS}

Figura 1 - Loop do Transtorno Obsessivo Compulsivo.

Figura 2 - Índice de autolimpeza dos grupos Naive (círculo preto, n=10), Veículo (quadrado azul, $\mathrm{n}=6$ ) e Ocitocina $10 \mu \mathrm{g} / \mu \mathrm{l}$ (triângulo vermelho, $\mathrm{n}=5$ ) sem estressor. 31

Figura 3 - Papel central do circuito CETC no transtorno obsessivo-compulsivo em humanos e comportamentos compulsivo-repetitivos em roedores. .40 


\section{LISTA DE TABELAS}

Tabela 1 - Manifestações clínicas do Transtorno Obsessivo Compulsivo em humanos e comportamentos animais que se assemelham. 


\section{LISTA DE ABREVIATURAS E SIGLAS}

ACTH: Hormônio adrenocorticotrópico

AVP: $\quad$ Vasopressina

AVPR1A: Receptor de vasopressina 1A

AVPR1B: Receptor de vasopressina 1B

AVPR2: $\quad$ Receptor de vasopressina 2

AVPR3: $\quad$ Receptor de vasopressina 3

BHH: Barreira hematoencefálica

CeA: $\quad$ Núcleo central da amígdala

CETC: Córtico-estriado-tálamo-cortical

COF: $\quad$ Córtex órbito frontal

CRH: Hormônio liberador de corticotrofina

DSM-V: Manual Diagnóstico e Estatístico de Transtornos Mentais V

ERP: $\quad$ Exposição e prevenção de resposta

FOCI: $\quad$ Florida Obsessive Compulsive Inventory

H: $\quad$ Horas

HPA: Hipotálamo-hipófise-adrenal

ISRS: Inibidores seletivos da recaptação de serotonina

Min: $\quad$ Minuto

MBT: $\quad$ Marble Burying Test

mCPP: $\quad$ Meta-chlorophenylpiperazine

NAc: $\quad$ Núcleo accumbens

OCI-SV: $\quad$ Obsessive-Compulsive Inventory, Short Version

OT: $\quad$ Ocitocina

OTr: Receptor de Ocitocina 
PVN: Núcleo Paraventricular do Hipotálamo

Seg: $\quad$ Segundos

SN: $\quad$ Substantia nigra (ou Substância negra)

SON: Núcleo Supraóptico

SNC: $\quad$ Sistema Nervoso Central

TCC: $\quad$ Terapia cognitiva-comportamental

TOC: $\quad$ Transtorno Obsessivo Compulsivo

WAR: Wistar Audiogenic Rat

Y-BOCS: Yale-Brown Obsessive-Compulsive Scale

$\mu \mathrm{g}: \quad$ Micrograma

$\mu \mathrm{L}: \quad$ Microlitro

mU/min: Miliunidades por minuto

nL: $\quad$ Nanolitro

5-HT: 5-Hidroxitriptamina

5-HT1 ${ }_{\mathrm{A}}$ : 5-Hidroxitriptamina $1 \mathrm{~A}$

5-HT1 1 : 5-Hidroxitriptamina 1B

5-HT1C: 5-Hidroxitriptamina $1 \mathrm{C}$

5-HT1 1 5-Hidroxitriptamina 1D

5-HT2 ${ }_{\mathrm{C}}$ : 5-Hidroxitriptamina $2 \mathrm{C}$

8-OH-DPAT: 8-hidroxi-2- (di-n-propilamino) -tetralina 


\section{SUMÁRIO}

Capítulo 1: O efeito da ocitocina e de suas variantes Prolina ${ }^{8}$-Ocitocina $\operatorname{Pro}^{8} \mathrm{OXT}$ e Valina ${ }^{3}$ Prolina ${ }^{8}$-Ocitocina $\left(\mathrm{Val}^{3} \mathrm{Pro}^{8} \mathrm{OXT}\right)$ no comportamento de autolimpeza ( grooming)... 17

1.1. Condições desfavoráveis que inviabilizaram o projeto ...........................................26

Capítulo 2: Projeto alternativo. Relação entre compulsão, estresse e ocitocina ..................... 27

1. Problemas que impediram a continuidade e finalização dos protocolos experimentais. ..32

Capítulo 3: Revisão crítica da literatura sobre modelos experimentais de transtorno obsessivo compulsivo

1. Introdução

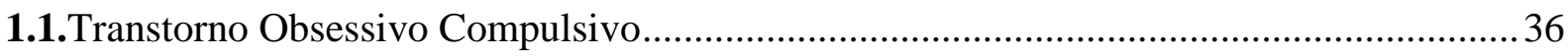

2. Análise do comportamento compulsivo através de modelos animais .............................43

2.1. Ferramentas comportamentais utilizadas para a validação de modelos animais de TOC.45

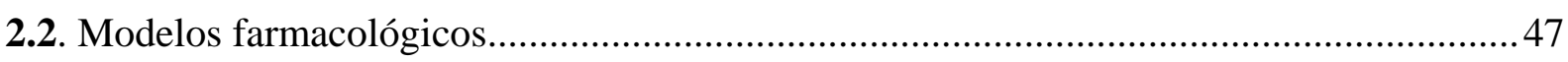

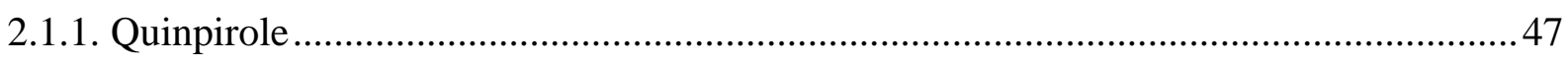

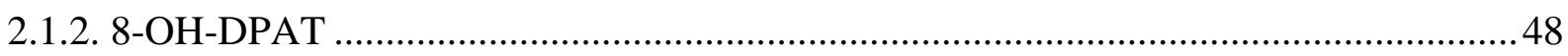

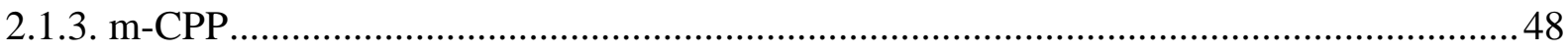

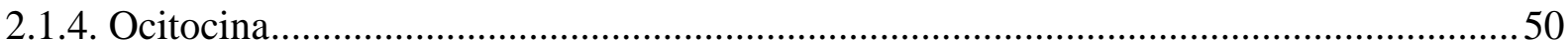

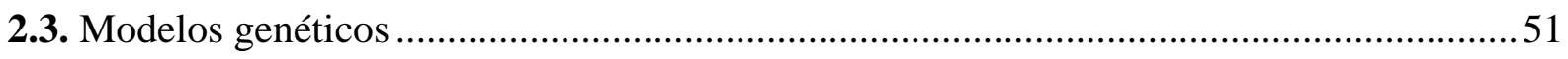

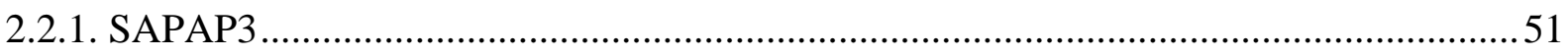

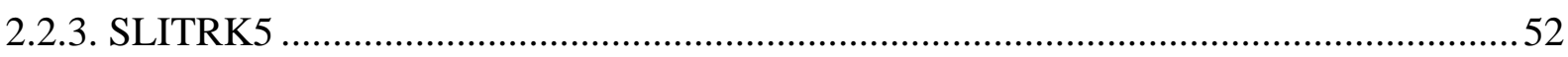

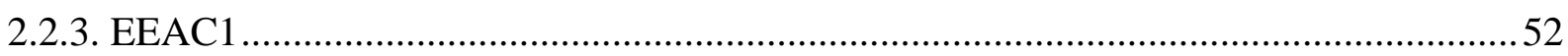

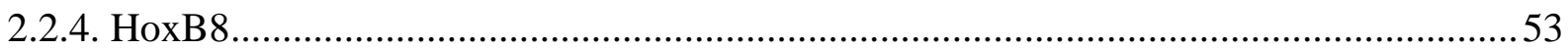

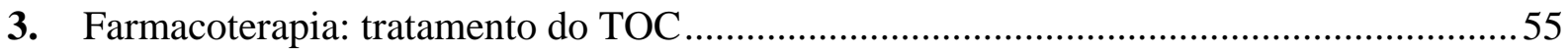

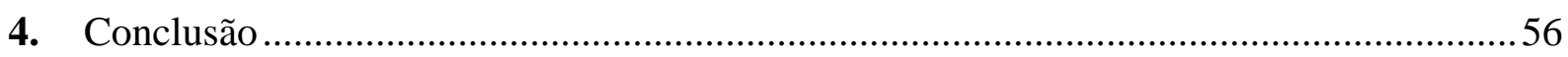

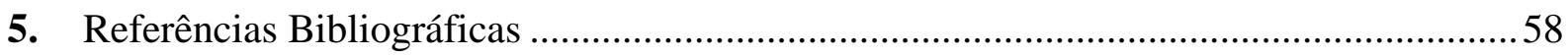


Capítulo 1: O efeito da ocitocina e de suas variantes Prolina ${ }^{8}$-Ocitocina Pro $^{8} \mathrm{OXT}$ e Valina ${ }^{3}$ Prolina ${ }^{8}$-Ocitocina $\left(\mathrm{Val}^{3} \mathrm{Pro}^{8} \mathrm{OXT}\right)$ no comportamento de autolimpeza (grooming)

O Transtorno obsessivo compulsivo (TOC) está entre as desordens psiquiátricas mais conhecidas no mundo. Esse transtorno afeta aproximadamente 2 a $3 \%$ da população geral e, embora haja avanços científicos e farmacológicos no tratamento do TOC, aproximadamente 10\% dos pacientes se mantêm gravemente incapacitados (DENYS, 2006; JENIKE, 2004). Além disso, o TOC é caracterizado por uma série de comportamentos obsessivos e compulsivos que impactam negativamente à qualidade de vida dos pacientes. As obsessões são pensamentos, impulsos ou imagens recorrentes e persistentes vivenciados como intrusivos e indesejados. Já as compulsões são comportamentos repetitivos ou atos mentais do indivíduo, executados em resposta a uma obsessão ou determinada regra, aplicada rigidamente (AMERICAN PSYCHIATRIC ASSOCIATION, 2013).

Os pensamentos obsessivos causam ansiedade e, na tentativa de controlar esse sentimento, os indivíduos geralmente realizam comportamentos compulsivos. Entretanto, as obsessões são constantes e induzem a incessante busca por alívio. Dessa forma, as compulsões tornam-se hábitos comuns e cíclicos (o loop do TOC) (PAULS et al., 2014) O loop do TOC (Figura 1), hipotetizado por Saxena e Rauch (2000), tem sido utilizado para representar as diferentes etapas pelas quais o indivíduo com TOC passaria. 


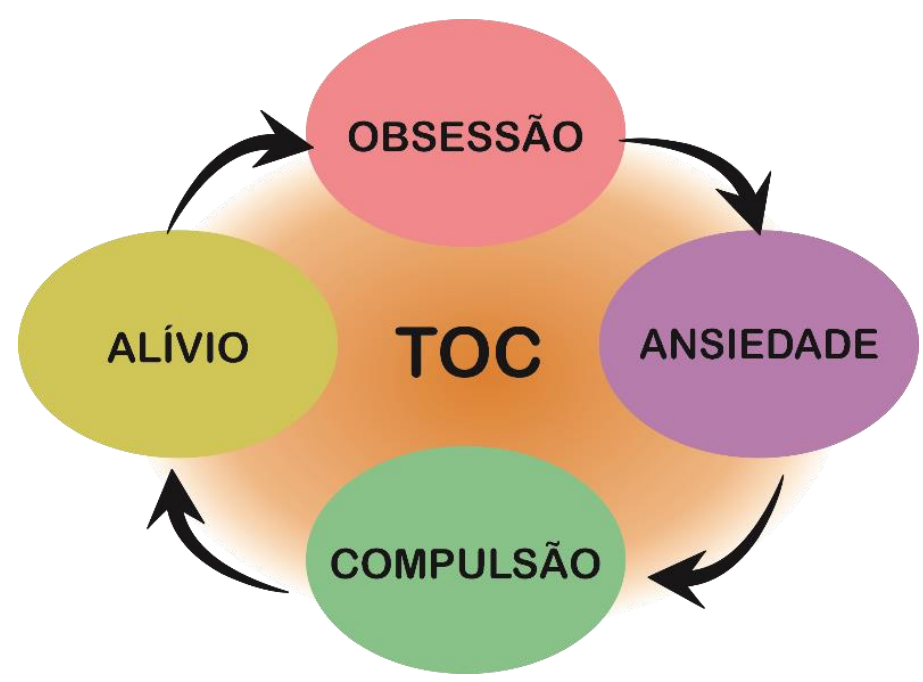

Figura 1. Loop do Transtorno Obsessivo Compulsivo. Esse ciclo representa as etapas as quais um indivíduo com TOC está susceptível. A obsessão pode ser por preocupação excessiva em contaminação/lavagem, verificação, acúmulo, dentre outras que foram citadas anteriormente. A obsessão causa angústia ou ansiedade, e o indivíduo realiza comportamentos a fim de neutralizar esses sentimentos, produzindo alívio temporário. Entretanto, esse alívio gera reforço dos comportamentos, provocando comportamentos repetitivos e compulsivos sempre que as obsessões retornam. Tomado de SAXENA e RAUCH (2000).

Embora a etiologia do TOC ainda não seja completamente elucidada (RONCHETTI; BÖHME; FERRÃO, 2004), estudos demonstram que a fisiopatologia desse transtorno pode estar relacionada a fatores genéticos (PAULS et al., 2014), alterações na circuitaria córticoestriado-tálamo-cortical (CETC) (TING; FENG, 2011), com participação de neurotransmissores como: 5-hidroxitriptofano (serotonina; 5-HT) (HESSE et al., 2005), glutamato (PITTENGER; BLOCH, 2014), ácido gama-aminobutiríco (GABA) (ROSENBERG; MACMILLAN; MOORE, 2001) e dopamina (DENYS, ZOHAR, WESTENBERG, 2004b; HESSE et al., 2005). Além disso, foram observados níveis elevados de OT no líquido cefalorraquidiano de pacientes com TOC (LECKMAN et al., 1994), embora não confirmados por ALTEMUS et al., 1999).

O funcionamento normal do circuito CETC ocorre mediado por duas vias, direta e indireta. A ação conjunta de ambas regula esse sistema através da neurotransmissão glutamatérgica, GABAérgica e dopaminérgica, de maneira que, comportamentos possam ser 
expressos ou inibidos (PAULS et al., 2014) permitindo, assim, a realização de movimentos voluntários (GRAYBIEL, RAUCH, 2000;PAULS et al., 2014).

Em estudos realizados com indivíduos com TOC, observou-se hiperativação e aumento do fluxo sanguíneo cerebral em áreas com íntima relação com a circuitaria CETC (MATAIX-COLS et al., 2004), como o córtex órbito-frontal bilateral, córtex cingulado anterior esquerdo, núcleo caudado, putâmen, globo pálido e tálamo (RAUCH et al., 1994; VAN DEN HEUVEL et al., 2005).

A fim de compreender a complexa fisiopatologia e etiologia do TOC, diversos estudos têm utilizado modelos animais que mimetizam sintomas psicopatológicos diversos. Baseandose no comportamento habitual de roedores, a autolimpeza (grooming) é geralmente realizada de forma natural, uma vez que está envolvida em processos fisiológicos diversos, como os de manutenção da pelagem, manutenção da temperatura, interação social e em situações de estresse (VELOSO et al., 2016). Contudo, o comportamento de grooming pode ser alterado em roedores, a fim de se mimetizar o comportamento de limpeza excessiva, ou excessive grooming behavior, presente em pacientes com TOC. Segundo GREER e CAPECCHI (2002), o excessive grooming behavior é um comportamento excessivo, que pode ocasionar até mesmo lesões na pele do animal.

O excessive grooming behavior, pode ser induzido farmacologicamente em roedores através da administração de drogas e pode ser mimético do comportamento compulsivo de lavagem excessiva por medo de contaminação, sintoma este característico de indivíduos com TOC (CALDWELL et al., 1986). GISPEN e ISAACSON (1981) apontaram que ratos machos injetados intraventricularmente com hormônio adrenocorticotrófico (ACTH) exibiram comportamentos de grooming excessivo quando comparados aos animais tratados com salina, que permaneceram a maior parte do tempo dormindo. Posteriormente, em 1986, Caldwell e colaboradores demonstraram que ratas tratadas com ocitocina (OT) também apresentam 
comportamentos de autolimpeza exacerbados quando comparados a animais tratados com salina (CALDWELL et al., 1986).

A OT é um nonapeptídeo cíclico (Cys-Tyr-Ile-Gln-Asn-Cys-Pro-Leu-Gly-NH2) que contém dois aminoácidos de cisteína que formam uma ligação dissulfeto (LEE et al., 2009). Sua composicação difere da vasopressina (AVP), também um nonapeptídeo, por apenas dois aminoácidos (CALDWELL et al., 1986).

O neuropeptídeo OT é produzido pela proteína precursora, o pré-pró-peptídio neurofisina 1 (LEONG et al., 2018). A OT é sintetizada principalmente em neurônios magnocelulares dos núcleos paraventricular (PVN) e supraópticos (SON) hipotalâmicos (CAZALIS; DAYANITHI; NORDMANN, 1985; MEYER-LINDENBERG et al., 2011). É transportado ao longo de projeções axonais para o lóbulo posterior da hipófise, onde é armazenada em vesículas secretoras e liberada na corrente sanguínea periférica, exercendo funções endócrinas como a lactação e a contração uterina (PENAGARIKANO et al., 2015). Em ratos adultos, a quantidade de OT na hipófise varia entre 0,5 - $1 \mu \mathrm{g}$ (LENG; LUDWIG, 2016).

Além da liberação periférica, a OT também é liberada dendriticamente no espaço extracelular da neurohipófise, exercendo funções de neurotransmissor e neuromodulador localmente e em diferentes regiões espalhadas pelo cérebro, como amígadala, hipocampo, estriado, córtex cingular anterior, núcleo leito da estria terminal, núcleo accumbens (Nac) e núcleo supraquiasmático (MEYER-LINDENBERG et al., 2011). Apesar de drogas peptídicas como a OT terem sua distribuição limitada no sistema nervoso central (SNC) por não atravessarem a barreira hematoencefálica $(\mathrm{BHH})$ e apresentarem alto grau de degradação, tem-se, ainda, considerado estudos com o seu uso (ILLUM, 2003; TANAKA et al., 2018).

Em mamíferos Eutheria como humanos, a OT se liga a quatro diferentes tipos de 
receptores: OTr (receptor de OT), AVPR1A (receptor de AVP 1A), AVPR1B (receptor de AVP 1B), AVPR2 (receptor de AVP 2) (MEYER-LINDENBERG et al., 2011), e AVPR3 (receptor de AVP 3) (LEITE, 2014). Além disso, os OTrs estão presentes em várias regiões cerebrais como o núcleo central da amígdala $(\mathrm{Ce} A)$, núcleo medial da amígdala $(\mathrm{Me} A)$ e núcleo basomedial da amígdala (TERENZI; INGRAM, 2005).

O OTr pertence à família da rodopsina, que esta acoplada a uma proteína da família GPCR (GIMPL; FAHRENHOLZ, 2001; CALDWELL et al. 2008). Desta forma, o OTr é acoplado a proteína $\mathrm{G}$ quinase $(\mathrm{Gq})$ e sua ativação ocasiona modificações na atividade da Fosfolipase $\mathrm{C}$ e na proteína Cinase C. O OTr também pode se acoplar a duas proteínas diferentes, sendo elas $\mathrm{Gq} / 11$ e na proteína $\mathrm{G}$ inibitória (Gi/o). A ativação dessas duas vias de sinalização pode ser uma explicação para as diversas funções que a OT exerce (CHINI; FANELLI; 2000; DEVOST; WRZAL; ZINGG，2008; GIMPL; REITZ; BRAUER; TROSSEN, 2008; RIMOLDI et al., 2003; LEONG et al., 2018).

Embora o principal receptor de OT seja o OTr, quando as concentrações deste neuropeptídeo estão acima do nível fisiológico, ele se liga aos receptores AVP e medeia através dessa ligação, os efeitos comportamentais sociais (BOWEN, MCGREGOR, 2014; SALA et al., 2011; LEONG et al., 2018). Os AVPr também estão acoplados a proteína G, e se localizam especialmente nos leitos vasculares (AVPR1), rins (AVPR2), e pituitária (AVPR3) (ZENTENO-SAVIN et al., 2000; LEITE, 2014). A liberação plasmática de AVP está associada à ativação de osmorreceptores que detectam pequenos aumentos na osmolalidade plasmática (BIRNBAUMER, 2000).

A OT em áreas como PVN, área tegmental ventral (VTA) e substância negra (SN), está envolvida com o comportamento materno; enquanto que no hipocampo, geralmente está associada ao processo de aprendizado e memória (HASHIMOTO; UEZONO; UETA, 2012). Além disso, a OT pode influenciar o comportamento social e de ansiedade (FERGUSON et 
al., 2001; JIN et al., 2007; DE DREU et al.; 2010; INSEL, 2010; LABUSCHAGNE ET AL., 2010; MAIRESSE et al., 2015) e atuar como um hormônio anti-estresse (WINDLE et al., 1997, 2004; BARTZ et al., 2011; MAIRESSE et al., 2015).

A OT também apresenta efeito ansiolítico (NEUMANN et al., 2000; BALE et al., 2001; MANTELLA et al., 2004; HEINRICHS et al., 2003; de OLIVEIRA et al., 2011 ). Em ratos, após administração de OT intracerebroventricularmente (i.c.v.), os niveis plasmáticos de corticosterona foram suprimidos após 10 minutos de estresse sonoro (WINDLE et al., 1997; MAIRESSE et al., 2015). Quando administrada em humanos, via intranasal, a OT aumentou o apoio social e o número de interações interpessoais suprimindo a secreção de cortisol (HEINRICHS et al., 2003; HASHIMOTO; UEZONO; UETA, 2012), além de respostas relativas ao estresse psicossocial (KIRSCH et al., 2005; HASHIMOTO; UEZONO; UETA, 2012).

A OT também apresenta efeitos antinociceptivos através da modulação do processamento central da dor, devido à sua capacidade de modular a nocicepção central. Ratos que receberam OT intratecalmente demonstraram aumento dos efeitos antinociceptivos (LUNDEBERG et al., 1993; YANG et al., 2007; HASHIMOTO; UEZONO; UETA, 2012) sendo este efeito reproduzido em humanos (YANG, 1994; HASHIMOTO; UEZONO; UETA, 2012). LOUVEL et al. (1996), demonstraram que pacientes com a Síndrome do intestino irritável que receberam infusão contínua de OT a 20 $\mathrm{mU} / \mathrm{min}$ apresentaram diminuição da dor abdominal.

Outros trabalhos apontam que estímulos dolorosos seriam capazes de aumentar a concentração de OT em várias regiões cerebrais como o SON (YANG et al., 2011d), núcleo hipotalâmico ventromedial, núcleo talâmico reticular, locus ceruleus, núcleo magno da rafe, hipófise posterior, medula espinhal (YANG et al., 2007) e no líquido de perfusão da substância cinzenta periaquedutal (YANG et al., 2011a; YANG et al., 2011b; SILVA, 2016). 
A sequência de aminoácidos da OT é diferente entre mamíferos placentários (PARREIRAS-E-SILVA et al., 2017), sendo observadas substituições do aminoácido leucina por prolina na posição 8 ( $\left.\mathrm{PRO}^{8} \mathrm{OXT}\right)$ em quatro espécies de macacos do Novo Mundo (LEE et al., 2011), além da substituição de isoleucina por valina na posição 3 (VAL $\left.{ }^{3} \mathrm{PRO}^{8} \mathrm{OXT}\right)$. Os macacos do Novo Mundo ou primatas Neotropicais pertencem à infraordem Platyrrhini. São encontrados em florestas tropicais da América do Sul, e apresentam características como porte médio, nariz largo e achatado, e narinas localizadas mais lateralmente (REIS et al., 2006). A variante $\mathrm{PRO}^{8} \mathrm{OXT}$ está presente no gênero da família Cebidae (PERELMAN et al., 2011), enquanto a $\mathrm{VAL}^{3} \mathrm{PRO}^{8} \mathrm{OXT}$ está presente na família Cebidae, subfamília Callitrichinae. Essas alterações de substituições permitiram que alguns macacos do Novo Mundo apresentassem comportamentos como monogamia social, e comportamento de cuidado dos machos (PARREIRAS-E-SILVA et al., 2017). SMITH e GINSBURG (1961) demonstraram através de experimentos in vivo e in vitro que o aminoácido valina na posição 3 da OT pode causar aumento da contração uterina. FRENCH et al. (2016) observaram que o macaco do Novo Mundo, Sagui-de-tufos pretos (Callithrix penicillata) ao ser tratado com $\mathrm{PRO}^{8} \mathrm{OXT}$ via intranasal apresentou diminuição do comportamento altruísta, por ter compartilhado seu alimento com macacos estranhos.

Além disso, a administração intranasal de variantes da OT (Pro ${ }^{8}$ OXT e $\mathrm{Val}^{3} \mathrm{Pro}^{8} \mathrm{OXT}$ ) induziu o comportamento de cuidado parental em ratos fêmeas, que agruparam mais rapidamente seus filhotes quando comparadas as fêmeas tratadas com OT. Em ratos machos, a administração intranasal de variantes da OT fez com que os animais entrassem em contato com seus filhotes mais rapidamente, quando comparados aos animais tratados com salina. Logo, os roedores machos tratados com as variantes da OT demostraram maior motivação para entrar em contato com os filhotes (PARREIRAS-ESILVA et al., 2017), reproduzindo um dos efeitos geralmente produzidos pela OT, de 
cuidado maternal e comportamento social (BRIDGES, 2015). Entretanto, diferentes respostas induzidas pela OT estão correlacionadas à área e via de administração. A microinjeção no PVN, VTA, subiculum ventral e núcleo cortical posterior medial da amígdala, aumentam o nível de dopamina no núcleo accumbens (GIL, 2010), por exemplo. Nos ventrículos, essa administração desencadeia um importante efeito amnésico (BOHUS et al., 1978), além de induzir hypergrooming (DELANOY; DUNN; TINTNER, 1978; DRAGO et al., 1986).

Estudos apontam que o comportamento de hypergrooming, induzido experimentalmente em roedores pela microinjeção de OT ou de outras drogas, é considerado um importante marcador do transtorno compulsivo (KORFF; HARVEY, 2006; AYERS et al., 2011; SHAVITT et al., 2014). Nosso laboratório, ao longo dos anos, tem se dedicado ao estudo do comportamento compulsivo através de modelos animais, e do papel da OT sobre esse transtorno, mais especificamente na indução do comportamento de grooming excessivo ou hypergrooming. Nesse sentido, estudos desenvolvidos em nosso laboratório demonstraram que a microinjeção bilateral de OT no núcleo central da amígdala (CeA) de animais Wistar (MARRONI et al., 2007) e da linhagem geneticamente selecionada pela sua susceptibilidade a epilepsia, o Wistar Audiogenic Rat (WAR) (MARRONI, 2011; SANTOS, 2014), induziu comportamento de hypergrooming (MARRONI et al., 2019 [pre-print]).

Logo, analisar o efeito da OT e de suas variantes $\mathrm{PRO}^{8} \mathrm{OXT}$ e $\mathrm{VAL}^{3} \mathrm{PRO}^{8} \mathrm{OXT}$ na indução do comportamento de hypergrooming em ratos Wistar Hannover nos auxiliaria a compreender a fisiopatologia desta compulsão neste modelo experimental. Além disso, contribuiria para confirmar a hipótese de que as variantes $\operatorname{Pro}^{8} \mathrm{OXT}$ e $\mathrm{Val}^{3} \operatorname{Pro}^{8} \mathrm{OXT}$, são capazes de induzir o comportamento de hypergrooming. 
Desta maneira, neste estudo hipotetizamos que a microinjeção bilateral de OT e suas variantes, aplicadas no CeA, conseguiriam induzir o comportamento de hypergrooming em ratos Wistar Hannover.

O objetivo do presente estudo foi investigar os efeitos da OT, e suas variantes, Pro $^{8} \mathrm{OXT}$ e $\mathrm{Val}^{3} \mathrm{Pro}^{8} \mathrm{OXT}$, na indução do hypergrooming, em animais da linhagem Wistar

\section{Hannover.}

Para isso, foram utilizados ratos Wistar Hannover machos $(\mathrm{n}=47),(270-310 \mathrm{~g})$, provenientes do Biotério Central do Campus de Ribeirão Preto, da Universidade de São Paulo. Os animais foram submetidos a um ciclo claro-escuro de 12/12 horas (h), com água e alimentação ad libitum, alojados no Biotério de manutenção do Departamento de Fisiologia, em caixas de polietileno com tampa de ferro $(40,5 \times 33,5 \times 21 \mathrm{~cm})$, com, no máximo, 4 ratos/caixa. O projeto foi aprovado pelo Comitê de Ética da FMRP-USP (Protocolo $\mathrm{n}^{\circ}$ 064/2018), realizado de acordo com as recomendações do Conselho Nacional de Controle de Experimentação Animal - CONCEA. Os animais foram microinjetados bilateralmente com OT $(5 \mu \mathrm{g} / \mu \mathrm{L})$ e suas variantes, $\operatorname{Pro}^{8} \mathrm{OXT}(5 \mu \mathrm{g} / \mu \mathrm{L})$ e Val $^{3} \operatorname{Pro}^{8} \mathrm{OXT}(5 \mu \mathrm{g} / \mu \mathrm{L})$ no CeA. Após serem microinjetados, os animais foram filmados por 60 minutos e tiveram seus comportamentos de autolimpeza contabilizados através da Escala de Gispen (Gispen et al., 1975; MARRONI et al., 2007), ou índice de autolimpeza. Essa escala permite ao pesquisador avaliar, de 15 em 15 segundos, os comportamentos dos animais e, ao realizarem qualquer comportamento de autolimpeza dentro dessa janela de tempo, os roedores recebem 1 ponto. Após os 60 minutos, o pesquisador avaliou o comportamentos dos grupos em questão, bem como a pontuação máxima que cada animal antingiu, sendo o máximo de 240 pontos. Também foi realizada a análise neuroetológica, que consiste em uma representação gráfica, o fluxograma (GARCIA-CAIRASCO et al., 1992), construído por meio de uma avaliação detalhada dos itens comportamentais 
expressos pelos animais segundo a segundo em termos de sequência temporal, baseando-se em um dicionário comportamental. Veja detalhes da utilização desta metodologia no modelo de hypergrooming em MARRONI et al. (2007; 2019)

1.1. Condições desfavoráveis que inviabilizaram o projeto

No ano de 2018, o Campus da USP de Ribeirão Preto - São Paulo, passou por situações inesperadas, tais como, troca da linhagem dos animais de Wistar para Wistar Hannover e a troca da ração (fora do controle de nosso Laboratório; de fato fomos informados deste evento meses após o seu início), que certamente deve ter interferido no metabolismo e, dentre muitos outros, em parâmetros cardiorespiratórios, renais, endócrinos de animais em experimentação. Nenhuma dessas potenciais alterações foi avaliada por nós e não fomos informados do eventual efeito das mesmas em múltiplos animais e seus sistemas, durante os meses dos eventos. Consequentemente, o impacto natural sobre o comportamento geral dos animais, literalmente em qualquer protocolo, inviabilizaria a execução dos mesmos e, sobretudo a interpretação dos resultados dos experimentos até agora realizados.

De qualquer maneira, como os dados correspondentes a estas janelas de tempo do Mestrado permitiram que fosse feito o Exame Geral de Qualificação (aprovado em 28/02/2019), os mesmos, organizados como apresentação (ver anexo). Neste cenário, em uma atitude de alta resiliência extremamente necessária para o momento, nosso grupo de pesquisa reformulou o projeto inicial, como ilustrado no Capítulo 2. 
Capítulo 2: Projeto alternativo. Relação entre compulsão, estresse e ocitocina

Segundo MIRANDA e BORDIN (2001), em 70\% dos casos de TOC, houve com antecedência algum evento estressante, e que teve impacto na intensidade dos sintomas desse transtorno (JORDAN et al., 1991; AFONSO, 2006). Além disso, a resposta ao estresse e a atividade do eixo hipotálamo-hipófise-adrenal (HPA) são considerados de extrema importância no cenário dos transtornos psiquiátricos (MORGADO et al., 2013).

Desta forma, é importante considerar o papel do estresse sobre os sintomas obsessivos-compulsivos, uma vez que pacientes com TOC estão inclinados a sofrer consideravelmente, já que existe relação entre tolerância ao estresse e pensamentos obsessivos (COLES et al., 2005; COUGLE et al., 2011; MORGADO et al., 2013). Morgado et al. (2013) apontaram a hipótese de que o estresse influencia o TOC, mais diretamente os sintomas obsessivos-compulsivos. Entretanto, novos estudos são necessários para analisar a associação entre eles (STEIN et al., 2020).

O eixo HPA tem papel importante no sistema neuroendócrino por controlar reações ao estresse (TEICHER et al., 2002), e processos fisiológicos, como a digestão, o humor e as emoções (GROENINK et al., 2002). A literatura aponta que o hipotálamo possui relação na regulação do estresse, assim como, na modulação dos impactos do sistema endócrino sobre as manifestações comportamentais (CHENG et al., 2015; KRUK et al., 1998). A associação entre estresse e TOC foi sugerida após estudos demonstrarem que as obsessões causam alto grau de sofrimento em indivíduos com o transtorno, resultando em possível estímulo para respostas relacionadas ao estresse, com a participação do eixo HPA (MORGADO et al., 2013). 
Os efeitos do estresse sobre o sistema nervoso central (SNC), têm sido investigados há mais de 50 anos ( THIERRY et al., 1968; YARIBEYGI et al., 2017). Estudos demonstram que o estresse provoca alterações em diferentes estruturas cerebrais (LUPIEN et al., 2009; YARIBEYGI et al., 2017) como hipocampo (ADMON et al., 2009; GRASSI-OLIVEIRA; ASHY; STEIN, 2008), amígdala (ANDERSEN et al., 2008; MORALES-MEDINA et al., 2009), núcleo accumbens (NaC) (MORALES-MEDINA et al. 2009), córtex pré-frontal (CPF) (ANDERSEN et al. 2008) e córtex visual (CHOI et al., 2012; HANSON et al., 2012; OLIVARES et al., 2010; TOMODA et al., 2009, 2012). Nesse contexto, foi demonstrado que o estresse contribui para o aumento do risco para o surgimento de doenças neuropsiquiátricas, como ansiedade e depressão (GODOY et al., 2018), e doenças neurodegenerativas, como a doença de Parkinson e doença de Alzheimer (BRIONES et al., 2012; HUI et al., 2017; JUSTICE, 2018).

O estresse está intimamente relacionado ao sistema neuroendócrino (YARIBEYGI et al., 2017). A secreção do Hormônio liberador de corticotrofina (CRH) e da AVP, ambos pelo PVN, ocorre frente à exposição a um estressor e ambas ativam o eixo HPA (STRATAKIS, CHROUSOS, 1995; DE KLOET; JOËLS; HOLSBOER, 2005; TSIGOS; CHROUSOS, 2002; ZIMPRICH et al., 2014). Estes dois hormônios provocam a liberação do hormônio adrenocorticotrópico (ACTH) da hipófise anterior para a circulação. Nela, o ACTH é transportado até as glândulas suprarrenais, local de síntese e secreção dos corticosteroides (cortisol em humanos e corticosterona em roedores). O cortisol apresenta feedback negativo na hipófise e no hipotálamo, suprimindo a liberação de CRH e ACTH frente ao estresse (ZIMPRICH et al., 2014).

Tal qual a AVP, outro neuropeptídeo relacionado com o estresse é a OT. Conforme já descrito, a OT é sintetizada no PVN e SON e acessórios do hipotálamo (MOHR et al., 1988; SOFRONIEW, 1983; WINTER; JUREK, 2019). O PVN apresenta duas populações distintas 
de neurônios, denominados magnocelulares e parvocelulares. Projeções destes neurônios estão integradas a circuitos neuronais de forma que suas saídas (outputs) alimentam neurônios do CRH do PVN (WINTER; JUREK, 2019). Existem várias evidências que relacionam a exposição a estressores diversos, como imobilização, agitação, nado forçado, com a liberação de CRH e OT (NEUMANN et al., 2000; NISHIOKA et al., 1998; TORNER et al., 2017; WINTER; JUREK, 2019). A relação entre a liberação de OT com o estressor pode ser elucidada (WOTJAK et al., 1998; DABROWSKA et al., 2011; LI; HASSETT; SENG, 2019) através de sua liberação do PVN no momento exato ou imediatamente após o estresse agudo. Além disso, os efeitos do estresse dependem do contexto e do tipo de estressor e nem sempre a liberação periférica e central de OT coincidem (ENGELMANN; LANDGRAF; WOTJAK, 2004; WINTER; JUREK, 2019). O estresse crônico por contenção em roedores, por exemplo, causa a liberação central de OT no PVN, mas não no plasma (BABYGIRIJA et al., 2012; WINTER; JUREK, 2019). Outra importante função já descrita da OT é a de imediata potencialização do efeito na secreção do ACTH induzida por CRH (LANG et al., 1983; GIBBS, 1985; GIBBS, 1986; GIBBS, 1984; SUH et al., 1986; ENGELMANN; LANDGRAF; WOTJAK, 2004; WINTER; JUREK, 2019).

Assim, após reestruturarmos nosso projeto decidimos manter o tratamento com OT e associá-lo a estressores físicos, uma vez que, em nosso laboratório são desenvolvidas pesquisas relacionadas a estresse e sua influência sob transtornos mentais (GODOY et al., 2018), entre eles depressão, ansiedade, transtorno bipolar e TOC (STEIN et al., 2020).

Diante do exposto, a hipótese do presente trabalho é que o estresse por contenção com agitação (GODOY et al., 2018) associado à aplicação de OT no CeA promova o hypergrooming. Além disso, acreditamos que a associação do estressor com a microinjeção de OT no CeA seja mais eficiente em induzir o comportamento compulsivo de autolimpeza (hypergrooming), quando comparada ao grupo sem estressor. Caracterizando desta forma, o 
envolvimento direto do fator estresse potencializando o comportamento de limpeza, o mesmo observado em pacientes com TOC.

Assim, o objetivo do estudo foi verificar se o estresse associado à aplicação de OT promove a exacerbação do comportamento de autolimpeza.

Foram utilizados ratos Sprague Dawley machos $(\mathrm{n}=12),(270-310 \mathrm{~g})$, provenientes do Biotério Central do Campus de Ribeirão Preto, da Universidade de São Paulo. Os animais foram submetidos a um ciclo claro-escuro de 12/12 horas (h), com água e alimentação ad libitum, alojados no Biotério de manutenção do Departamento de Fisiologia, em caixas de polietileno com tampa de ferro $(40,5 \times 33,5 \times 21 \mathrm{~cm})$, com, no máximo, 4 ratos/caixa. O projeto foi aprovado pelo Comitê de Ética da FMRP-USP (Protocolo $\mathrm{n}^{\circ}$ 064/2018), realizado de acordo com as recomendações do Conselho Nacional de Controle de Experimentação Animal - CONCEA. Todos os animais do grupo sem estressor foram submetidos a cirurgia estereotáxica (realizada pelo Técnico de Nível Superior Flávio Del Vechio) para implantação de cânulas bilaterais que permitiram a microinjeção de OT no CeA (MARRONI et al., 2007). Após a cirurgia, os ratos permaneceram três dias em período de recuperação e em seguida foram submetidos por três dias ao período de handling e habituação. No dia seguinte ao último dia de handling e habituação, os animais foram microinjetados com veículo e OT no CeA e filmados por 60 minutos. 90 minutos após a administração do veículo e OT, foram coletados os sangues dos animais para análise da CORT e, em seguida, os roedores foram perfundidos, e tiveram seus cérebros coletados para análises histológicas. Além disso, também foi realizada análise comportamental, por meio da escala de GISPEN et al. (1975).

Para análise estatística e comparações das pontuações na escala de Gispen durante o decurso temporal de 60 minutos, utilizou-se a análise de variância (ANOVA), seguida pelo teste de Bonferroni para múltiplas comparações. Os valores de $p$ iguais ou inferiores a 5\% 
foram considerados significativos. Para a análise estatística e confecção dos gráficos foi utilizado o Software GraphPad Prism 8.0.2.

Os animais foram divididos em dois grupos: veículo $(\mathrm{n}=6)$ e OT $(10 \mu \mathrm{g} / \mathrm{ul})(\mathrm{n}=5)$.

Foram avaliados os efeitos das variáveis, tempo e tratamento sobre o parâmetro pontuação da Escala de Gispen. Para estas variáveis, não foram encontradas diferenças significativas ( $>>0,05$; Figura 2).

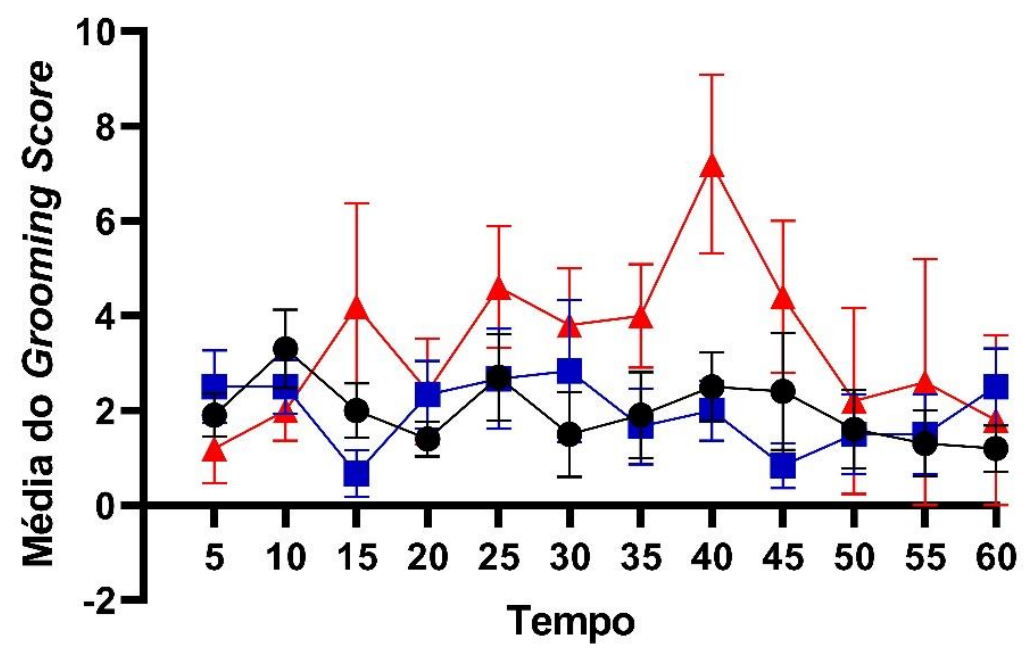

Figura 2. Índice de autolimpeza (GISPEN et al., 1995) dos grupos Naive (círculo preto, n=10), Veículo (quadrado azul, $\mathbf{n = 6 )}$ e Ocitocina $10 \mu \mathrm{g} / \mu \mathrm{l}$ (triângulo vermelho, $\mathrm{n}=5$ ) sem estressor. Pontuação obtida no decurso temporal versus efeito dos tratamentos sobre o comportamento de grooming (autolimpeza). No eixo Y estão as médias \pm erro padrão observadas durante os 60 minutos, representados no eixo $\mathrm{X}$ (intervalados a cada 5 minutos). Two-Way ANOVA, medidas repetidas, Bonferroni, $\mathrm{p}>0,05$.

Dados de MARRONI et al. (2007; 2019; SANTOS, 2011) demonstraram que a microinjeção bilateral de OT $(10 \mu \mathrm{g} / \mu \mathrm{l})$ no CeA aumenta os comportamentos de grooming em uma janela temporal (40 minutos). Contudo, o presente resultado é considerado preliminar, já que não conseguimos realizar a verificação da localização das cânulas (comparar com comprovação histológica realizada no final do Capítulo 1 (apresentação do EGQ), o que nos impossibilita concluir se este aumento do comportamento de autolimpeza é confiável.

Também seriam realizados os experimentos nos quais os animais antes de serem microinjetados com veículo e OT, seriam submetidos ao estressor físico (contenção física com agitação). Brevemente, os roedores seriam contidos em tubo de acrílico e colocados na parte 
superior de um agitador, a uma velocidade de $30 \mathrm{rpm}$, por um período de 60 minutos (GA̧DEK-MICHALSKA; BUGAJSKI, 2003; GODOY et al., 2018). E, logo após o término da exposição ao estressor, os animais seriam microinjetados com veículo ou OT. No entanto, esses experimentos tiveram que ser interrompidos devido a todos os protocolos de segurança sanitária, que incluíram suspensão de atividades no laboratório (desde março de 2020) e fornecimento de animais, decorrentes da COVID-19.

1. Problemas que impediram a continuidade e finalização dos protocolos experimentais.

Esperávamos finalizar os experimentos sem estressor e iniciar os experimentos com estressor. Entretanto, devido à Pandemia de COVID-19 que assolou não só o Brasil, mas todo o mundo, as atividades do Departamento foram interrompidas. Em uma correta atitude das autoridades, a fim de evitar a exposição ao vírus, as pesquisas que não estavam relacionadas ao COVID - 19 tiveram que ser pausadas. Serviços de rotina, como o Biotério Central, que disponibiliza os animais para diversas pesquisas, também tiveram suas atividades reduzidas drasticamente, além da própria disponibilização dos animais aos laboratórios.

Como tentativa de finalizar os experimentos ainda este ano e valorizar o trabalho que a aluna teve no decorrer de todo o seu Mestrado, decidimos prorrogar o prazo para o depósito desta Dissertação. Porém, este prazo está se encerrando e, desta forma, estabelecemos que os experimentos serão retomados e concluídos após ser aprovado o retorno das atividades laboratoriais.

Portanto, devido ao fato de não dispormos de data prevista para o retorno das atividades experimentais completas, valorizarmos o trabalho feito até aqui e agregar à literatura o conhecimento adquirido neste processo, optamos por realizar uma revisão crítica da literatura acerca dos modelos animais existentes para o estudo de compulsão e TOC, e as limitações observadas nesses modelos. 
De fato, e nosso laboratório tem sido produzidas ao longo dos anos e mais recentemente, revisões científicas extremamente significantes e de alto impacto (GARCIACAIRASCO, 2001; LEITE, GARCIA-CAIRASCO E CAVALHEIRO, 2001; GARCIACAIRASCO, 2009; TEJADA et al,, 2011; GARCIA-CAIRASCO; UMEOKA; CORTES DE OLIVEIRA, 2017; GODOY et al., 2018; LAZARINI-LOPES et al., 2020). Logo, consideramos ser de extrema importância a realização dessa revisão, já que representa o quanto os modelos animais são relevantes para a compreensão do TOC, suas limitações e as dificuldades que os pesquisadores enfrentam ao utilizá-los. 
Capítulo 3: Revisão crítica da literatura sobre modelos experimentais de transtorno obsessivo compulsivo

1. Introdução

Considerado o quarto transtorno mental mais recorrente no mundo (OLIVEIRA et al., 2012), o transtorno obsessivo compulsivo (TOC) é apontado como um transtorno neuropsiquiátrico complexo e heterogêneo. O TOC é uma desordem neuropsiquiátrica caracterizada principalmente por obsessões e comportamentos compulsivos (AMERICAN PSYCHIATRIC ASSOCIATION, 2013). Os tipos de obsessões e compulsões são bastante variáveis nesse transtorno, o que remete à heterogeneidade dos fenótipos clínicos e à complexidade da fisiopatologia (MIGUEL et al., 2005).

O TOC afeta aproximadamente 2-3\% da população geral (FONTENELLE; MENDLOWICZ; VERSIANI, 2006; STEIN et al., 2020). No estudo de DEL-PORTO(2001) foi demonstrado que cerca de $2 \%$ dos suicídios entre adolescentes nos Estados Unidos (em um total de 31.000, em 1990) foram devidos ao TOC, com e sem comorbidades associadas. Segundo NAUTA, BATELAAN e BALKOM (2012), no Brasil, aproximadamente 2,5\% da população é diagnosticada com TOC, abrangendo um amplo espectro de idade, que vai de crianças e adolescentes até os adultos (PAULS et al., 2014). Segundo STEIN et al. (2020), o TOC é mais frequente em mulheres adultas, quando comparado a homens adultos. $\mathrm{O}$ fato de o TOC ter uma característica crônica contribui para que os pacientes se tornem gravemente incapacitados (OLIVEIRA et al., 2012). Indivíduos com TOC têm sua qualidade de vida comprometida, impactando também a vida dos familiares em especial no ambiente doméstico, já que provoca impactos econômicos, sobrecarga emocional do paciente e familiares, causando prejuízos em sua saúde mental (ARGIMON; BICCA; RINALDI, 2007). Foi observado em pacientes com TOC uma baixa autoestima, problemas na relação conjugal, dificuldades acadêmicas e profissionais e problemas de relacionamentos interpessoais 
(COUTO et al., 2010). Faz-se comum, entre crianças e adolescentes com este transtorno, o baixo desempenho escolar (BERNARD, 2011).

Embora estudos científicos tenham identificado e descrito os sintomas obsessivoscompulsivos, a etiologia do TOC continua desconhecida (ZIKE et al., 2017). Ao longo dos anos cientistas basearam seus estudos sobre esse transtorno testando hipóteses que envolviam o desequilíbrio da circuitaria córtico-estriatal-tálamo-cortical (CETC) e de neutronsmissores (CORDIOLI, 2014), de mutações genéticas, e fatores ambientais (MURPHY et al., 2013). Através dessas hipóteses pesquisadores criaram modelos animais com o objetivo de mimetizar características comportamentais do TOC. No entanto, apesar da ampla utilização e funcionalidade nas respostas científicas, existem limitações quanto ao uso dos modelos, já que o adequado modelo animal implica em assumir que o mesmo expresse eventos comportamentais muito semelhantes à manifestação clínica que o pesquisador deseja estudar (KORFF; HARVEY, 2006).

O conhecimento da etiologia desse transtorno está associado ao surgimento de terapias mais eficientes, e o impacto disso reflete diretamente na descoberta de novos fármacos. Embora os inibidores seletivos da recaptação de serotonina (ISRS), descobertos em 1980 (GOODMAN, MCDOUGLE, PRICE, 1992) sejam os mais indicados para o tratamento do TOC, uma grande parcela dos pacientes não apresenta melhora dos sintomas quando tratados com eles (COSTA et al., 2016).

Embora existam vários modelos animais descritos na literatura, acreditamos que o modelo ideal para o estudo do TOC ainda não foi criado. Logo, a elaboração de novos modelos é necessária porque pode possibilitar a compreensão da etiologia desse transtorno. Desta forma, o objetivo dessa revisão é demonstrar os motivos pelos quais a fisiopatologia do TOC não é tão bem elucidada, e o quanto isso influencia na descoberta ou não de tratamentos eficazes. 


\subsection{Transtorno Obsessivo Compulsivo}

Segundo RACHMAN e SILVA (1978), pensamentos, imagens ou impulsos intrusivos podem ser considerados normais e observados na maior parte da população. Para alguns indivíduos estes eventos não representam prejuízos e desaparecem espontaneamente. Porém, quando os mesmos se tornam persistentes, intrusivos, recorrentes e provocam ansiedade, são prejudiciais e culminam, posteriormente, na caracterização do TOC.

São exemplos de obsessões o medo por contaminação, as preocupações com danos (medo de que algo ruim possa acontecer), a busca por simetria, exatidão e ordem, as preocupações religiosas ou moralistas, pensamentos proibidos, como sexuais e agressivos, busca por garantias ou confissões (GONZALEZ, 1999; BARRETT; HEALY, 2003; LACK, 2012).

Os comportamentos compulsivos são definidos por limpar ou lavar, verificar, contar, repetir, arrumar, confessar, orar, buscar garantias, tocar, bater, esfregar e evitar (LACK, 2012; SWEDO et al., 1989) e acúmulo (AMERICAN PSYCHIATRIC ASSOCIATION, 2013). O desafio no tratamento do TOC é diminuir estes comportamentos de busca que, em muitas ocasiões, torna-se repetitivo e estereotipado, característico do TOC (KORFF; HARVEY, 2006).

Em indivíduos com TOC não há o encerramento da expressão do comportamento de busca por recompensa, gerando comportamentos estereotipados. Muitos pacientes com TOC são conscientes que seus sintomas compulsivos são excessivos e desejam ter mais controle sobre eles (STEIN et al., 2020). Contudo, essa sequência, na maioria dos casos, se torna duradoura e o indivíduo não consegue interromper este ciclo com facilidade, originando o ciclo do TOC. Dentre as manifestações clínicas mais comuns estão a limpeza e a verificação excessiva (TORRES; SMAIRA, 2001). SAXENA e RAUCH (2000) hipotetizaram o loop do TOC (Figura 1), no qual indivíduos com esse transtorno apresentam pensamentos obsessivos 
que geram ansiedade, e a fim de reduzí-la, os indivíduos realizam comportamentos compulsivos que ocasionam alívio temporário, porém, esses comportamentos se tornam repetitivos (ou ritualísticos) tornando-se difíceis de serem interrompidos.

De acordo com o Diagnostic and Statistical Manual of Mental Disorders 5 (DSM-V) (2013), a avaliação clínica é fundamental para o diagnóstico do TOC, embasada pela presença de obsessões e/ou compulsões. Nesta edição do DSM V o TOC passou da categoria de "transtornos de ansiedade" para "transtornos obsessivo-compulsivos e relacionados", uma vez que a própria ansiedade é uma manifestação secundária ao TOC e não componente central (LECKMAN et al., 2010; HIRSCHTRITT; BLOCH; MATHEWS, 2017; VAN AMERINGEN; PATTERSON; SIMPSON, 2014).

As ferramentas de triagem mais utilizadas atualmente são, Escala ObsessivoCompulsiva de Yale-Brown (Yale-Brown Obsessive-Compulsive Scale -Y-BOCS) (GOODMAN et al., 1989; GOODMAN et al., 1989), Inventário obsessivo-compulsivo, versão curta (Obsessive-Compulsive Inventory, Short Version (OCI-SV) (FOA et al., 2002), Inventário Obsessivo Compulsivo da Flórida (Florida Obsessive Compulsive Inventory FOCI). O $Y$-BOCS avalia a presença de obsessões e compulsões, gravidade dos sintomas associados e, é uma escala longa. Já o $O C I-S V$ é considerado curto por apresentar 18 itens em que são avaliados o grau de sofrimento associado (DE SOUZA et al., 2008; FOA et al., 1998). Por último, o FOCI também é uma avaliação breve da presença de sintomas do TOC e de sua gravidade (ZHANG et al., 2017).

Além dessa triagem, a realização de estudos de neuroimagem consegue mapear áreas cerebrais que estão envolvidas na fisiopatologia do TOC e na modulação de comportamentos repetitivos (SHEPPARD et al., 1999). Segundo a AMERICAN PSYCHIATRIC ASSOCIATION (2013), normalmente pacientes com TOC apresentam outras psicopatologias associadas. 
TORRES et al. (2006) apontam que mais de 50\% dos indivíduos com TOC possuem ao menos um transtorno psiquiátrico comórbido, sendo os mais comuns: transtorno de ansiedade ou transtorno depressivo maior (BARTZ; HOLLANDER, 2006; RUSCIO et al., 2010; ULLRICH et al., 2018) e transtorno bipolar (AMERICAN PSYCHIATRIC ASSOCIATION, 2013). Além disso, eventos estressantes geralmente antecedem o início do TOC, acentuando os sintomas obsessivos-compulsivos (TORO et al., .1992; FINDLEY et al., 2003).

Embora o TOC seja um transtorno bastante discutido, sua base neurobiológica é complexa e ainda não foi completamente elucidada (REIMER et al., 2018; ULLRICH et al., 2018). As maiores descobertas sobre a circuitaria envolvida são decorrentes de trabalhos de neuroimagem funcional, nos quais pesquisadores observaram um possível vínculo entre manifestações clínicas do TOC e mudanças na atividade no circuito córtico-estriado-tálamocortical (CETC) (GRAYBIEL, RAUCH, 2000; ULLRICH et al., 2018) associado aos neurotransmissores glutamato e ácido gama-aminobutírico (GABA). Outros estudos indicam a participação de neurotransmissores como a serotonina (5-hidroxitriptamina - 5-HT) e a dopamina (DA) (CORDIOLI, 2014), além do envolvimento de hormônios ovarianos (estrógeno e progesterona) (MITRA et al., 2016), apontados como moduladores do TOC por provocarem ou intensificarem os sintomas em mulheres (GOLTSEKER et al., 2015).

O funcionamento normal do circuito CETC, envolve saídas (eferentes) glutamatérgicas do córtex cerebral até o estriado. São descritas duas vias, direta e indireta, que correlacionam áreas cerebrais aos sintomas obsessivo-compulsivos. Esses dois trajetos favorecem ou inibem comportamentos, sendo que, a via direta apresenta entradas (aferentes) excitatórias do córtex cerebral ao estriado (caudado e putâmen). Deste partem neurônios GABAérgicos ao globo pálido segmento interno e substância negra reticulada, promovendo a inibição destas estruturas. Com esta inibição, o tálamo deixa de receber aferências inibitórias 
promovendo a excitação, via glutamato, ao córtex órbitofrontal, permitindo a realização dos movimentos voluntários. Na via indireta há a participação do globo pálido segmento externo e núcleos subtalâmicos, antagonizando a via direta. O córtex cerebral envia projeções glutamatérgicas ao estriado, que, por sua vez, envia projeções GABAérgicas ao globo pálido segmentos interno e externo. O globo pálido segmento externo envia eferência inibitória aos núcleos subtalâmicos. Estes enviam projeções glutamatérgicas ao globo pálido segmento interno e deste partem projeções GABAérgicas ao tálamo que, inibido, deixa de enviar sinal excitatório ao córtex órbitofrontal, impedindo a geração de movimentos indesejados (BAXTER; CRUCINI, 1995; SAXENA; RAUCH, 2000; WANG; SIMPSON; DULAWA, 2009).

Os núcleos da base eram considerados importantes apenas no controle do comportamento motor. No entanto, já foi demonstrado que eles possuem outras funções como memória implícita e processamento de vivências cognitivas (pensamentos, ideias e imagens) (MIGUEL FILHO, 1995). D acordo com GRAYBIEL e RAUCH (2000), alterações da circuitaria CETC seriam os principais agentes envolvidos na fisiopatologia do TOC (MILAD; RAUCH, 2012; TING; FENG, 2011; CORDIOLI, 2014). Esses achados culminaram na hipótese, denominada modelo frontoestriatal ou corticoestriatal (SAXENA; RAUCH, 2000).

Os núcleos da base abrangem características de aprendizagem e reforço, ou seja, funções cognitivas e motivacionais, que se relacionam com o TOC. Frequentemente, pacientes com TOC apresentam comportamentos repetitivos, dificuldade em cessar rituais, e comportamentos motores considerados lentos (FERNANDES; CARVALHO, 2016).

Nesse transtorno, há um desequilíbrio entre as vias direta e indireta, além da participação dos neurotransmissores glutamato, GABA, 5-HT e DA que possui papel fundamental em processos cognitivos e afetivos, como o processamento de recompensas, possivelmente alterado no TOC (STEIN et al., 2020) (Figura 3). 

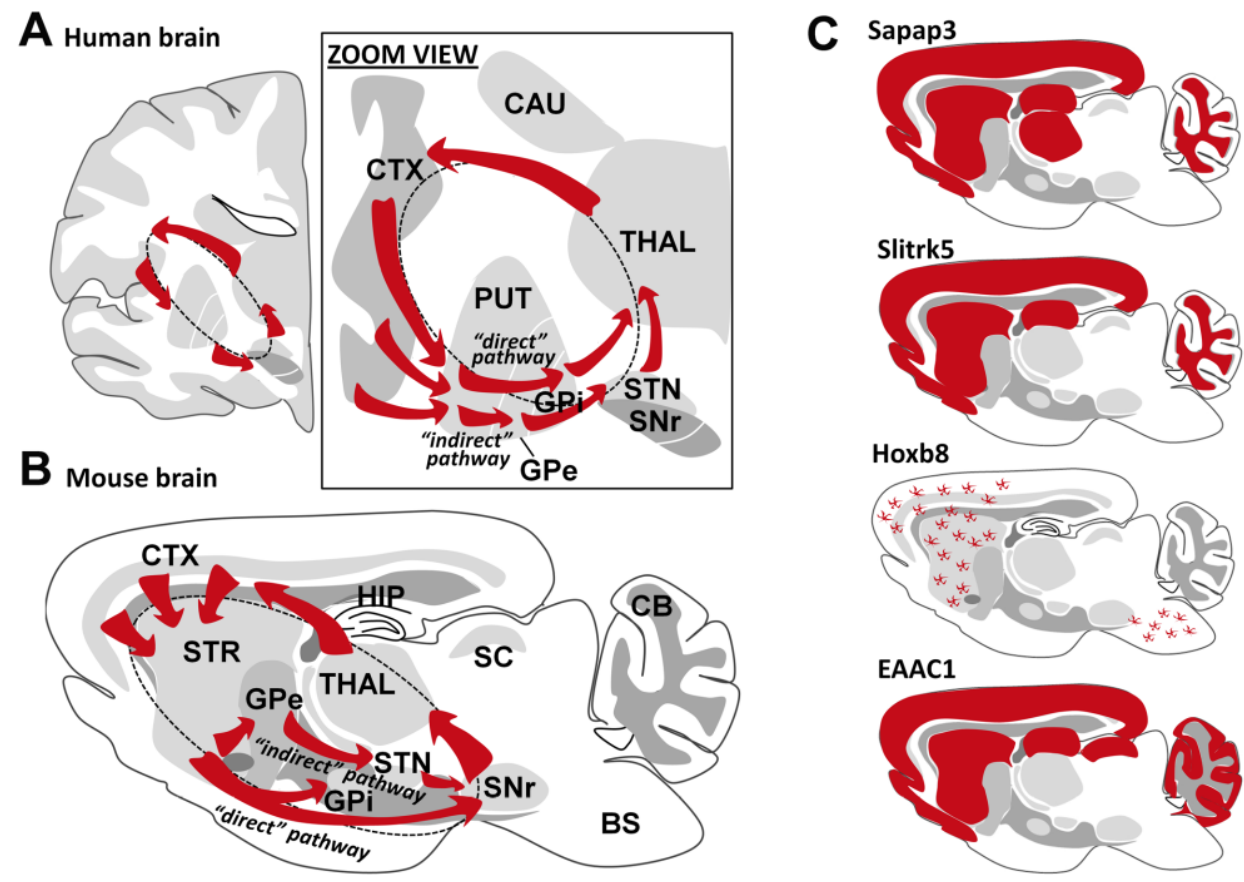

Figura 3- Papel central do circuito CETC no transtorno obsessivo-compulsivo (TOC) em humanos e comportamentos compulsivo-repetitivos em roedores. A. Diagrama de uma seção do cérebro humano (coronal) ilustrando o loop da circuitaria CETC de forma simplificada. No painel direito, temos a visão ampliada do loop ilustrando as vias de projeção "direta" e "indireta" mescladas, mas funcionalmente distintas, dos núcleos da base que parecem exercer controle oposto sobre a seleção de comportamentos motores. B. Diagrama da seção do cérebro (corte sagital) de roedor ilustrando o loop da circuitaria CETC. Abreviaturas: CTX, córtex; STR, estriado; CAU, caudado; PUT, putâmen; HIP, hipocampo; THAL, tálamo; STN, núcleo subtalâmico; SNr, substantia nigra pars reticulata; GPe, globus pallidus porção externa; GPi, globus pallidus porção interna; SC, colículo superior; BS, tronco cerebral; CB cerebelo. C. Diagrama altamente simplificado dos padrões de expressão dos genes candidatos de TOC em todo o cérebro do roedor, demonstrando extensa sobreposição de expressão nas regiões do cérebro que compõem o circuito CETC. (Adaptado de TING; FENG, 2011).

O glutamato apresenta ação excitatória e está presente no cérebro e na medula espinhal de mamíferos (CURTIS, WATKINS 1960, HAYASHI 1952), atuando em receptores $N$ methyl-D-aspartate (NMDA), a-amino-3-hydroxy-5-methyl-4-isoxazolepropionic acid (AMPA) e Kainato (MELDRUM, 2018). Pesquisas sobre o envolvimento desse neurotransmissor no TOC têm sido consideradas promissoras, visto que foram observados níveis anormais de glutamato em pacientes com TOC, além de se relacionarem à hiperatividade metabólica nos circuitos córtico-estriado-talâmico, o que corrobora a realização de estudos sobre mutações em genes relacionados ao glutamato. As mutações podem ser no gene da proteína associada ao SAP90/PSD95- 3 (SAPAP3/DLGAP3), no receptor ionotrôpico glutamatérgico N-methyl D-aspartato 2B (GRIN2B, NMDAR2B), 
receptores ionotrópicos, kainato 2 e 3 (GRIK2/EAA4 e GRIK3/EAA5) e, no transportador do glutamato de alta afinidade neuronal/epitelial (SLC1A1, EAAC1) (SANTOS SAMPAIO, 2013).

As proteínas da família SAPAP são componentes de densidade pós-sináptica (PSD) que interagem com as famílias de proteínas PSD95 e Shank, proteínas de arcabouço póssináptico de vários domínios em sinapses excitatórias. Unidos, estes grupos de proteínas formam um complexo de arcabouço chave que controla o fluxo e orientação de receptores de neurotransmissores e moléculas de sinalização em direção a membrana pós-sináptica das sinapses excitatórias. A proteína da família SAPAP pode ser codificada por quatro genes, sendo os genes SAPAP 1, 3 e 4 fortemente e diferencialmente expressos em várias áreas cerebrais (KINDLER et al., 2004; WELCH; WANG; FENG, 2004), enquanto a SAPAP3 é o único gene bastante expresso no estriado. Juntos estes dados sugerem que desequilíbrios na transmissão excitatória em sinapses corticoestriatais podem estar associados a vários fatores do TOC (WELCH et al., 2007).

Diferente do glutamato, o GABA é o principal neurotransmissor inibitório presente no córtex cerebral de mamíferos, e pode atuar em receptores $\mathrm{GABA}_{\mathrm{A}}$ e $\mathrm{GABA}_{\mathrm{B}}(\mathrm{MCCORMICK}$, 1989). Desequilíbrios no sistema GABAérgico foram verificados em vários transtornos mentais (GONZALEZ-BURGOS; LEWIS, 2012; HAN et al., 2014), como o TOC (GREENBERG et al., 2000; ZAI et al., 2005; RICHTER et al., 2012), uma vez que foi comprovada a ação inibitória das vias GABAérgicas sobre as vias glutamatérgicas nas áreas do córtex órbito frontal, estriado, tálamo e cíngulo anterior (RODRIGUEZ et al., 2016). Além disso, mutações genéticas no receptor para GABA (GABRR1), foram observadas em estudos realizados com humanos diagnosticados com TOC (SANTOS SAMPAIO, 2013).

PORSOLT (1993) apontou em seu trabalho a associação da 5-HT em psicopatologias como depressão, ansiedade, psicose, agressão psicopatológica, e TOC. Apresenta sete 
subtipos de receptores (5-HT $1-7$ ) (OLIVEIRA, 2013), dos quais, os tipos 5- $\mathrm{HT}_{1 \mathrm{~A}}$ e 5-HT $2 \mathrm{~A}$ (CARHART-HARRIS; NUTT, 2017) estão bastante relacionados a transtornos psiquiátricos e a seus tratamentos (CHATTOPADHYAY, 2007). A relação entre o TOC e 5-HT descrita por GRAEFF, 2001), foi demonstrada devido à inervação serotoninérgica prosencefálica, advinda de áreas como núcleo mediano da rafe (NMR) e núcleo dorsal da rafe (NDR). O NMR projeta fibras serotoninérgicas para estruturas límbicas, enquanto o NDR inerva principalmente os núcleos da base. Desta forma, a projeção da via serotonérgica que parte do NDR para o núcleo caudado tem sido apontada por mediar a fisiopatogenia do TOC. Além disso, receptores 5-HT subtipo 5- $\mathrm{HT}_{1 \mathrm{~B}}$ e 5-HT $\mathrm{H}_{1 \mathrm{D}}$ encontrados no estriado, também foram indicados como possíveis participantes, explicando o fato de fármacos como Sumatriptan, agonista seletivo de 5-HT $\mathrm{HD}_{1 \mathrm{D}}$, acentuar os sintomas do TOC, enquanto os ISRS, previamente citados, reduzem os sintomas obsessivos-compulsivos, tornando está classe de medicamentos, a primeira escolha para o tratamento do TOC (CORDIOLI, 2014).

SANTOS SAMPAIO (2013) demonstrou a relação entre o TOC e o envolvimento de genes e tipos de receptores relacionados à serotonina. São exemplos, o gene do transportador de serotonina (SLC6A4, 5-HTT, SERT, 5HTTLPR) importante alvo dos fármacos ISRS; receptor de serotonina tipo $2 \mathrm{~A}\left(5-\mathrm{HTR}_{2 \mathrm{~A}}\right)$; tipo $1 \mathrm{~B}\left(5-\mathrm{HTR}_{1 \mathrm{~B}}\right)$; tipo $2 \mathrm{C}\left(5-\mathrm{HTR}_{2 \mathrm{C}}\right)$, triptofano hidroxilase 1 (TPH1), e triptofano hidroxilase 2 (TPH2).

A participação da DA no TOC é elucidada através da inervação dopaminérgica no circuito fronto-núcleos da base-tálamo. Aproximadamente $80 \%$ da DA está presente no cérebro, e seus receptores tipo D1 $\left(\mathrm{D}_{1}\right.$ e $\left.\mathrm{D}_{5}\right)$ e $\mathrm{D} 2\left(\mathrm{D}_{2}, \mathrm{D}_{3}\right.$ e $\left.\mathrm{D}_{4}\right)$, estão associados aos efeitos que este neurotransmissor produz (VALLONE; PICETTI; BORRELLI, 2000). A DA está relacionada ao controle dos movimentos e apresenta relação direta com a doença de Parkinson, uma vez que nessa os níveis de DA estão reduzidos. Além de seu envolvimento na doença de Parkinson, estudos pré-clínicos e clínicos, demonstraram que a DA também está 
associada ao TOC (DENYS et al., 2004), já que há a disfunção nos núcleos da base, altamente inervados por DA, resultam no aparecimento de sintomas obsessivos-compulsivos (CARMIN et al., 2002). A literatura aponta a correlação entre a DA e a circuitaria CETC (principalmente no núcleo caudado), prejudicando as atividades nas vias direta e indireta (SAXENA; RAUCH, 2000; ALEXANDER; CRUTCHER, 1990).

Fatores genéticos como alterações em genes relacionados a DA, podem ocasionar o aparecimento de sintomas obsessivos-compulsivos, ou comportamentos estereotipados bastante semelhantes aos comportamentos observados no TOC. Algumas das alterações são no gene do transportador de dopamina (DAT1 ou SLC6A3), e em outros em receptores, como $\mathrm{D}_{2}$ (DRD2), $\mathrm{D}_{3}(\mathrm{DRD} 3)$, e $\mathrm{D}_{4}$ (DRD4) (SANTOS SAMPAIO, 2013).

A modelagem animal do TOC é dificil já que os comportamentos compulsivos e estereotipados podem ser mimetizados, não assim as obsessões (MAN et al., 2004). Sabe-se também que as manifestações cognitivas e motoras do TOC estão diretamente associadas (KORFF; HARVEY, 2006). Portanto, consegue-se compreender o porquê a modelagem de comportamentos compulsivos é significativa para modelos de TOC.

2. Análise do comportamento compulsivo através de modelos animais

De acordo com WILNER (1991), modelos animais de TOC devem apresentar três tipos de validade. Na primeira, denominada validade de face ou aparente, os sintomas devem ser mimetizados assim como observados em humanos. A segunda validade é a de constructo, que se refere à dependência ou esclarecimento dos mecanismos implícitos consequentes do TOC; e, por último, a validade preditiva, que representa quando o tratamento utilizado em humanos possui o mesmo efeito em modelos animais (OVERALL, 2000; NUNES; HALLAK, 2014; MCGONIGLE 2014). 
Algumas das manifestações clínicas observadas no TOC podem ser reproduzidas em animais (GISPEN, ISAACSON, 1981; DRAGO; BOHUS, 1981), por meio de manipulação genética (PAULS et al., 2014) e estressores ambientais (MARINHO et al., 2011). Comportamentos compulsivos como checking (verificação excessiva) e exacerbated grooming (limpeza exacerbada) (MARRONI et al., 2007), por exemplo, têm sido mimetizados em roedores.

O comportamento de exploração em roedores é considerado natural quando os animais são confrontados com ambientes novos (MONTGOMERY, 1950). Entretanto, esse comportamento pode se tornar anormal, e ser descrito como exploração excessiva ou excessive checking behavior, que em ratos é demonstrado como verificação excessiva de um determinado espaço, que o animal volta repetidamente para conferi-lo (ALKHATIB; DVORKIN-GHEVA; SZECHTMAN, 2013).

O grooming é outro comportamento bastante observado em roedores. Os animais seguem uma sequência padronizada para realizá-lo, dada na direção céfalo-caudal (GOLANI; FENTRESS, 1985; BERRIDGE; FENTRESS， 1987; BERRIDGE; ALDRIDGE，2000; KALUEFF et al., 2007; KALUEFF et al., 2016a). Apesar de o grooming ser considerado fisiológico em animais, ele pode ser modificado e se tornar excessivo (AHMARI et al., 2013; KALUEFF et al., 2016; ROTH et al., 2013).

Entretanto, o grooming não pode ser considerado de forma isolada e com completa exatidão como modelo fixo de qualquer patologia (KALUEFF et al., 2016). O que se observa é que quando este comportamento se torna excessivo pode ser comparado com o comportamento compulsivo de limpeza semelhante ao notado em pacientes com TOC (MARRONI et al., 2007). A manifestação da autolimpeza excessiva está intimamente associada aos núcleos da base, além de ser modulada pela dopamina (HOFFMAN, 2011). Além disso, Presti; Mikes e Lewis (2003) apontam que comportamentos estereotipados são 
decorrentes da elevada atividade de feedback dos circuitos motores dos núcleos da base.

O grooming também pode ser modulado pelo sistema límbico, especialmente hipotálamo e amígdala, através do núcleo basolateral da amígdala (BLA), do núcleo central amígdala (CeA) e porção dorsal do núcleo medial da amígdala (MeApd). A amígdala está relacionada a comportamentos motivacionais, de medo, ansiedade e desejo (HONG; KIM; ANDERSON, 2014). Enquanto o hipotálamo participa da regulação neuroendócrina das funções cerebrais e comportamentais, como o próprio grooming, através de áreas como núcleo paraventricular (PVN) e hipotálamo dorsal (KALUEFF et al., 2016b). Em estudos com roedores, os autores verificaram que a administração no $\mathrm{CeA}$ de orexina $\mathrm{B}$, neuropeptídeo expresso no hipotálamo lateral com alta afinidade a receptores acoplados à proteína G, foi capaz de provocar aumento do grooming em hamsters (ALÒ et al., 2015). Já a administração de drogas no hipotálamo provoca aumento da autolimpeza em ratos, apontando que o PVN e o hipotálamo dorsal podem fazer parte de uma região específica responsável pela limpeza (ROELING et al., 1993).

2.1. Ferramentas comportamentais utilizadas para a validação de modelos animais de TOC

Existem instrumentos comportamentais que podem ser utilizados para auxiliar na validação dos modelos animais. Através desses testes conseguimos avaliar, por exemplo, comportamentos de verificação e grooming excessivo. Dentre as ferramentas comportamentais temos o teste de labirinto em cruz elevado (LCE) que é bastante utilizado no estudo da ansiedade e consiste em um labirinto formado por dois braços fechados por paredes e dois abertos (PELLOW; FILE, 1986). Os parâmetros usados para análise neste teste são: frequência de entradas, tempo de permanência em cada braço, comportamentos de deslocamento, levantar, esticar. $\mathrm{O}$ avaliador considera que a escolha entre braços abertos e fechados, além das entradas e tempo gasto nesses braços, é um índice extremamente importante na análise do comportamento do tipo ansioso, ou seja, quanto mais ansioso o 
animal estiver, maior será o tempo gasto nos braços fechados (HANDLEY; MITHANI, 1984; MORATO, 2006; PELLOW; FILE, 1986).

Dois testes utilizados por pesquisadores para a verificação dos comportamentos decorrentes do TOC são: O labirinto em Y que consiste em três braços fechados, e permite ao pesquisador avaliar a capacidade de memória espacial em roedores, analisando a capacidade de memorização do animal pelo local que acabou de explorar (TOYAMA, 2012). Já o labirinto em T elevado é obtido através do labirinto em cruz elevado (HANDLEY; MITHANI, 1984; MORATO, 2006; PELLOW; FILE, 1986), que consiste em um labirinto formado por dois braços fechados por paredes e dois abertos. Porém, no labirinto em T, a entrada de um dos braços fechados foi bloqueada. Assim, o animal é colocado na extremidade do braço fechado por três consecutivas, e o parâmetro aprendizagem é verificado através do tempo que o rato leva para sair do braço fechado durante as três tentativas. Posteriormente, o roedor é inserido na extremidade de um dos braços abertos e também será analisado por três períodos seguidos o parâmetro de fuga. Este teste é normalmente utilizado como modelo animal de transtornos de ansiedade generalizada, pânico e memória (VIANA; TOMAZ; GRAEFF, 1994).

Outro teste bastante utilizado é o campo aberto, que pode apresentar dois formatos, circular e quadrado. Esse teste é utilizado para analisar comportamento de ansiedade e atividade locomotora em roedores (SEIBENHENER; WOOTEN, 2015). E o marble burying test (MBT) que consiste em uma caixa em que são colocadas 24 bolas de gude (diâmetro 1 $\mathrm{cm}$ ) igualmente espalhadas na caixa coberta com aproximadamente $5 \mathrm{~cm}$ de maravalha. Ao final do teste são consideradas as esferas que estiverem cobertas (enterradas; buryed) pelo animal com 2/3 de maravalha sobre ela (GYERTÝAN, 1995). 
2.2. Modelos farmacológicos

\subsubsection{Quinpirole}

O tratamento crônico com Quinpirole, agonista do receptor de dopamina tipo D2, descrito por SZECHTMAN; SULIS; EILAM (1998) é capaz de induzir, em roedores, o checking behavior. Roedores tratados com essa droga apresentaram comportamento locomotor persistente no labirinto em Y e em campo aberto (SZECHTMAN; SULIS; EILAM, 1998) e quando expostos a lugares ou a objetos, esses animais tendem a verificar de maneira repetida o mesmo quadrante (HOFFMAN, 2011). DE HAAS et al. (2011) demonstraram que ratos Sprague - Dawley machos tratados cronicamente com Quinpirole por cinco semanas e submetidos ao teste de campo aberto apesentaram comportamento de verificação excessiva quando comparados a animais tratados com salina. Em outro estudo com administração crônica da mesma droga, em ratos Sprague - Dawley jovens, STRAATHOF et al. (2020) verificaram que estes animais também apresentaram comportamento de verificação excessiva em comparação aos animais controle.

O tratamento crônico com Quinpirole é eficiente em induzir o comportamento de verificação excessiva em roedores, reforçando a hipótese de que o sistema dopaminérgico exerce papel no TOC (GOODMAN et al., 1990). No entanto, em estudos clínicos com indivíduos com TOC, o Quinpirole não foi apontado como agravante dos sintomas obsessivos-compulsivos, provocando, em alguns casos, a melhora dos sintomas (INSEL et al., 1983). Além disso, a Clomipramina, inibidor não seletivo da recaptação de serotonina, fármaco utilizado no tratamento em indivíduos com TOC, também foi capaz de diminuir o comportamento de verificação excessiva em roedores (AUSTIN et al., 1991).

Portanto, este modelo pode auxiliar na compreensão de mecanismos fisiopatológicos importantes para o TOC, oferecendo ao pesquisador novas possibilidades pré-clínicas para tratamentos farmacológicos (AHMARI, 2015). Assim, o modelo aqui discutido possui boa 
qualidade de face, e preditiva. Mas, a validade de constructo é difícil de ser avaliada (SZECHTMAN; SULIS; EILAM, 1998; ZIKE et al., 2017).

\subsubsection{8-OH-DPAT}

Outra droga capaz de provocar o checking compulsive behavior é a 8-hidroxi-2- (di-npropilamino) -tetralina (8-OH-DPAT), agonista serotoninérgico 5-HT $1 \mathrm{~A}$ com atividade também em 5-HT 7 (YADIN; FRIEDMAN; BRIDGER, 1991). De acordo com Dek et al. (2015), ratos tratados com 8-OHDPAT, apresentaram diminuição do comportamento de alternância espontânea no labirinto em T elevado, sendo este comportamento considerado perseverante. ALKHATIB; DVORKIN-GHEVA; SZECHTMAN (2013) demonstraram que a 8-OH-DPAT também induz este mesmo comportamento em roedores quando submetidos ao campo aberto.

De acordo com Arora et al. (2013), camundongos machos Swiss albino adultos tratados com 8-OH-DPAT e submetidos ao LCE e MBT, apresentaram comportamento de verificação excessiva no LCE e aumento de bolas enterradas no MBT. Os comportamentos de excessive checking e MBT podem ser antagonizados pela Fluoxetina, favorecendo a validade preditiva (FERNÁNDEZ-GUASTI; ULLOA; NICOLINI, 2003).

Em humanos não foram observados comportamentos compulsivos que poderiam ser provocados por drogas agonistas 5-HT $\mathrm{HT}_{1 \mathrm{~A}}$ (ZIKE et al., 2017); além disso, apesar da administração aguda de 8-OH-DPAT reduzir, em roedores, o comportamento de alternância espontânea no labirinto em T, esse comportamento também pode ser sugestivo de prejuízo na memória de trabalho (DEK et al., 2015). Portanto, ZIKE et al. (2017) apontaram que esse modelo apresenta limitações na validação dos três domínios descritos anteriormente.

\subsection{3. m-CPP}


A metaclorofenilpiperazina (mCPP), agonista não seletivo de serotonina, foi uma das primeiras drogas utilizadas para o entendimento do TOC. Ela atua no sistema nervoso central (SNC) através dos receptores de serotonina do tipo $1_{\mathrm{A}-\mathrm{D}}$ e do tipo $2_{\mathrm{C}}\left(5-\mathrm{HT}_{1 \mathrm{~A}}, 5-\mathrm{HT}_{1 \mathrm{~B}}, 5-\mathrm{HT}_{1 \mathrm{C}}\right.$,

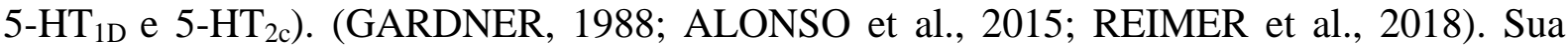
administração em roedores resultou no aumento da duração e frequência do grooming (KITCHENER; DOURISH, 1994; GRAF et al., 2003; REIMER et al., 2018; WRIGHT; RODGERS, 2014) e mastigação ritualística (STEWART; JENNER; MARSDEN, 1989; KREISS et al., 2013; REIMER et al., 2018), eventos comumente observados em pacientes com TOC (REIMER et al., 2018).

Graf et al. (2003) trataram ratos Sprague-Dawley machos com injeção intraperitoneal (i.p.) de m-CPP e observaram que os animais apresentaram aumento do comportamento de autolimpeza quando comparados aos animais controle. Além disso, Bagdy; Kalogeras; Szemeredi (1992) verificaram que ratos Sprague-Dawley machos após o tratamento com mCPP através de uma cânula na veia femoral esquerda apresentam comportamento de grooming excessivo, ereção peniana e aumento da concentração plasmática de OT. Contudo, esses animais ao serem tratados com Mianserina, antogonista de receptores $\alpha$-adrenérgicos, fármaco utilizado no tratamento da depressão, apresentaram diminuição do grooming, da ereção peniana e diminuição das respostas plasmáticas de OT. Em estudos clínicos, indivíduos com TOC que receberam m-CPP via oral apresentaram aumento dos sintomas obsessivos-compulsivos (ZOHAR et al., 1987), e quando tratados via oral com Metergolina, um antagonista com alta afinidade em 5- $\mathrm{HT}_{2 \mathrm{C}}$ e 5- $\mathrm{HT}_{2 \mathrm{~B}}$, apresentaram redução dos sintomas obsessivos-compulsivos (PIGOTT et al., 1991).

A relação entre m-CPP e o sistema serotoninérgico pode possibilitar a compreensão de como este sistema associa-se ao TOC. Já que foi demonstrada semelhança entre o comportamento de autolimpeza em animais e o TOC em humanos (GRAYBIEL; SAKA, 
2002). Portanto, o modelo farmacológico m-CPP e o papel da serotonina, são importantes para o possível entendimento da fisiopatologia desse transtorno, como os receptores, citados anteriormente, influenciam no surgimento dos sintomas obsessivos-compulsivos e a até mesmo a sua gravidade (GROSS-ISSEROFF et al., 2004).

\subsubsection{Ocitocina}

Drago et al. demonstraram em 1986 que a microinjeção intracerebroventricular (i.c.v.) de OT é capaz de provocar aumento do comportamento de autolimpeza em ratos SpragueDawley machos e fêmeas. Posteriormente, LECKMAN et al. (1994) demonstraram que a OT pode estar envolvida na fisiopatologia do TOC, já que níveis desse neuropeptídio estão elevados no líquido cefalorraquidiano de indivíduos com TOC. Entretanto, ALEMUS et al. (1999) encontraram dados divergentes. Para ALTEMUS et al (1999), resultados descritos por Leckman et al (1994) poderiam ter sido influenciados por uma metodologia diferente da utilizada em seu estudo. Enquanto Altemus et al. (1999) realizava a coleta de líquor entre $9 \mathrm{~h}$ e 10 h, LECKMAN et al. (1994) executavam o mesmo procedimento às 12 h 30 min, horário em que se observa o pico circadiano da expressão de OT.

Segundo GATI (2003), ratos da linhagem WAR, um modelo desenvolvido para o estudo da epilepsia, foram microinjetados com OT $(2,5 \mu \mathrm{g} / \mu \mathrm{l})$ no CeA e observou-se que a microinjeção foi capaz de retardar o desenvolvimento da crise audiogênica. Demonstrando que a OT apresentou efeito anticonvulsivo parcial. Em outro estudo, os autores verificaram que ratos Wistar machos microinjetados bilateralmente no CeA com OT $(2,5 \mu \mathrm{g} / \mu \mathrm{l}$ e $5 \mu \mathrm{g} / \mu \mathrm{l})$ apresentaram comportamento de hypergrooming, assim como a microinjeção de $5 \mu \mathrm{g} / \mu 1$ provocou alterações cardiorrespiratórias como aumento da pressão arterial, frequência cardíaca e ventilação (GRANJEIRO et al., 2014; MARRONI et al., 2007). Também foi verificado que ratos WAR machos microinjetados bilateralmente no CeA com OT $(2,5 \mu \mathrm{g} / \mu \mathrm{l}$ e $5 \mu \mathrm{g} / \mu \mathrm{l})$ apresentaram hypergrooming, além disso, foi demonstrado que a linhagem WAR 
apresenta comprometimento do sistema serotoninérgico (MARRONI, 2011; SANTOS, 2014) e foram apontados o envolvimento de áreas corticais e subcorticais, que normalmente são observadas durante a expressão de rituais ou comportamentos compulsivos (MARRONI et al., 2019 [pre-print]).

O comportamento de autolimpeza exacerbada induzido pela OT em roedores (PEDERSEN et al., 1988) pode representar um importante resultado no entendimento da fisiopatologia do TOC, Mais recentemente, (MARRONI et al., 2019 [pre-print]) observaram a ativação (Fos+) de áreas como córtex pré-frontal, substância negra parte reticulada e compacta, mencionadas anteriormente, consideradas importantes por participarem do circuito CETC.

2.3. Modelos genéticos 2.2.1. SAPAP3

Welch et al. (2007) sugere que a deleção de SAPAP3 ${ }^{-/-}$em camundongos, leve ao aumento dos comportamentos ansiogênico e compulsivo de limpeza. Outros estudos corroboram os achados associando-os a danos em sinapses cortico-estriatais e a indução do comportamento compulsivo de limpeza (BURGUIÈRE et al., 2015; STEIN et al., 2020). Indivíduos com TOC e deleção de $\mathrm{SAPAP} 3^{-/-}$apresentam alterações na projeção do córtex ao estriado, além de demonstrarem comportamento compulsivo de autolimpeza ((VAN DEN BOOM et al., 2019)). O tratamento com ISRS em humanos com TOC e em roedores foi eficaz na redução dos sintomas obsessivos-compulsivos em indivíduos, e comportamentos de grooming excessivo em ratos, conferindo ao modelo validade preditiva (BURGUIÈRE et al., 2015; STEIN et al., 2020).

Bienvenu et al. (2009) sugerem que o gene Sapap3 é promissor no estudo de comportamento de limpeza exacerbada em humanos. Aspectos como comportamento compulsivo, aumento da ansiedade e déficits cognitivos são alguns dos comportamentos 
observados em roedores, que se assemelham a comportamentos notados em pacientes com TOC. Porém, ainda são necessários novos estudos para compreender e comprovar essa associação genética da SAPAP3 ${ }^{-/-}$com esse transtorno (VAN DEN BOOM et al., 2019).

\subsubsection{SLITRK5}

O SLITRK, pertencente à família de proteínas integrais de membrana, controla o progresso de neurites no neurodesenvolvimento (ARUGA; MIKOSHIBA, 2003). Pesquisas realizadas em camundongos Slitrk $5^{-/-}$demonstraram elevação nos níveis de expressão de FosB, provocada pelo aumento da atividade neuronal restrita ao córtex orbitofrontal. Foram encontradas também anormalidades anatômicas no corpo estriado, como diminuição do volume, de dendritos estriatais, e de receptores glutamatérgicos. Foram observados comportamentos de autolimpeza excessiva nesses animais. Além disso, quando esses camundongos foram expostos ao MBT , apresentam aumento no comportamento de enterrar as bolas de gude, além de, aumento do comportamento ansiogênico, observado nos testes de campo aberto e LCE (SHMELKOV et al., 2010). Após tratamento crônico (21 dias) com Fluoxetina, os animais tiveram melhora nos comportamentos compulsivos (ALONSO et al., 2015). Song et al. (2017) demonstraram que mutações em SLITRK5 contribuem para o risco genético de TOC em humanos. Além disso, sugere-se que essa informação esteja associada ao desequilíbrio sináptico de neurônios corticoestriatais, e consequentemente na fisiopatologia do TOC.

\subsubsection{EEAC1}

Os EEATS são conhecidos como transportadores de aminoácidos excitatórios dependentes de sódio, sua função é regular as concentrações extracelulares de glutamato no SNC. Eles agem limitando a difusão de glutamato em regiões extrasinápticas (SCIMEMI; TIAN; DIAMOND, 2009; TING; FENG, 2011), e medeiam o transporte de cisteína neuronal 
(AOYAMA et al., 2006; TING; FENG, 2011). Estudos identificaram cinco tipos de EAATs. A exemplificar; o transportador de glutamato-aspartato (GLAST ou EAAT1) localizado principalmente nos astrócitos; o transportador de glutamato 1 (GLT-1 ou EAAT2); e os EAAC1 ou EAAT3, EAAT4 e EAAT5, localizados em neurônios. Os EAAT4 e EAAT5 localizam-se nas células de Purkinje cerebelares e da retina, enquanto o EAAC1 é altamente expresso em neurônios de todo o sistema nervoso (AOYAMA et al., 2006; ARRIZA et al., 1997; ROTHSTEIN et al., 1994; SHASHIDHARAN et al., 1997).

Aoyama et al. (2006) demonstraram que ratos Knockout EAAC1 ${ }^{-/-}$apresentaram maior comportamento agressivo e aumento do comportamento de autolimpeza. Além disso, cerca de $30 \%$ dos roedores sofreram perda de pelo. Contudo, esse modelo não apresenta boa validade de face, uma vez que, diferente dos demais modelos genéticos para animais knockout, nesse modelo observamos o aumento da expressão de EAAT3 (WENDLAND et al., 2009). Entretanto, foi apontado que esse modelo apresenta forte validade de constructo, divergindo neste ponto, dos modelos genéticos citados acima (SAMUELS et al., 2011; ZIKE et al., 2017).

\subsubsection{HoxB8}

O HoxB8 é um dos 39 fatores de transcrição da família Hox (GREER; CAPECCHI, 2002). Greer e Capecchi, (2002), apontaram que camundongos Knockout HoxB8 ${ }^{-/-}$apresentam comportamento de autolimpeza excessiva, o que resulta em extensas perdas de pelos e lesões cutâneas. No entanto, ZIKE et al. (2017), sugeriram que, diferente dos modelos genéticos anteriores, não existem dados que comprovem a participação do gene HoxB8 ou de sua família na fisiopatologia do TOC em humanos. Este modelo apresenta evidente validade de face, porém, não foram verificadas validade de constructo e preditiva, por meio do tratamento com ISRS. 
A Tabela 1 abaixo demonstra algumas manifestações clínicas compulsivas descritas na literatura que podem ser mimetizadas em modelos animais experimentais.

Tabela 1 - Manifestações clínicas do Transtorno Obsessivo Compulsivo (TOC) em humanos, que podem ser mimetizadas em modelos animais experimentais.

\begin{tabular}{|c|c|c|c|}
\hline $\begin{array}{c}\text { Manifestações } \\
\text { clínicas observadas } \\
\text { em humanos }\end{array}$ & Referência & $\begin{array}{c}\text { Comportamentos } \\
\text { observados em } \\
\text { animais }\end{array}$ & Referência \\
\hline Verificação & $\begin{array}{l}\text { Henderson, Pollard, } \\
1988 . \\
\text { Rasmussen, Eisen, } \\
1991 . \\
\text { Szechtman et al., } \\
2001 . \\
\text { Hinds et al., } 2012 . \\
\text { Salkovskis, Millar, } \\
\text { Gregory, 2016. }\end{array}$ & Checking & $\begin{array}{l}\text { Szechtman, } \\
\text { Sulis, Eilam, } \\
1998 . \\
\text { Szechtman et } \\
\text { al., 2001. } \\
\\
\text { Alkhatib, } \\
\text { Dvorkin- } \\
\text { Gheva, } \\
\text { Szechtman, } \\
2013 . \\
\text { Eagle et al., } \\
2014 . \\
\\
\text { Dorfman, } \\
\text { Szechtman, } \\
\text { Eilam, 2019. }\end{array}$ \\
\hline Limpeza & $\begin{array}{l}\text { Hodgson, Rachman, } \\
1972 . \\
\text { Rachman, } 2003 . \\
\text { Hinds et al., } 2012 . \\
\text { Taylor, Purdon, } \\
\text { 2016. } \\
\text { Wahl et al., } 2020 .\end{array}$ & Excessive Grooming & $\begin{array}{l}\text { Welch et al., } \\
2007 . \\
\text { Berridge et } \\
\text { al., } 2005 . \\
\text { Marroni et al., } \\
2007 . \\
\text { Ahmari et al., } \\
2013 . \\
\text { Szechtman } \text { et } \\
\text { al., } 2017 .\end{array}$ \\
\hline
\end{tabular}




\section{Farmacoterapia: tratamento do TOC}

A farmacoterapia para o TOC se dá, como discutido anteriormente, através do uso de ISRS e psicoterapia (KORAN et al., 2007; PITTENGER; BLOCH, 2014)). A abordagem terapêutica entre crianças e adolescentes difere do indicado a adultos. Apesar de estudos demonstrarem os benefícios dos ISRS em crianças, as precauções com os efeitos colaterais são consideráveis (SOOMRO, 2012). Fármacos como a Fluoxetina, Sertralina, Fluvoxamina e Clomipramina foram aprovados para uso pediátrico. Entretanto, doses altas utilizadas em adultos não são capazes de produzir efeitos benéficos em crianças (PITTENGER; BLOCH, 2014). Apesar dos ISRS serem a primeira escolha de tratamento farmacológico, esses medicamentos são efetivos somente para alguns indivíduos (ABRAMOWITZ; WHEATON; STORCH, 2008). Porém, esse resultado pode ser melhorado através da possibilidade de associação entre o uso dos ISRS e de antipsicóticos (Risperidona) (BLOCH et al., 2006).

Vista como terapia de primeira escolha no tratamento do TOC, a terapia cognitivacomportamental (TCC), por meio da exposição e prevenção de resposta (ERP) (FINEBERG et al., 2015), baseia-se na avaliação, psicoeducação, lista de sintomas, diário de sintomas obsessivos-compulsivos, exposição e prevenção de resposta, além de modelação, técnicas cognitivas, prevenção de recaída e alta (NEUFELD, FALCONE, RANGÉ, 2015). A EPR, consiste na exposição do confronto de forma sistemática, constante e duradoura de estímulos que causam ansiedade e o desejo de realizar rituais compulsivos. O tratamento com EPR compreende expor o indivíduo com TOC a situações que causem desconforto. Como exemplo, solicita-se ao paciente que acredita que o número 13 está associado ao azar, escrever tal número imaginando que ele realmente lhe causaria algum prejuízo. Além disso, esse paciente teria que se negar a executar qualquer ritual a fim de diminuir a ansiedade ou afastar 
o azar. Desta forma, esse indivíduo não poderia realizar orações, ou verificar se ele está seguro (ABRAMOWITZ; TAYLOR; MCKAY, 2009).

Portanto, o tratamento com EPR é possível através da exposição in vivo ou imaginária. Ambas as formas possuem vantagens significativas e duradouras em que o paciente dispensa o ritual e aprende que a ansiedade diminui. Embora estudos discutam sobre a eficácia da EPR, alguns autores ainda demonstram que pacientes que aderiam a essa alternativa terapêutica continuam a apresentar sintomas importantes do TOC (NEUFELD; FALCONE; RANGÉ, 2015). McKay et al. (2015), demonstraram que a associação da EPR às técnicas de reestruturação cognitiva pode oferecer melhora no tratamento, sobretudo das obsessões. São considerados características clínicas, subtipos e gravidade dos sintomas no momento de propor a abordagem terapêutica (PETERSEN, 2019).

\section{Conclusão}

Apesar de modelos biológicos para o TOC apontarem para o desequilíbrio entre neurotransmissores, mutações genéticas, e atividade anormal da circuitaria CETC, esses modelos ainda não conseguiram explicar ou mimetizar completamente o transtorno. Mesmo que existam modelos animais que demonstrem certo grau de similaridade com as alterações que ocorrem em humanos com TOC, a etiologia desse transtorno ainda permanece sem respostas.

Analisando os três tipos de validade descritos anteriormente, percebemos que as validades de face e preditivas são de fácil alcance do pesquisador. Enquanto a validade de constructo permanece como a mais desafiadora. Isto relaciona-se a busca pelo conhecimento da etiologia do TOC. De forma geral, os modelos genéticos apresentam prós e contras, assim como os modelos farmacológicos. Nem todos os estudos sobre mutações genéticas conseguem demonstrar boa validade preditiva, por mais que apresentem boa validade de face. 
Já os modelos farmacológicos apresentam boa validade preditiva, e de face, porém, a validade de constructo é difícil de ser verificada com tanta similaridade ao que é descrito como alterado ou anormal no TOC em humanos. Portanto, é interessante investigar o papel dessa validade (constructo), e os fatores que podem influenciá-la, correlacionando - a à gravidade dos sintomas obsessivos-compulsivos, assim como, a efetividade de tratamentos farmacológicos. 


\section{Referências Bibliográficas}

ABRAMOWITZ, J. S.; TAYLOR, S.; MCKAY, D. Obsessive-compulsive disorder. The Lancet, v. 374, n. 9688, p. 491-499, 2009.

ABRAMOWITZ, J. S.; WHEATON, M. G.; STORCH, E. A. The status of hoarding as a symptom of obsessive-compulsive disorder. Behaviour Research and Therapy, v. 46, n. 9, p. 1026-1033, 2008.

ADMON, R. et al. Human vulnerability to stress depends on amygdala's predisposition and hippocampal plasticity. Proceedings of the National Academy of Sciences of the United States of America, v. 106, n. 33, p. 14120-14125, 2009.

AFONSO, F. 2006. Stress e TOC: um estudo exploratório. 78f. Dissertação (Mestrado em Psicologia Clínica) - Programa de Pós-graduação em Psicologia do Centro de Ciências da Vida da Pontífica, Universidade Católica de Campinas. 2006.

AHMARI, S. E. et al. Repeated Cortico-Striatal Stimulation Generates Persistent OCD-Like Behavior. Science, v. 340, n. 6137, p. 1234-1239, 2013.

AHMARI, S. E. Using mice to model Obsessive Compulsive Disorder: From genes to circuits. Neuroscience, v. 321, p. 121-137, 2016.

ALEXANDER, G. E.; CRUTCHER, M. D. Functional architecture of basal ganglia circuits: neural substrates of parallel processing. Trends in Neurosciences, v. 13, n. 7, p. 266-271, 1990.

ALKHATIB, A. H.; DVORKIN-GHEVA, A.; SZECHTMAN, H. Quinpirole and 8-OHDPAT induce compulsive checking behavior in male rats by acting on different functional parts of an OCD neurocircuit. Behavioural Pharmacology, v. 24, n. 1, p. 65-73, 2013.

ALÒ, R. et al. Central amygdalar nucleus treated with orexin neuropeptides evoke differing feeding and grooming responses in the hamster. Journal of the Neurological Sciences, v. 351, n. 1-2, p. 46-51, 2015.

ALONSO, P. et al. Animal models of obsessive-compulsive disorder: utility and limitations. v.11, p. 1939-1955, 2015.

ALTEMUS, M. et al. Normal CSF oxytocin and NPY levels in OCD. Biological Psychiatry, v. 45, n. 7, p. 931-933, 1999.

American Psychiatric Association. Diagnostic and Statistical Manual of Mental Disorders. 5th ed. Arlington, VA: American Psychiatric Publishing; 2013.

ANDERSEN, S. L. et al. Preliminary Evidence for Sensitive Periods in the Effect of Childhood Sexual Abuse on Regional Brain Development. J Neuropsychiatry Clin Neurosci. v. 20, 2008.

AOYAMA, K. et al. Neuronal glutathione deficiency and age-dependent neurodegeneration in the EAAC1 deficient mouse. Nature Neuroscience, v. 9, n. 1, p. 119-126, 2006.

ARGIMON, I. I. DE L.; BICCA, M. G.; RINALDI, J. Obsessive-compulsive disorder in adolescence. Revista Brasileira de Terapias Cognitivas, v. 3, n. 1, p. 4-11, 2007.

ARRIZA, J. L. et al. Excitatory amino acid transporter 5, a retinal glutamate transporter 
coupled to a chloride conductance. Proceedings of the National Academy of Sciences of the United States of America, v. 94, n. 8, p. 4155-4160, 1997.

ARUGA, J.; MIKOSHIBA, K. Identification and characterization of Slitrk, a novel neuronal transmembrane protein family controlling neurite outgrowth. Mol Cell Neurosci.; v.24, p.117-129, 2003.

AUSTIN, L. S. et al. Dopamine blocking activity of clomipramine in patients with obsessivecompulsive disorder. Biological Psychiatry, v. 30, n. 3, p. 225-232, 1991.

AYERS, L. W. et al. Oxytocin Reduces Background Anxiety in a Fear-Potentiated Startle Paradigm: Peripheral vs Central Administration. Neuropsychopharmacology, v. 36, n. 12, p. 2488-2497, 2011.

BABYGIRIJA, R. et al. Central and peripheral release of oxytocin following chronic homotypic stress in rats. Autonomic Neuroscience: Basic and Clinical, v. 167, n. 1-2, p. 56-60, 2012.

BAGDY, G.; KALOGERAS, K. T.; SZEMEREDI, K. Effect of 5-HT1C and 5-HT2 receptor stimulation on excessive grooming, penile erection and plasma oxytocin concentrations. European Journal of Pharmacology, v. 229, n. 1, p. 9-14, 1992.

BALE, T.L. et al. CNS Region-Specific Oxytocin Receptor Expression: Importance in Regulation of Anxiety and Sex Behavior. The Journal of Neuroscience. v. 21, n. 7, p. 25462552, 2001.

BARRETT, P. M.; HEALY, L. J. An examination of the cognitive processes involved in childhood obsessive-compulsive disorder. Behaviour Research and Therapy, v. 41, n. 3, p. 285-299, 2003.

BARTZ, J. et al. Oxytocin can hinder trust and cooperation in borderline personality disorder. Social Cognitive and Affective Neuroscience, v. 6, n. 5, p. 556-563, 2011.

BARTZ, J. A.; HOLLANDER, E. Is obsessive-compulsive disorder an anxiety disorder? Progress in Neuro-Psychopharmacology and Biological Psychiatry, v. 30, n. 3, p. 338352, 2006.

BAXTER, M.; CRUCINI, M. J. Business Cycles and the Asset Structure of Foreign Trade. International Economic Review, v. 36, n. 4, p. 821, 1995.

BERRIDGE, K.C. et al. Sequential super-stereotypy of an instinctive fixed action pattern in hyper-dopaminergic mutant mice: a model of obsessive compulsive disorder and Tourette's. BMC Biology. v. 3, n. 4, 2005,

BERRIDGE, K. C.; ALDRIDGE, J. W. Super-stereotypy II: Enhancement of a complex movement sequence by intraventricular dopamine D1 agonists. Synapse, v. 37, n. 3, p. 205$215,2000$.

BERRIDGE, K. C.; FENTRESS, J. C. Disruption of natural grooming chains. Psychobiology, v. 15, n. 4, p. 336-342, 1987.

BIENVENU, O. J. et al. Sapap3 and pathological grooming in humans: Results from the OCD collaborative genetics study. American Journal of Medical Genetics, Part B: Neuropsychiatric Genetics, v. 150, n. 5, p. 710-720, 2009.

BIRNBAUMER, M. Vasopressin receptors. Trends in Endocrinology and Metabolism, v. 
11, n. 10, p. 406-410, 2000.

BLOCH, M. H. et al. A systematic review: Antipsychotic augmentation with treatment refractory obsessive-compulsive disorder. Molecular Psychiatry, v. 11, n. 7, p. 622-632, 2006.

BOHUS, B. et al. Opposite effects of oxytocin and vasopressin on avoidance behaviour and hippocampal theta rhythm in the rat. Neuropharmacology, v. 17, n. 4-5, p. 239-247, 1978.

BRIDGES, R. S. Neuroendocrine regulation of maternal behavior. Frontiers in Neuroendocrinology, v. 36, p. 178-196, 2015.

BRIONES, A. et al. Stress-induced anhedonia is associated with an increase in Alzheimer's disease-related markers. British Journal of Pharmacology, v. 165, n. 4, p. 897-907, 2012.

BOWEN, M.T.; MCGREGOR, I.S. Oxytocin and vasopressin modulate the social response to threat: A preclinical study. The International Journal of Neuropsychopharmacology. v. 17, n. 10, p. 1621-1633, 2014.

BURGUIÈRE, E. et al. Striatal circuits, habits, and implications for obsessive-compulsive disorder. Current Opinion in Neurobiology, v. 30, p. 59-65, 2015.

CALDWELL, J. D. et al. A comparison of grooming behavior potencies of neurohypophyseal nonapeptides. Regulatory Peptides, v. 14, n. 3, p. 261-271, 1986.

CARHART-HARRIS, R. L.; NUTT, D. J. Serotonin and brain function: A tale of two receptors. Journal of Psychopharmacology, v. 31, n. 9, p. 1091-1120, 2017.

CARMIN, C. N. et al. Treatment of late-onset OCD following basal ganglia infarct. Depression and Anxiety, v. 15, n. 2, p. 87-90, 2002.

CAZALIS, M.; DAYANITHI, G.; NORDMANN, J. J. The role of patterned burst and interburst interval on the excitation-coupling mechanism in the isolated rat neural lobe. The Journal of physiology, v. 369, n. 1, p. 45-60, 1985.

CHATTOPADHYAY, A. Serotonin receptors in neurobiology. Frontiers in Neuroscience. 2007.

CHENG, B. et al. Gray matter alterations in post-traumatic stress disorder, obsessivecompulsive disorder, and social anxiety disorder. Frontiers in Behavioral Neuroscience, v. 9, n. AUGUST, p. 1-10, 2015.

CHINI, B.; FANELLI, F. Molecular basis of ligand binding and receptor activation in the oxytocin and vasopressin receptor family. Experimental Physiology. v. 85, p. 59s-66s, 2000.

CHOI, A. L. et al. Develomental neurotoxity fluoride Review. Environmental Health Perspectives, v. 120, n. 10, p. 1362-1368, 2012.

COLES, M. E. et al. Not just right experiences and obsessive-compulsive features: Experimental and self-monitoring perspectives. Behaviour Research and Therapy, v. 43, n. 2, p. 153-167, 2005.

CORDIOLI, A. V. Toc: Manual de Terapia Cognitivocomportamental para o transtorno obsessivo-compulsivo.Porto Alegre, RS: Artmed. 2ed. 2014.

COSTA, D.L.da. Potencialização de inibidores da recaptura de serotonina com $N$ - 
acetilcisteína no tratamento do transtorno obsessivo-compulsivo resistente: estudo duplo-cego e controlado. (2016). 120 f. Tese (Doutorado em Psiquiatria) - Faculdade de Medicina de São Paulo, Universidade de São Paulo. 2016.

COUGLE, J. R. et al. Distress tolerance and obsessions: An integrative analysis. Depression and Anxiety, v. 28, n. 10, p. 906-914, 2011.

COUTO, L.S.R.B.; et al.A heterogeneidade do Transtorno Obsessivo-Compulsivo (TOC): uma revisão seletiva da literatura. Contextos Clínic. [Internet] v. 3, n. 2, 2010.

CURTIS, D.R.; WATKINS, J.C. The excitation and depression of spinal neurones by structurally related amino acids. J. Neurochem. v. 6, p.117-141, 1960.

DABROWSKA, J. et al. Neuroanatomical evidence for reciprocal regulation of the corticotrophin-releasing factor and oxytocin systems in the hypothalamus and the bed nucleus of the stria terminalis of the rat: Implications for balancing stress and affect. Psychoneuroendocrinology, v. 36, n. 9, p. 1312-1326, 2011.

DE DREU, C.K.W. et al. The neuropeptide oxytocin regulates parochial altruism inintergroup conflict among humans. Science. v. 328, p. 1408-1411, 2010.

DE HAAS, R. et al. Behavioral pattern analysis and dopamine release in quinpirole-induced repetitive behavior in rats. Journal of Psychopharmacology, v. 25, n. 12, p. 1712-1719, 2011.

DE KLOET, E. R.; JOËLS, M.; HOLSBOER, F. Stress and the brain: From adaptation to disease. Nature Reviews Neuroscience, v. 6, n. 6, p. 463-475, 2005.

De OLIVEIRA, D.C.G. 2011. Estudo dos efeitos da ocitocina em modelos de ansiedade generalizada e de pânico em ratos e em voluntários saudáveis. 140f. Tese (Doutorado em Ciências) - Faculdade de Medicina de Ribeirão Preto, Universidade de São Paulo.

DE SOUZA, F. P. et al. Obsessive-compulsive inventory and obsessive-compulsive inventory-revised scales: Translation into Brazilian Portuguese and cross-cultural adaptation. Revista Brasileira de Psiquiatria, v. 30, n. 1, p. 42-46, 2008.

DEK, E. C. P. et al. Perseveration causes automatization of checking behavior in obsessivecompulsive disorder. Behaviour Research and Therapy, v. 71, p. 1-9, 2015.

DELANOY, R. L.; DUNN, A. J.; TINTNER, R. Behavioral responses to intracerebroventricularly administered neurohypophyseal peptides in mice. Hormones and Behavior, v. 11, n. 3, p. 348-362, 1978.

DEL-PORTO, J.A. Epidemiologia e aspectos transculturais do transtorno obsessivocompulsivo. Rev Bras Psiquiatr. v. 23(Supl II), p. 3-5, 2001.

DENYS, D. et al. Low level of dopaminergic D2 receptor binding in obsessive-compulsive disorder. Biological Psychiatry, v. 55, n. 10, p. 1041-1045, 2004.

DENYS, D. Pharmacotherapy of Obsessive-compulsive Disorder and Obsessive-Compulsive Spectrum Disorders. Psychiatric Clinics of North America, v. 29, n. 2, p. 553-584, 2006.

DEVOST, D.; WRZAL, P.; ZINGG, H.H. Oxytocin receptor signalling. Progress in Brain Research. v. 170, p. 167-176, 2008. 
DORFMAN, A.; SZECHTMAN, H.; EILAM, D. Social interaction modulates the intensity of compulsive checking in a rat model of obsessive-compulsive disorder (OCD). Behavioural Brain Research. v. 359, p. 156-164, 2019.

DRAGO, F. et al. Oxytocin potently enhances novelty-induced grooming behavior in the rat. Brain Research, v. 368, n. 2, p. 287-295, 1986.

DRAGO, F.; BOHUS, B. Hyperprolactinemia-induced excessive grooming in the rat: timecourse and element analysis. Behavioral and Neural Biology, v. 33, n. 1, p. 117-122, 1981.

EAGLE, D. M. et al. The dopamine D2/D3 receptor agonist quinpirole increases checkinglike behaviour in an operant observing response task with uncertain reinforcement: A novel possible model of OCD. Behavioural Brain Research. v. 264, p. 207-229, 2014.

EBERT, U.; LÖSCHER, W. Differences is mossy fibre sprouting during conventional and rapid amygdala kindling of the rat. Neuroscience Letters, v.190, p. 199 - 202, 1995.

ENGELMANN, M.; LANDGRAF, R.; WOTJAK, C. T. The hypothalamic-neurohypophysial system regulates the hypothalamic- pituitary-adrenal axis under stress: An old concept revisited. Frontiers in Neuroendocrinology, v. 25, n. 3-4, p. 132-149, 2004.

FERGUSON, J.N. et al. Oxytocin in the medialamygdala is essential for social recognition in the mouse. J. Neurosci. v. 21, p .8278-8285, 2001.

FERNANDES, P. A.; CARVALHO, M. R. DE. Alterações Neurobiológicas Verificadas a partir do Tratamento com Terapia Cognitivo-comportamental no Transtorno ObsessivoCompulsivo. Psicologia: Teoria e Pesquisa, v. 32, n. 2, p. 1-9, 2016.

FERNÁNDEZ-GUASTI, A.; ULLOA, R. E.; NICOLINI, H. Age differences in the sensitivity to clomipramine in an animal model of obsessive-compulsive disorder. Psychopharmacology, v. 166, n. 3, p. 195-201, 2003.

FINDLEY, D.B. et al. Development of the Yale Children's Global Stress Index (YCGSI) and its application in children and adolescents ith Tourette's syndrome and obsessive-compulsive disorder. J Am Acad Child Adolesc Psychiatry. v. 42, p. 450-457, 2003.

FINEBERG, N. A. et al. Obsessive-compulsive disorder (OCD): Practical strategies for pharmacological and somatic treatment in adults. Psychiatry Research, v. 227, n. 1, p. 114$125,2015$.

FOA, E. B. et al. The validation of a new obsessive-compulsive Inventory. Psychological Assessment, v. 10, n. September, p. 206-221, 1998.

FOA, E. B. et al. The obsessive-compulsive inventory: Development and validation of a short version. Psychological Assessment, v. 14, n. 4, p. 485-496, 2002.

FONTENELLE, L. F.; MENDLOWICZ, M. V.; VERSIANI, M. Clinical subtypes of obsessive-compulsive disorder based on the presence of checking and washing compulsions. Revista Brasileira de Psiquiatria, v. 27, n. 3, p. 201-207, 2005.

FONTENELLE, L. F.; MENDLOWICZ, M. V.; VERSIANI, M. The descriptive epidemiology of obsessive-compulsive disorder. Progress in Neuro-Psychopharmacology and Biological Psychiatry, v. 30, n. 3, p. 327-337, 2006.

FRENCH, J.A. et al. Neuropeptide diversity and the regulation of social behaviorin New World primates. Frontiers in Neuroendocrinology. 2016. 
GA̧DEK-MICHALSKA, A.; BUGAJSKI, J. Repeated handling, restraint, or chronic crowding impair the hypothalamic-pituitary-adrenocortical response to acute restraint stress. Journal of Physiology and Pharmacology, v. 54, n. 3, p. 449-459, 2003.

GARCIA-CAIRASCO, N. et al. New insights into behavioral evaluation of audiogenic seizures. A comparison of two ethological methods. Behavioural Brain Research, v. 48, n. 1, p. 49-56, 1992.

GARCIA-CAIRASCO, N. Learning about brain physiology and complexity from the study of the epilepsies. Brazilian Journal of Medical and Biological Research, v. 42, n. 1, p. 76-86, 2009.

GARCIA-CAIRASCO, N.; UMEOKA, E. H. L.; CORTES DE OLIVEIRA, J. A. The Wistar Audiogenic Rat (WAR) strain and its contributions to epileptology and related comorbidities: History and perspectives. Epilepsy and Behavior, v. 71, p. 250-273, 2017.

GARDNER, C. R. Potential Use of D R U G S M O D U L a T I N G 5Ht. v. 19, n. 3, p. 347$356,1988$.

GATI, C. del. C. Indução do comportamento de autolimpeza exacerbada "(Hypergrooming)" pela injeção intramigdaliana de ocitocina em ratos Wistar e seu efeito na expressão de crises audiogênicas em animais da cepa Wistar Audiogenic Rat (WAR). 2003. 82 f. Dissertação (Mestrado em Fisiologia) - Faculdade de Medicina de Ribeirão Preto, Universidade de São Paulo. 2003.

GIBBS, D. M. Dissociation of oxytocin, vasopressin and corticotropin secretion during different types of stress. Life Sciences, v. 35, n. 5, p. 487-491, 1984.

GIBBS, D. M. Immunoneutralization of oxytocin attenuates stress-induced corticotropin secretion in the rat. Regulatory Peptides, v. 12, n. 4, p. 273-277, 1985.

GIBBS, D. M. Oxytocin inhibits ACTH and peripheral catecholamine secretion in the urethane-anesthetized rat. Regulatory Peptides, v. 14, n. 2, p. 125-132, 1986.

GIL, M. Oxytocin in the medial preoptic area facilitates male sexual behavior in the rat. Department of Psychology, v. Dr. phil., n. 4, p. 435-443, 2010.

GIMPL, G. et al. Oxytocin receptors: Ligand binding, signalling and cholesterol dependence. Progress in Brain Research. v. 170, p. 193-204, 2008.

GIMPL, G.; FAHRENHOLZ, F.; GENE, C. The Oxytocin Receptor System: Structure , Function, and Regulation. v. 81, n. 2, p. 629-683, 2001.

GISPEN, WILLEM HENDRIK; WIEGANT, VICTOR M.; GREVEN, HONK M.; WIED, D. DE. THE INDUCTION OF EXCESSIVE GROOMING IN THE RAT BY INTRAVENTRICUIAR APPLICATION OF PEPTIDES DERIVED FROM ACTH STRUCTURE-ACTIVITY STUDIES. Life Sciences, v. 17, n. 5, p. 645-652, 1975.

GISPEN, W. H.; ISAACSON, R. L. ACTH-induced excessive grooming in the rat. Pharmacology and Therapeutics. v. 2, 1981.

GODOY, L. D. et al. A comprehensive overview on stress neurobiology: Basic concepts and clinical implications. Frontiers in Behavioral Neuroscience, v. 12, n. July, p. 1-23, 2018.

GOODMAN, W.; McDOUGLE, C.; PRICE, L. Pharmacotherapy of obsessive compulsive 
disorder. J Clin Psychiatry. v. 53, 1992.

GOODMAN, W.K. et al. Beyond the serotonin hypothesis: a role for dopamine in some forms of obsessive compulsive disorder? J Clin Psychiatry. v. 51, p. 36-58, 1990. GOODMAN, W. K. et al. The Yale-Brown obsessive compulsive scale: II. Validity. Archives of General Psychiatry, v. 46, n. 11, p. 1012 - 1016, 1989.

GOODMAN, W. K. et al. The Yale-Brown obsessive compulsive scale: I.Development, use, and reliability. Archives of General Psychiatry. v. 46, n. 11, p. 1006-1011, 1989.

GOLANI, I.; FENTRESS, J. C. Early ontogeny of face grooming in mice. Developmental Psychobiology, v. 18, n. 6, p. 529-544, 1985.

GOLTSEKER, K. et al. Signal attenuation as a rat model of obsessive compulsive disorder. Journal of Visualized Experiments, n. 95, p. 1-8, 2015.

GONZALEZ-BURGOS, G.; LEWIS, D. A. NMDA receptor hypofunction, parvalbuminpositive neurons, and cortical gamma oscillations in schizophrenia. Schizophrenia Bulletin, v. 38, n. 5, p. 950-957, 2012.

GONZALEZ, C. H. Transtorno obsessivo-compulsivo. v. 21, n. 1, 1999.

GRAEFF, F. G. Aspectos neuroquímicos: o papel da serotonina no TOC. Revista Brasileira de Psiquiatria, v. 23, n. suppl 2, p. 35-37, 2001.

GRAF, M. et al. m-CPP-induced self-grooming is mediated by 5-HT2C receptors. Behavioural Brain Research, v. 142, n. 1-2, p. 175-179, 2003.

GRAEFF, F.G. Serotonergic systems. Psychiatr Clin N Am. v. 20, p. 723-39, 1997.

GRANJEIRO, É. M. et al. Behavioral and cardiorespiratory responses to bilateral microinjections of oxytocin into the central nucleus of amygdala of wistar rats, an experimental model of compulsion. PLoS ONE, v. 9, n. 7, p. 1-11, 2014.

GRASSI-OLIVEIRA, R.; ASHY, M.; STEIN, L. M. Psychobiology of childhood maltreatment: Effects of allostatic load? Revista Brasileira de Psiquiatria, v. 30, n. 1, p. 60 68, 2008.

GRAYBIEL, A.M.; RAUCH, S.L. Toward a neurobiology of obsessive-compulsive disorder. Neuron. v. 28, p. 343-347, 2000.

GRAYBIEL, A. M.; SAKA, E. A genetic basis for obsessive grooming. Neuron, v. 33, n. 1, p. 1-2, 2002.

GREENBERG, B. D. et al. Altered cortical excitability in obsessive-compulsive disorder. Neurology, v. 54, n. 1, p. 142-147, 2000.

GREER, J. M.; CAPECCHI, M. R. Hoxb8 Is Required for Normal Grooming Behavior in Mice. Neuron, v. 33, n. 1, p. 23-34, 2002.

GROENINK, L. et al. HPA axis dysregulation in mice overexpressing corticotropin releasing hormone. Biological Psychiatry, v. 51, n. 11, p. 875-881, 2002.

GROSS-ISSEROFF, R. et al. Serotonergic dissection of obsessive compulsive symptoms: A challenge study with $\mathrm{m}$-chlorophenylpiperazine and sumatriptan. Neuropsychobiology, v. 50, n. 3, p. 200-205, 2004. 
GYERTYÁN, I. Analysis of the marble burying response: marbles serve to measure digging rather than evoke burying. Behavioural Pharmacology. v. 6, p. 24-31, 1995.

HAN, W. Y. et al. Oxytocin via its receptor affects restraint stress-induced methamphetamine CPP reinstatement in mice: Involvement of the medial prefrontal cortex and dorsal hippocampus glutamatergic system. Pharmacology Biochemistry and Behavior, v. 119, p. 80-87, 2014.

HANDLEY, S. L.; MITHANI, S. Effects of alpha-adrenoceptor agonists and antagonists in a maze-exploration model of 'fear'-motivated behaviour. Naunyn-Schmiedeberg's Archives of Pharmacology, v. 327, n. 1, p. 1-5, 1984.

HANSON, L. R. et al. Intranasal delivery of deferoxamine reduces spatial memory loss in APP/PS1 mice. Drug Delivery and Translational Research, v. 2, n. 3, p. 160-168, 2012.

HASHIMOTO, H.; UEZONO, Y.; UETA, Y. Pathophysiological function of oxytocin secreted by neuropeptides: A mini review. Pathophysiology, v. 19, n. 4, p. 283-298, 2012.

HAYASHI, T. A phisiologycal study of epileptic seizures following cortical stimulation in animals and its application to human clinics. Jpn. J. Phisiol. v. 3, p. 46-64, 1952.

HEINRICHS, M. et al. Social support and oxytocin interact to suppress cortisol and subjective responses to psychosocial stress. Biological Psychiatry, v. 54, n. 12, p. 13891398, 2003.

HENDERSON, J.G. Jr; POLLARD, C.A. Three types of obsessive compulsive disorder in a community sample. J Clin Psychol. v. 44, p. 747- 752, 1988.

HESSE, S. et al. Serotonin and dopamine transporter imaging in patients with obsessivecompulsive disorder. Psychiatry Research - Neuroimaging, v. 140, n. 1, p. 63-72, 2005.

HINDS, A. L. et al. When too much is not enough: Obsessive-compulsive disorder as a pathology of stopping, rather than starting. PLoS ONE. v. 7, p. 1-9, 2012.

HIRSCHTRITT, M. E.; BLOCH, M. H.; MATHEWS, C. A. Obsessive-compulsive disorder advances in diagnosis and treatment. JAMA - Journal of the American Medical Association, v. 317, n. 13, p. 1358-1367, 2017.

HODGSON, R. J.;RACHMAN, S. The effects of contamination and washing in obsessional patients. Behaviour Research and Therapy. v. 10, n. 2, p. 111-117, 1972.

HOFFMAN, K. L. Animal models of obsessive compulsive disorder: Recent findings and future directions. Expert Opinion on Drug Discovery, v. 6, n. 7, p. 725-737, 2011.

HONG, W.; KIM, D. W.; ANDERSON, D. J. Antagonistic control of social versus repetitive self-grooming behaviors by separable amygdala neuronal subsets. Cell, v. 158, n. 6, p. 13481361, 2014.

HUI, J. et al. Maternal separation exacerbates Alzheimer's disease-like behavioral and pathological changes in adult APPswe/PS1dE9 mice. Behavioural Brain Research, v. 318, p. 18-23, 2017.

ILLUM, L. Nasal drug delivery-possibilities, problems and solutions. Journal of Controlled Release. v. 87, p. 187-198; 2003. 
INSEL, T.R. The challenge of translation in social neuroscience: a review ofoxytocin, vasopressin, and affiliative behavior. Neuron. v. 65, p. 768-779, 2010.

INSEL, T. R. et al. D-Amphetamine in obsessive-compulsive disorder. Psychopharmacology, v. 80, n. 3, p. 231-235, 1983.

JENIKE, M.A. Obsessive-Compulsive Disorder. The New England Journal of Medicine. v. 350, n. 3; 2004.

JIN, D. et al. CD38 iscritical for social behaviour by regulating oxytocin secretion. Nature. v. 446, p .41-45, 2007.

JORDAN, B. K. et al. Lifetime and Current Prevalence of Specific Psychiatric Disorders Among Vietnam Veterans and Controls. Archives of General Psychiatry, v. 48, n. 3, p. 207 $215,1991$.

JUSTICE, N. J. The relationship between stress and Alzheimer's disease. Neurobiology of Stress, v. 8, n. January, p. 127-133, 2018.

KALUEFF, A. V. et al. Analyzing grooming microstructure in neurobehavioral experiments. Nature Protocols, v. 2, n. 10, p. 2538-2544, 2007.

KALUEFF, A. V. et al. Neurobiology of rodent self-grooming and its value for translational neuroscience. Nature Reviews Neuroscience, v. 17, n. 1, p. 45-59, $2016 \mathrm{a}$.

KALUEFF, A. V. et al. Neurobiology of rodent self-grooming and its value for translational neuroscience. Nature Reviews Neuroscience, v. 17, n. 1, p. 45-59, 2016 b.

KINDLER, S. et al. Distinct spatiotemporal expression of SAPAP transcripts in the developing rat brain: a novel dendritically localized mRNA. Brain Res. Mol. Brain Res. v. 126, p. 14-21, 2004.

KIRSCH, P. et al. Oxytocin modulates neural circuitry for social cognition and fear in humans. Journal of Neuroscience, v. 25, n. 49, p. 11489-11493, 2005.

KITCHENER, S. J.; DOURISH, C. T. An examination of the behavioural specificity of hypophagia induced by 5-HT1B, 5-HT1C and 5-HT2 receptor agonists using the postprandial satiety sequence in rats. Psychopharmacology, v. 113, n. 3-4, p. 369-377, 1994.

KORAN, L.M. et al. Practice guideline for the treatment of patients with obsessivecompulsive disorder. Am J Psychiatry, 164, p. 5-53, 2007.

KORFF, S.; HARVEY, B. H. Animal Models of Obsessive-Compulsive Disorder: Rationale to Understanding Psychobiology and Pharmacology. Psychiatric Clinics of North America, v. 29, n. 2, p. 371-390, 2006.

KREISS, D. S. et al. Ritualistic Chewing Behavior induced by $\mathrm{mCPP}$ in the rat is an animal model of Obsessive Compulsive Disorder. Pharmacology Biochemistry and Behavior, v. 104, n. 1, p. 119-124, 2013.

KRUK, M. R. et al. The hypothalamus: Cross-roads of endocrine and behavioural regulation in grooming and aggression. Neuroscience and Biobehavioral Reviews, v. 23, n. 2, p. 163$177,1998$.

LABUSCHAGNE, I. et al. Oxytoci attenuates amygdala reactivity to fear in generalized socialanxiety disorder. Neuropsychopharmacology. v. 35, p. 2403-2413, 2010. 
LACK, C. W. Obsessive-compulsive disorder: Evidence-based treatments and future directions for research. World Journal of Psychiatry, v. 2, n. 6, p. 86, 2012.

LAZARINI-LOPES, W. et al. The anticonvulsant effects of cannabidiol in experimental models of epileptic seizures: From behavior and mechanisms to clinical insights. Neuroscience and Biobehavioral Reviews, v. 111, n. November 2019, p. 166-182, 2020.

LECKMAN, J. F. et al. Elevated cerebrospinal fluid levels of oxytocin in obsessivecompulsive disorder: Comparison with Tourette's syndrome and healthy controls . Archives of General Psychiatry, v. 51, n. 10, p. 782-792, 1994.

LECKMAN, J. F. et al. Obsessive-compulsive disorder: A review of the diagnostic criteria and possible subtypes and dimensional specifiers for DSM-V. Depression and Anxiety, v. 27, n. 6, p. 507-527, 2010.

LEE, A.G, et al. A novel form of oxytocin in New World monkeys. Biol Lett. v. 7, p. 584$587,2011$.

LEE, H.J. et al. Oxytocin: The Great Facilitator of Life. Progress in Neurobiology. 2009.

LEITE, M.C.G. 2014. Participação de endocanabinóides, arginina-vasopressina e endotelina-1 em um modelo de sepse severa (CLP) em ratos. 102f. Dissertação (Mestrado em Farmacologia) - Programa de Pós-Graduação em Farmcaologia, Universidade Federal do Paraná. 2014.

LENG, G.; LUDWIG, M. Intranasal Oxytocin: Myths and Delusions. Biological Psychiatry, v. 79, n. 3, p. 243-250, 2016.

LEONG, K. C. et al. Oxytocin and Rodent Models of Addiction. International Review of Neurobiology, v. 140, p. 201-247, 2018.

LI, Y.; HASSETT, A. L.; SENG, J. S. Exploring the mutual regulation between oxytocin and cortisol as a marker of resilience. Archives of Psychiatric Nursing, v. 33, n. 2, p. 164-173, 2019.

LOUVEL, D. et al. Oxytocin increases thresholds of colonic visceral perception in patients with irritable bowel syndrome. Gut, v. 39, n. 5, p. 741-747, 1996.

LUNDEBERG, T. et al. Oxytocin modulates the effects of galanin in carrageenan-induced hyperalgesia in rats. Brain Research, v. 608, n. 2, p. 181-185, 1993.

LUPIEN, S. J. et al. Effects of stress throughout the lifespan on the brain, behaviour and cognition. Nature Reviews Neuroscience, v. 10, n. 6, p. 434-445, 2009.

MAIRESSE, J. et al. Activation of presynaptic oxytocin receptors enhances glutamate release in the ventral hippocampus of prenatally restraint stressed rats. Psychoneuroendocrinology, v. 62 , p. 36-46, 2015.

MAN J. et al. Animal models for obsessive-compulsive disorder. Current Neuropharmacology. v. 2, p. 169-81, 2004.

MANTELLA, R.C. Enhanced corticosterone concentrations and attenuated Fos expression. in the medial amygdala of female oxytocin knockout mice exposed to psychogenic stress. Am J Physiol Regul Integr Comp Physiol. v. 287, p. R1494-R1504, 2004.

MARINHO, E. et al. Transtorno Obsessivo Compulsivo Em Crianças E Adolescentes: 
Revisão De Literatura E Abordagem Odontológica. Arquivos em Odontologia, v. 47, n. 4, p. 230-236, 2011.

MARRONI, S. et al. Oxytocin, Compulsion and Epilepsy: Insights from a Complex Behavioral and Neuronal Networks Association. Oxytocin, Compulsion and Epilepsy: Insights from a Complex Behavioral and Neuronal Networks Association, p. 638452, 2019.

MARRONI, S.S. Avaliação da expressão do sistema ocitocinérgico nos modelos experimentais de epilepsia e compulsão. 2011. Tese (Doutorado em Ciências Médicas) Departamento de Neurociências e Ciências do Comportamento, Universidade de São Paulo.

MARRONI, S. S. et al. Neuroanatomical and cellular substrates of hypergrooming induced by microinjection of oxytocin in central nucleus of amygdala, an experimental model of compulsive behavior. Molecular Psychiatry, v. 12, n. 12, p. 1103-1117, 2007.

MATAIX-COLS, D. et al. Distinct neural correlates of washing, checking, and hoarding symptom dimensions in obsessive-compulsive disorder. Archives of General Psychiatry, v. 61, n. 6, p. 564-576, 2004.

MCCORMICK, D. A. GABA as an inhibitory neurotransmitter in human cerebral cortex. Journal of Neurophysiology, v. 62, n. 5, p. 1018-1027, 1989.

MCGONIGLE, P. Animal models of CNS disorders. Biochem Pharmacol. v. 87, p. 140-149, 2014.

MCKAY, D. et al. Efficacy of cognitive-behavioral therapy for obsessive-compulsive disorder. Psychiatry Research, v. 227, n. 1, p. 104-113, 2015.

MELDRUM, B. S. Glutamate and Glutamine in the Brain Glutamate as a Neurotransmitter in the Brain : Review of Physiology and Pathology 1. n. May, p. 1007-1015, 2018.

MEYER-LINDENBERG, A. et al. Oxytocin and vasopressin in the human brain: Social neuropeptides for translational medicine. Nature Reviews Neuroscience, v. 12, n. 9, p. 524 538, 2011.

MIGUEL, E. C. et al. Obsessive-compulsive disorder phenotypes: Implications for genetic studies. Molecular Psychiatry, v. 10, n. 3, p. 258-275, 2005.

MIGUEL FILHO, E. C. Transtorno obsessivo-compulsivo e os gânglios da base. Arquivos de Neuro-Psiquiatria, v. 53, n. 4, p. 858-859, 1995.

MILAD, M. R.; RAUCH, S. L. Obsessive-compulsive disorder: Beyond segregated corticostriatal pathways. Trends in Cognitive Sciences, v. 16, n. 1, p. 43-51, 2012.

MIRANDA, M. A.; BORDIN, I. A. Curso clínico e prognóstico do transtorno obsessivocompulsivo. Revista Brasileira de Psiquiatria, v. 23, n. suppl 2, p. 10-12, 2001.

MITRA, S. et al. Ovarian Sex Hormones Modulate Compulsive, Affective and Cognitive Functions in A Non-Induced Mouse Model of Obsessive-Compulsive Disorder. Frontiers in Behavioral Neuroscience. v. 10, 2016.

MOHR, E. et al. Expression of the vasopressin and oxytocin genes in rats occurs in mutually exclusive sets of hypothalamic neurons. FEBS Letters, v. 242, n. 1, p. 144-148, 1988.

MORALES-MEDINA, J. C. et al. Morphological reorganization after repeated corticosterone 
administration in the hippocampus, nucleus accumbens and amygdala in the rat. Journal of Chemical Neuroanatomy, v. 38, n. 4, p. 266-272, 2009.

MORATO, S. O Papel da visão na aversão aos espaços abertos no labirinto em cruz elevado. Psicologia USP, v. 17, n. 4, p. 159-174, 2006.

MORGADO, P. et al. Perceived stress in obsessive-compulsive disorder is related with obsessive but not compulsive symptoms. Frontiers in Psychiatry, v. 4, n. APR, p. 1-6, 2013.

MONTGOMERY, K.C. The relation between exploratory behavior and Spontaneous alternation in the white rat. 1950.

MURPHY, D. L. et al. Anxiety and affective disorder comorbidity related to serotonin and other neurotransmitter systems: Obsessive-compulsive disorder as an example of overlapping clinical and genetic heterogeneity. Philosophical Transactions of the Royal Society B: Biological Sciences, v. 368, n. 1615, 2013.

NAUTA, K. J.; BATELAAN, N. M.; VAN BALKOM, A. J. Obsessive-compulsive disorder from a family perspective: implications for a treatment and research. Tijdschrift voor Psychiatrie, v. 54, n. 5, 439-448, 2012.

NEUFELD, C. B.; FALCONE, E. M. O.; RANGÉ, B. ProCognitiva: Programa de atualização em terapia cognitiva comportamental. Porto Alegre: Artmed v. 2, 2015.

NEUMANN, I. D. et al. Brain oxytocin inhibits the (re)activity of the hypothalamo-pituitaryadrenal axis in male rats: Involvement of hypothalamic and limbic brain regions. Regulatory Peptides, v. 96, n. 1-2, p. 31-38, 2000.

NISHIOKA, T. et al. Stress increases oxytocin release within the hypothalamic paraventricular nucleus. Brain Research, v. 781, n. 1-2, p. 57-61, 1998.

NUNES, E. A.; HALLAK, J. E. C. Modelos animais em psiquiatria: Avanços e desafios. Revista Latinoamericana de Psicopatologia Fundamental, v. 17, n. 3, p. 528-543, 2014.

OLIVARES E., F. et al. The standardized candle method for typeii plateau supernovae. Astrophysical Journal, v. 715, n. 2, p. 833-853, 2010.

OLIVEIRA, F. C. D. E. Avaliação do papel da serotonina e seus receptores no desenvolvimento da constipação intestinal. p. 1-45, 2013.

OVERALL K.L. Natural animal models of human psychiatric conditions: assessment of mechanisms and validity. Prog Neuropsychopharmacol Biol Psychiatry. v. 24, p. 727-76, 2000 .

PARREIRAS-E-SILVA, L. T. et al. Functional New World monkey oxytocin forms elicit an altered signaling profile and promotes parental care in rats. Proceedings of the National Academy of Sciences of the United States of America, v. 114, n. 34, p. 9044-9049, 2017.

PAULS, D. L. et al. Obsessive-compulsive disorder: An integrative genetic and neurobiological perspective. Nature Reviews Neuroscience, v. 15, n. 6, p. 410-424, 2014.

PEDERSEN, C. A. et al. Grooming Behavioral Effects of Oxytocin: Pharmacology, Ontogeny, and Comparisons with Other Nonapeptides. Annals of the New York Academy of Sciences, v. 525, n. 1, p. 245-256, 1988.

PELLOW, S.; FILE, S. E. Anxiolytic and anxiogenic drug effects on exploratory activity in an elevated plus-maze: A novel test of anxiety in the rat. Pharmacology, Biochemistry and 
Behavior, v. 24, n. 3, p. 525-529, 1986.

PENAGARIKANO, O. et al. Exogenous and evoked oxytocin restores social behavior in the Cntnap2 mouse model of autism. Science Translational Medicine, v. 7, n. 271, p. 271ra8271ra8, 2015.

PERELMAN, P. et al. A molecular phylogeny of living primates. PLoS Genet. 2011.

PETERSEN, M. L. A terapia cognitivo-comportamental no tratamento das compulsões mentais. Revista Brasileira de Terapias Cognitivas, v. 15, n. 2, p. 92-99, 2019.

PIGOTT, T. A. et al. Metergoline blocks the behavioral and neuroendocrine effects of orally administered m-chlorophenylpiperazine in patients with obsessive-compulsive disorder. Biological Psychiatry, v. 29, n. 5, p. 418-426, 1991.

PITTENGER, C.; BLOCH, M. H. Pharmacological treatment of obsessive-compulsive disorder. Psychiatric Clinics of North America, v. 37, n. 3, p. 375-391, 2014.

PORSOLT, R. D. Serotonin: Neurotransmitter "a la mode". Report on the third international I.T.E.M.-LABO Symposium on strategies in psychopharmacology: Serotonin: Animal models and clinical targets. Pharmacopsychiatry, v. 26, n. 1, p. 20-24, 1993.

PRESTI, M. F.; MIKES, H. M.; LEWIS, M. H. Selective blockade of spontaneous motor stereotypy via intrastriatal pharmacological manipulation. Pharmacology Biochemistry and Behavior, v. 74, n. 4, p. 833-839, 2003.

RACHMAN, S. Fear of contamination. Behaviour. Research and Therapy. v. 42, n. 11, 1227-1255, 2003.

RACHMAN, S. Fear and Courage. San Francisco: W.H. Freeman. 1978.

RASMUSSEN, S.; EISEN, J.L. Phenomenology of OCD: clinical subtypes, heterogeneity and coexistence. In The Psychobiology of Obsessive- Compulsive Disorder. Edited by Zohar J, Insel T, Rasmussen S. New York: Springer Publishing Company. p. 13-43, 1991.

Rauch S.L. et al. Regional cerebral blood flow measured during symptom provocation in obsessive-compulsive disorder using oxygen 15-labeled carbon dioxide and positron emission tomography. Arch Gen Psychiatry. 1994, p. 51:62-70.

REIMER, A. E. et al. Fear extinction in an obsessive-compulsive disorder animal model: Influence of sex and estrous cycle. Neuropharmacology, v. 131, n. 2018, p. 104-115, 2018.

REIS, N.R. et al. Mamíferos do Brasil. Londrina. p. 437, 2006.

RICHTER, M. A. et al. Evidence for cortical inhibitory and excitatory dysfunction in obsessive compulsive disorder. Neuropsychopharmacology, v. 37, n. 5, p. 1144-1151, 2012.

RODRIGUEZ, C. I. et al. HHS Public Access. v. 233, n. 2, p. 141-147, 2016.

RIMOLDI, V. et al. Oxytocin receptor elicits different EGFR/MAPK activation patterns depending on its localization in caveolin-1 enriched domains. Oncogene. v. 22, n. 38, p. 6054-6060, 2003.

RONCHETTI, R.; BÖHME, E. S.; FERRÃO, Y. A. A hipótese imunológica no Transtorno Obsessivo-Compulsivo: revisão de um subtipo (PANDAS) com manifestação na infância. Revista de Psiquiatria do Rio Grande do Sul, v. 26, n. 1, p. 62-69, 2004. 
ROSENBERG, D. R.; MACMILLAN, S. N.; MOORE, G. J. Brain anatomy and chemistry may predict treatment response in paediatric obsessive-compulsive disorder. International Journal of Neuropsychopharmacology, v. 4, n. 2, p. 179-190, 2001.

ROTH, A. et al. Potential translational targets revealed by linking mouse grooming behavioral phenotypes to gene expression using public databases. Progress in NeuroPsychopharmacology and Biological Psychiatry, v. 40, n. 1, p. 312-325, 2013.

ROTHSTEIN, J. D. et al. Localization of neuronal and glial glutamate transporters. Neuron, v. 13, n. 3, p. 713-725, 1994.

RUSCIO, A.M. et al. The Epidemiology of Obsessive-Compulsive Disorder in the National Comorbidity Survey Replication. Mol Psychiatry. v. 15, n. 1, p. 53 - 63, 2010.

SALA, M. et al. Pharmacologic rescue of impaired cognitive flexibility, social deficits, increased aggression, and seizure susceptibility in oxytocin receptor null mice: A neurobehavioral model of autism. Biological Psychiatry. v. 69, n. 9, p. 875-882, 2011.

SALKOVSKIS, P. M. et al.. The Termination of Checking and the Role of Just Right Feelings: A Study of Obsessional Checkers Compared with Anxious and Non-clinical Controls. Behavioural and Cognitive Psychotherapy. v. 45, n. 02, p. 139-155, 2016.

SAMUELS, J. et al. Comprehensive family-based association study of the glutamate transporter gene SLC1A1 in obsessive-compulsive disorder. American Journal of Medical Genetics, Part B: Neuropsychiatric Genetics, v. 156, n. 4, p. 472-477, 2011.

SANTOS SAMPAIO, A. Estudos de associação genética no transtorno obsessivo-compulsivo Genetic association studies in obsessive-compulsive disorder. Rv Psiq CI[in, v. 40, n. 5, p. 177-90, 2013.

SANTOS, J.C. 2014. Relação entre os sistemas serotoninérgico e ocitocinérgico no modelo de compulsão induzido por microinjeção central de ocitocina em animais da cepa WistarAudiogenicRat (WAR). 110 f. Dissertação (Mestrado em Fisiologia) - Faculdade de Medicina de Ribeirão Preto, Universidade de São Paulo. 2014.

SAXENA, S.; RAUCH, S. L. Functional neuroimaging and the neuroanatomy of obsessivecompulsive disorder. Psychiatric Clinics of North America, v. 23, n. 3, p. 563-586, 2000.

SCIMEMI, A.; TIAN, H.; DIAMOND, J. S. Neuronal transporters regulate glutamate clearance, NMDA receptor activation, and synaptic plasticity in the hippocampus. Journal of Neuroscience, v. 29, n. 46, p. 14581-14595, 2009.

SEIBENHENER, M. L.; WOOTEN, M. C. Use of the open field maze to measure locomotor and anxiety-like behavior in mice. Journal of Visualized Experiments, n. 96, p. 1-6, 2015.

SHASHIDHARAN, P. et al. Immunohistochemical localization of the neuron-specific glutamate transporter EAAC1 (EAAT3) in rat brain and spinal cord revealed by a novel monoclonal antibody. Brain Research, v. 773, n. 1-2, p. 139-148, 1997.

SHAVITT, R. G. et al. Phenomenology of OCD: Lessons from a large multicenter study and implications for ICD-11. Journal of Psychiatric Research, v. 57, n. 1, p. 141-148, 2014.

SHEPPARD, D. M. et al. Tourette's and comorbid syndromes: Obsessive compulsive and attention deficit hyperactivity disorder. A common etiology? Clinical Psychology Review, v. 19, n. 5, p. 531-552, 1999. 
SHMELKOV, S. V. et al. Slitrk5 deficiency impairs corticostriatal circuitry and leads to obsessive-compulsive-like behaviors in mice. Nature Medicine, v. 16, n. 5, p. 598-602, 2010.

SILVA, J.U. 2016. Estudo dos efeitos da ocitocina em modelos de ansiedade generalizada e de pânico em ratos e em voluntaries saudáveis. 61f. Dissertação (Mestrado em Ciências) Instituto de Psicologia, Universidade de São Paulo. 2016.

SOFRONIEW, M. V. Morphology of Vasopressin and Oxytocin Neurones and Their Central and Vascular Projections. Progress in Brain Research, v. 60, n. C, p. 101-114, 1983.

SONG, M. et al. Rare synaptogenesis-impairing mutations in SLITRK5 are associated with obsessive compulsive disorder. PLoS ONE, v. 12, n. 1, p. 1-14, 2017.

SOOMRO, G. M. Obsessive compulsive disorder. BMJ clinical evidence, v. 2012, n. April 2011, p. 1-28, 2012.

SMITH, M.W.; GINSBURG, M. Fate of synthetic oxytocin analogues in the rat. Br Pharmacol Chemother. v. 16, p. 244-252, 1961.

STRATAKIS, C.A.; CHROUSOS, G.P. Neuroendocrinology and Pathophysiology of the Stress System. ANNALS NEW YORK ACADEMY OF SCIENCES. 1995.

STEIN, D.J. et al. Obsessive-compulsive disorder. Nat Rev Dis Primers. v.5, n.1, 2020.

STEWART, B. R.; JENNER, P.; MARSDEN, C. D. Induction of purposeless chewing behaviour in rats by 5-HT agonist drugs. European Journal of Pharmacology, v. 162, n. 1, p. 101-107, 1989.

STRAATHOF, M. et al. Structural and functional MRI of altered brain development in a novel adolescent rat model of quinpirole-induced compulsive checking behavior. European Neuropsychopharmacology, v. 33, p. 58-70, 2020.

SUH, B. Y. et al. Role of oxytocin in the modulation of ACTH release in women1. Neuroendocrinology, v. 44, n. 3, p. 309-313, 1986.

SWEDO, S. E. et al. Obsessive-Compulsive Disorder in Children and Adolescents: Clinical Phenomenology of 70 Consecutive Cases. Archives of General Psychiatry, v. 46, n. 4, p. 335-341, 1989.

SZECHTMAN, H. et al. Obsessive-compulsive disorder: Insights from animal models. Neurosci Biobehav Rev. v. 76, p. 254-279, 2017.

SZECHTMAN, H. et al. Compulsive checking behavior of quinpirole-sensitized rats as an animal model Obsessive-Compulsive Disorder(OCD): Form and control. BMC Neuroscience, v. 2, 2001.

SZECHTMAN, H.; SULIS, W.; EILAM, D. Quinpirole induces compulsive checking behavior in rats: A potential animal model of obsessive-compulsive disorder (OCD). Behavioral Neuroscience, v. 112, n. 6, p. 1475-1485, 1998.

TAYLOR, J.; PURDON, C. Responsibility and hand washing behaviour. Journal of Behavior Therapy and Experimental Psychiatry. v. 51, p. 43-50, 2016.

TEICHER, M. H. et al. Developmental neurobiology of childhood stress and trauma 
Psychiatric Clinicso of North America 25(2), 397-426. v. 25, p. 2002, 2002.

TERENZI, M. G.; INGRAM, C. D. Oxytocin-induced excitation of neurones in the rat central and medial amygdaloid nuclei. Neuroscience, v. 134, n. 1, p. 345-354, 2005.

THIERRY, A. M. et al. Effects of stress on the metabolism of norepinephrine, dopamine and serotonin in the central nervous system of the rat. I. Modifications of norepinephrine turnover. J Pharmacol Exp Ther. v. 163, p.163-71,1968.

TING, J. T.; FENG, G. Neurobiology of obsessive-compulsive disorder: Insights into neural circuitry dysfunction through mouse genetics. Current Opinion in Neurobiology, v. 21, n. 6, p. 842-848, 2011.

TOMODA, A. et al. Reduced prefrontal cortical gray matter volume in young adults exposed to harsh corporal punishment. NeuroImage, v. 47, n. SUPPL. 2, p. T66-T71, 2009.

TOMODA, A. et al. Reduced Visual Cortex Gray Matter Volume and Thickness in Young Adults Who Witnessed Domestic Violence during Childhood. PLoS ONE, v. 7, n. 12, p. 1$11,2012$.

TORNER, L. et al. Forced swimming-induced oxytocin release into blood and brain: Effects of adrenalectomy and corticosterone treatment. Psychoneuroendocrinology, v. 77, p. 165174, 2017.

TORO J. et al. Obsessive-compulsive disorder in childhood and adolescence: a clinical study. J Child Psychol Psychiatry. v. 33, p.1025-1037, 1992.

TORRES, A.R. et al. Obsessive-compulsive disorder: prevalence, comorbidity, impact, and help-seeking in the British National Psychiatric Morbidity Survey of 2000. Am. J. Psychiatry. v. 163, n.11, p. 1978-1985, 2006.

TORRES, A. R.; SMAIRA, S. I. Quadro clínico do transtorno obsessivo-compulsivo. Revista Brasileira de Psiquiatria, v. 23, n. suppl 2, p. 6-9, 2001.

TOYAMA, R. P. Avaliação Comportamental E Bioquímica De Camundongos Submetidos a Um Modelo Experimental De Inflamação Associada a Criolesão. p. 68, 2012.

TSIGOS, C.; CHROUSOS, G. P. Hypothalamic-pituitary-adrenal axis, neuroendocrine factors and stress. Journal of Psychosomatic Research, v. 53, n. 4, p. 865-871, 2002.

ULLRICH, M. et al. OCD-like behavior is caused by dysfunction of thalamo-amygdala circuits and upregulated TrkB/ERK-MAPK signaling as a result of SPRED2 deficiency. Molecular Psychiatry, v. 23, n. 2, p. 444-458, 2018.

VALLONE, D.; PICETTI, R.; BORRELLI, E. Structure and function of dopamine receptors. Neuroscience and Biobehavioral Reviews, v. 24, n. 1, p. 125-132, 2000.

VAN AMERINGEN, M.; PATTERSON, B.; SIMPSON, W. DSM-5 obsessive-compulsive and related disorders: Clinical implications of new criteria. Depression and Anxiety, v. 31, n. 6, p. 487-493, 2014.

VAN DEN BOOM, B. J. G. et al. Behavioral flexibility in a mouse model for obsessivecompulsive disorder: Impaired Pavlovian reversal learning in SAPAP3 mutants. Genes, Brain and Behavior, v. 18, n. 4, p. 1-11, 2019.

VAN DEN HEUVEL, O. A. et al. Frontal-striatal dysfunction during planning in obsessive- 
compulsive disorder. Archives of General Psychiatry, v. 62, n. 3, p. 301-310, 2005.

VELOSO, A. W. N. et al. Modulation of grooming behavior in rats by different test situations. Psychology and Neuroscience, v. 9, n. 1, p. 91-104, 2016.

VIANA, M.B.; TOMAZ, C.; GRAEFF, F.G. The elevated T-maze: a new animal model of anxiety and memory. Pharmacol Biochem Behav. v. 49, n. 3, p. 549-54, 1994.

WAHL, K.. et al. Cognitive Motivations for the Initiation of Ritualistic Hand Washing in Obsessive-Compulsive Disorder. Cognitive Therapy and Research. 2020.

WANG, L.; SIMPSON, H. B.; DULAWA, S. C. Assessing the validity of current mouse genetic models of obsessive-compulsive disorder. Behavioural Pharmacology, v. 20, n. 2, p. 119-133, 2009.

WELCH, J. M. et al. Cortico-striatal synaptic defects and OCD-like behaviours in Sapap3mutant mice. Nature, v. 448, n. 7156, p. 894-900, 2007.

WELCH, J. M.; WANG, D.; FENG, G. Differential mRNA Expression and Protein Localization of the SAP90/PSD-95-Associated Proteins (SAPAPs) in the Nervous System of the Mouse. Journal of Comparative Neurology, v. 472, n. 1, p. 24-39, 2004.

WENDLAND, J. R. et al. A haplotype containing quantitative trait loci for SLC1A1 gene expression and its association with obsessive-compulsive disorder. Archives of General Psychiatry, v. 66, n. 4, p. 408-416, 2009.

WILNER, P. Behavioral models in psycopharmacology. In: Wilner P, editor. Behavioral models in psychopharmacology: theoretical, industrial and clinical perspectives. Cambridge: Cambridge University Press. p. 3-18, 1991.

WINDLE, R. et al. Oxytocin Attenuates Stress-Induced c-fos mRNA Expression in Specific Forebrain Regions Associated with Modulation of Hypothalamo-Pituitary-Adrenal Activity. The Journal of Neuroscience. v. 24, n.12, p. 2974 -2982, 2004.

WINDLE, R. J. et al. Central oxytocin administration reduces stress-induced corticosterone release and anxiety behavior in rats. Endocrinology, v. 138, n. 7, p. 2829-2834, 1997.

WINTER, J.; JUREK, B. The interplay between oxytocin and the CRF system: regulation of the stress response. Cell and Tissue Research, v. 375, n. 1, p. 85-91, 2019.

WOTJAK, C. T. et al. Dissociated central and peripheral release of vasopressin, but not oxytocin, in response to repeated swim stress: New insights into the secretory capacities of peptidergic neurons. Neuroscience, v. 85, n. 4, p. 1209-1222, 1998.

WRIGHT, F. L.; RODGERS, R. J. On the behavioural specificity of hypophagia induced in male rats by mCPP, naltrexone, and their combination. Psychopharmacology, v. 231, n. 4, p. 787-800, 2014.

YADIN, E.; FRIEDMAN, E.; BRIDGER, W. H. Spontaneous alternation behavior: An animal model for obsessive-compulsive disorder? Pharmacology, Biochemistry and Behavior, v. 40, n. 2, p. 311-315, 1991.

YANG, J. et al. Central oxytocin enhances antinociception in the rat. Peptides, v. 28, n. 5, p. 1113-1119, 2007.

YANG, J. et al. Oxytocin, but not arginine vasopressin is involving in the antinociceptive role 
of hypothalamic supraoptic nucleus. Peptides, v. 32, n. 5, p. 1042-1046, $2011 \mathrm{a}$.

YANG, J. et al. Oxytocin in the periaqueductal grey regulates nociception in the rat. Regulatory Peptides, v. 169, n. 1-3, p. 39-42, 2011 b.

YANG, J. et al. Oxytocin in the periaqueductal gray participates in pain modulation in the rat by influencing endogenous opiate peptides. Peptides, v. 32, n. 6, p. 1255-1261, 2011c.

YARIBEYGI, H. et al. The impact of stress on body function: A review. EXCLI Journal, v. 16, p. 1057-1072, 2017.

ZAI, G. et al. Evidence for the gamma-amino-butyric acid type B receptor 1 (GABBR1) gene as a susceptibility factor in obsessive-compulsive disorder PARTE B. American Journal of Medical Genetics - Neuropsychiatric Genetics, v. 134 B, n. 1, p. 25-29, 2005.

ZHANG, C. C. et al. Florida Obsessive-Compulsive Inventory: Psychometric properties in a chinese psychotherapy-seeking sample. Journal of Obsessive-Compulsive and Related Disorders, v. 12, n. November 2016, p. 41-45, 2017.

ZENTENO-SAVIN, T. et al. Effects of arginine vasopressin in the heart are mediated by specific intravascular endothelial receptors. European Journal of Pharmacology, v. 410, n. 1, p. 15-23, 2000.

ZIKE, I. et al. Rodent models of obsessive compulsive disorder: Evaluating validity to interpret emerging neurobiology. Neuroscience, v. 345, n. September, p. 256-273, 2017.

ZIMPRICH, A. et al. A robust and reliable non-invasive test for stress responsivity in mice. Frontiers in Behavioral Neuroscience, v. 8, n. APR, p. 1-12, 2014.

ZOHAR, J. et al. Serotonergic Responsivity in Obsessive-Compulsive Disorder: Comparison of Patients and Healthy Controls. Archives of General Psychiatry, v. 44, n. 11, p. 946-951, 1987. 


\section{ANEXO}

Apresentação do Exame Geral de Qualificação (EGQ)

UNIVERSIDADE DE SÃO PAULO
FACULDADE DE MEDICIA DE RIBEIRÃO PRETO
DEPARTAMENTO DE FISIOLOGIA
Indução do comportamento de hypergrooming e análise
da eficácia da ocitocina e suas variantes, em ratos
Wistar Hannover
Mestranda: Adrieli Oliveira Raminelli
Orientador: Prof. Dr. Norberto Garcia-Cairasco
Ribeirão Preto/SP
W019

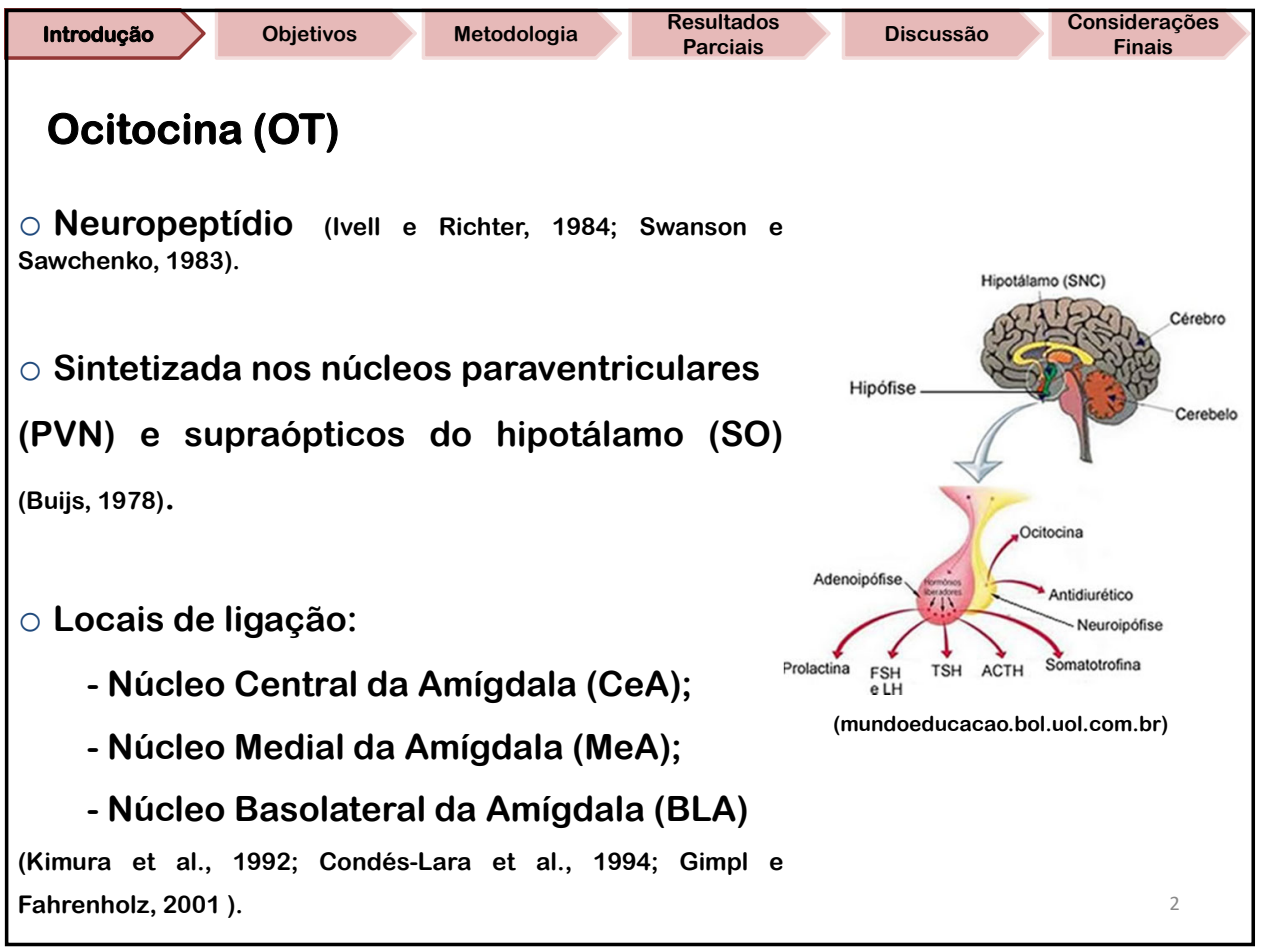




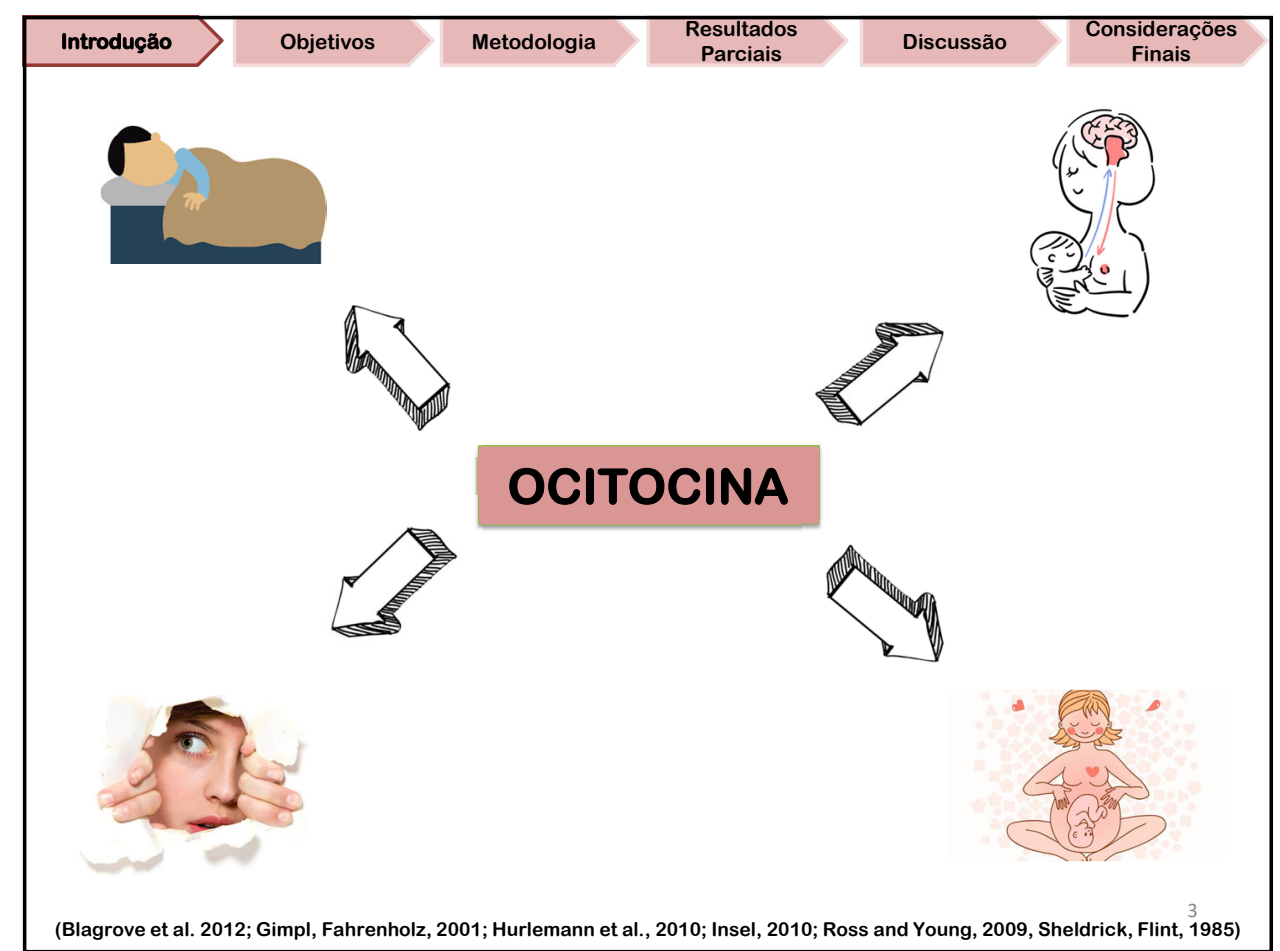

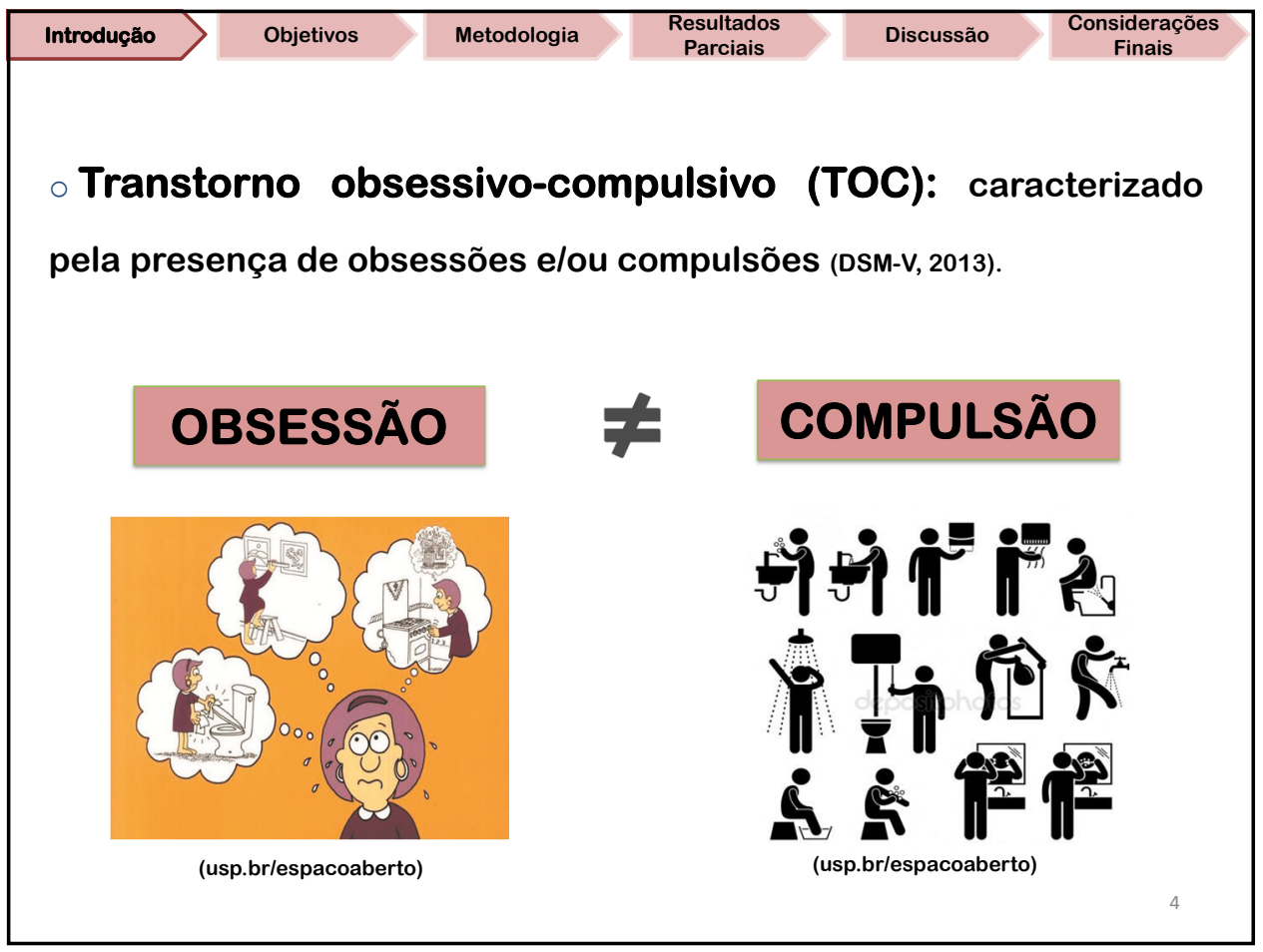




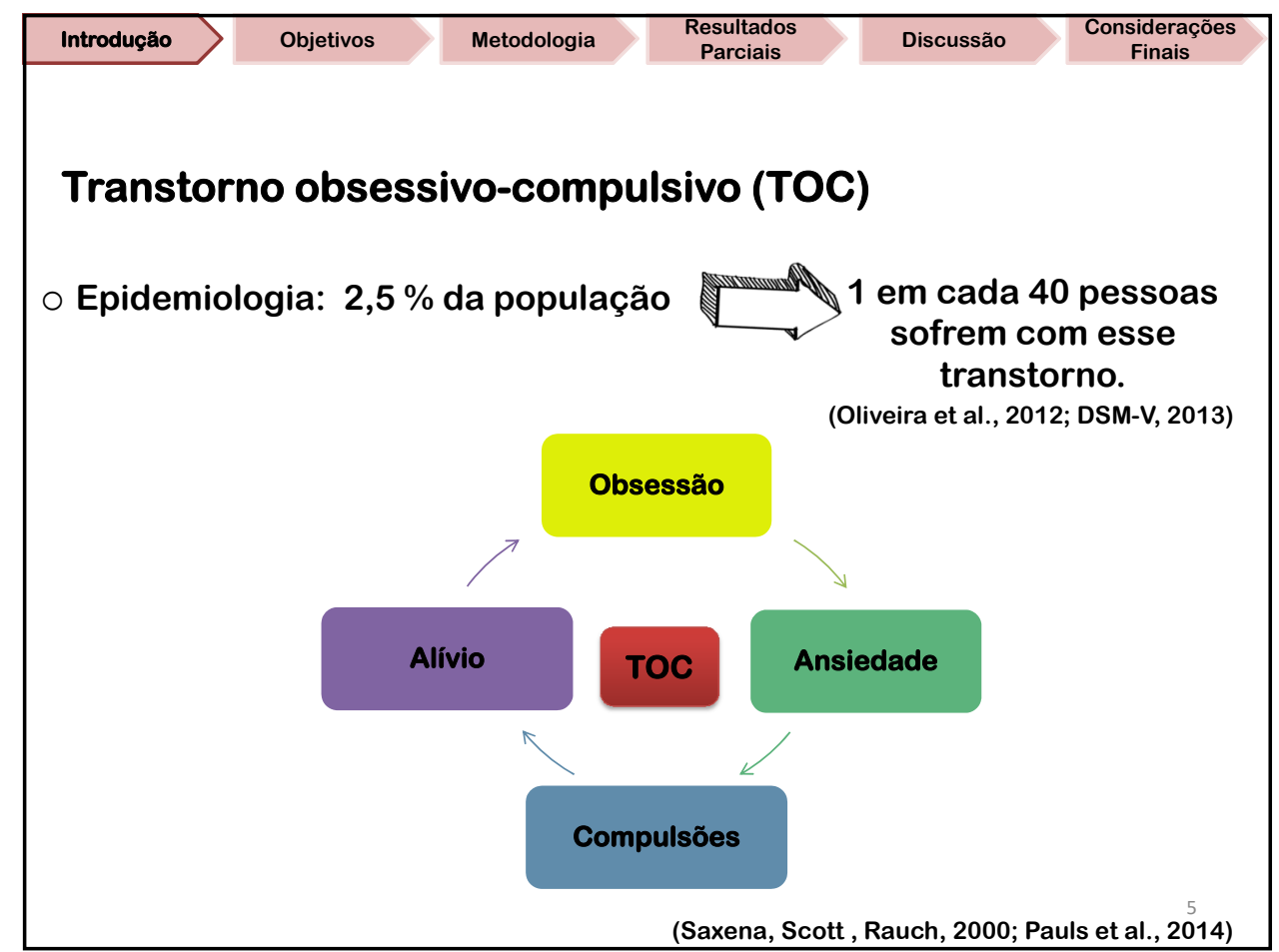

\begin{tabular}{|l|l|l|l|l|l|l|l}
\hline Introdução & Objetivos & Metodologia & $\begin{array}{c}\text { Resultados } \\
\text { Parciais }\end{array}$ & Discussão & $\begin{array}{c}\text { Considerações } \\
\text { Finais }\end{array}$ \\
\hline
\end{tabular}

\section{Ocitocina e Transtorno obsessivo-compulsivo (TOC)}

- Em modelos experimentais, a atividade de grooming pode ser induzida por várias manipulações (Spruijt, et al., 1985; Moody, Merali, Crawley, 1988).

- Microinjeção de OT no Núcleo Central da Amígdala (CeA)= hypergrooming $=$ comportamento compulsivo (Gatti, 2002; Marroni et al., 2007; Marroni, 2015).

- Wistar Audiogenic Rat (WAR) apresenta comportamento compulsivo basal (Marroni, 2011; Santos, 2014). 


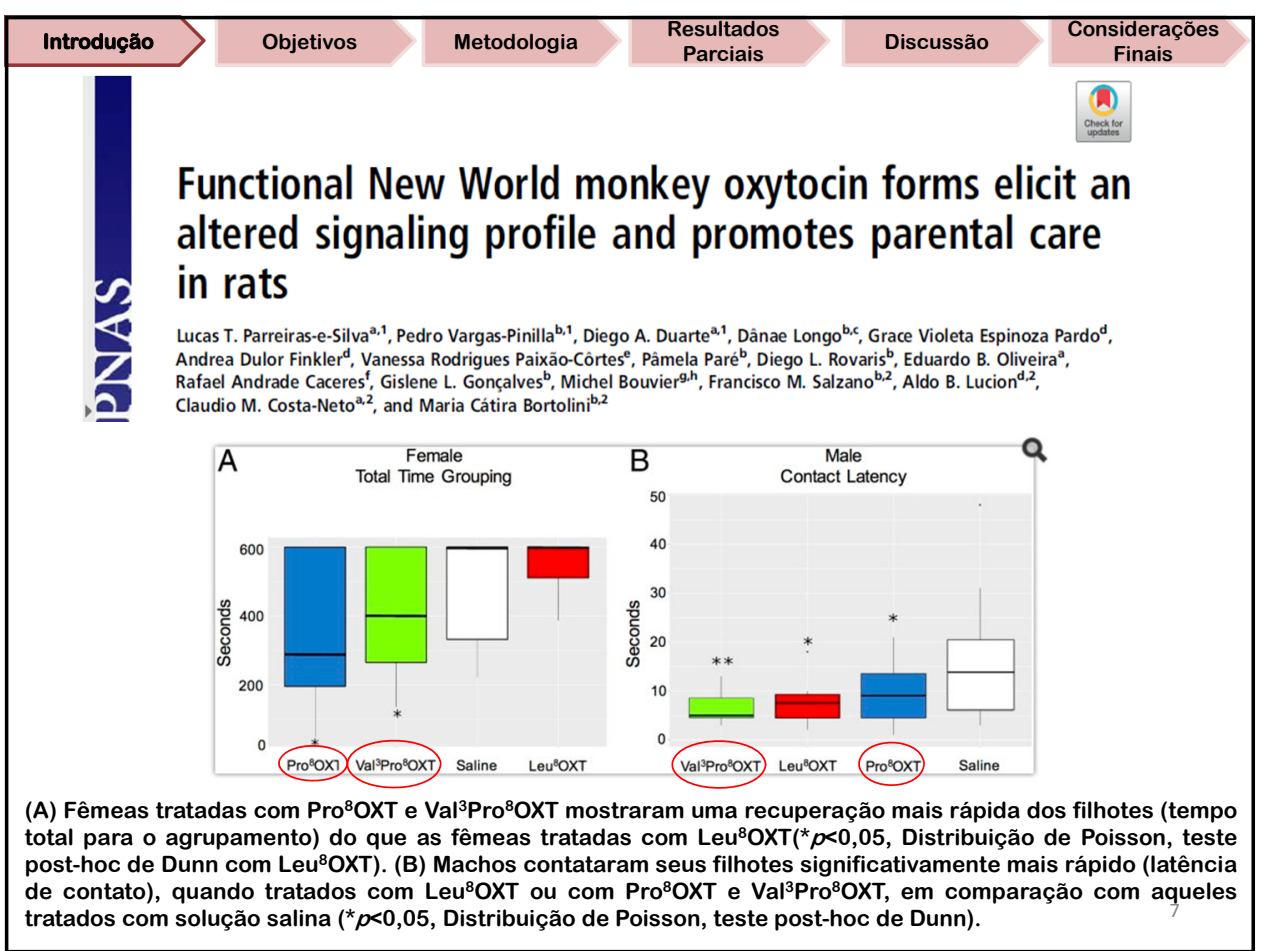

\begin{tabular}{|c|c|c|c|c|c|}
\hline Introdução & Objetivos & Metodologia & $\begin{array}{c}\text { Resultados } \\
\text { Parciais }\end{array}$ & Discussão & $\begin{array}{c}\text { Considerações } \\
\text { Finais }\end{array}$ \\
\hline
\end{tabular}

- Microinjeção bilateral de OT em animais Wistar (Marroni et al., 2007) e WAR (Gati, 2002; Marroni, 2011; Santos, 2014) induziu hypergrooming.

- Relação bidirecional entre TOC e Epilepsia, suportado pelo compartilhamento de mecanismos causais subjacentes comuns (Gatti, 2002; Marroni, 2015; Garcia-Cairasco et al., 2017).

- Avaliar se as variantes da OT (Prolina [Pro ${ }^{8} \mathrm{OXT}$ ] e Valina [Val ${ }^{3}$ Pro $\left.\left.^{8} \mathrm{OXT}\right]\right)$ possuem efeito semelhante ao da OT, na indução do comportamento de hypergrooming, seja pela administração central (diretamente no CeA) ou periférica (intranasal). 


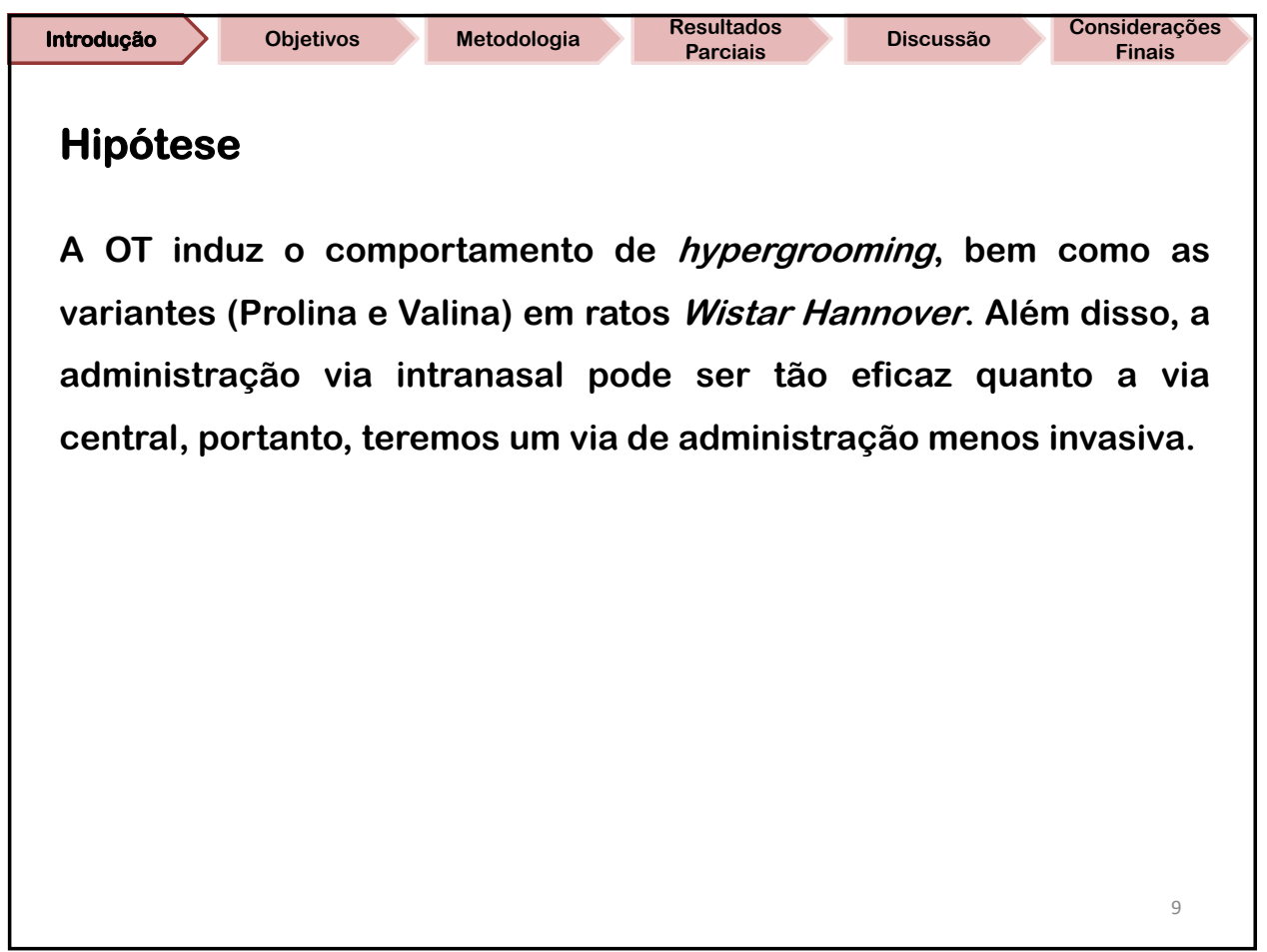

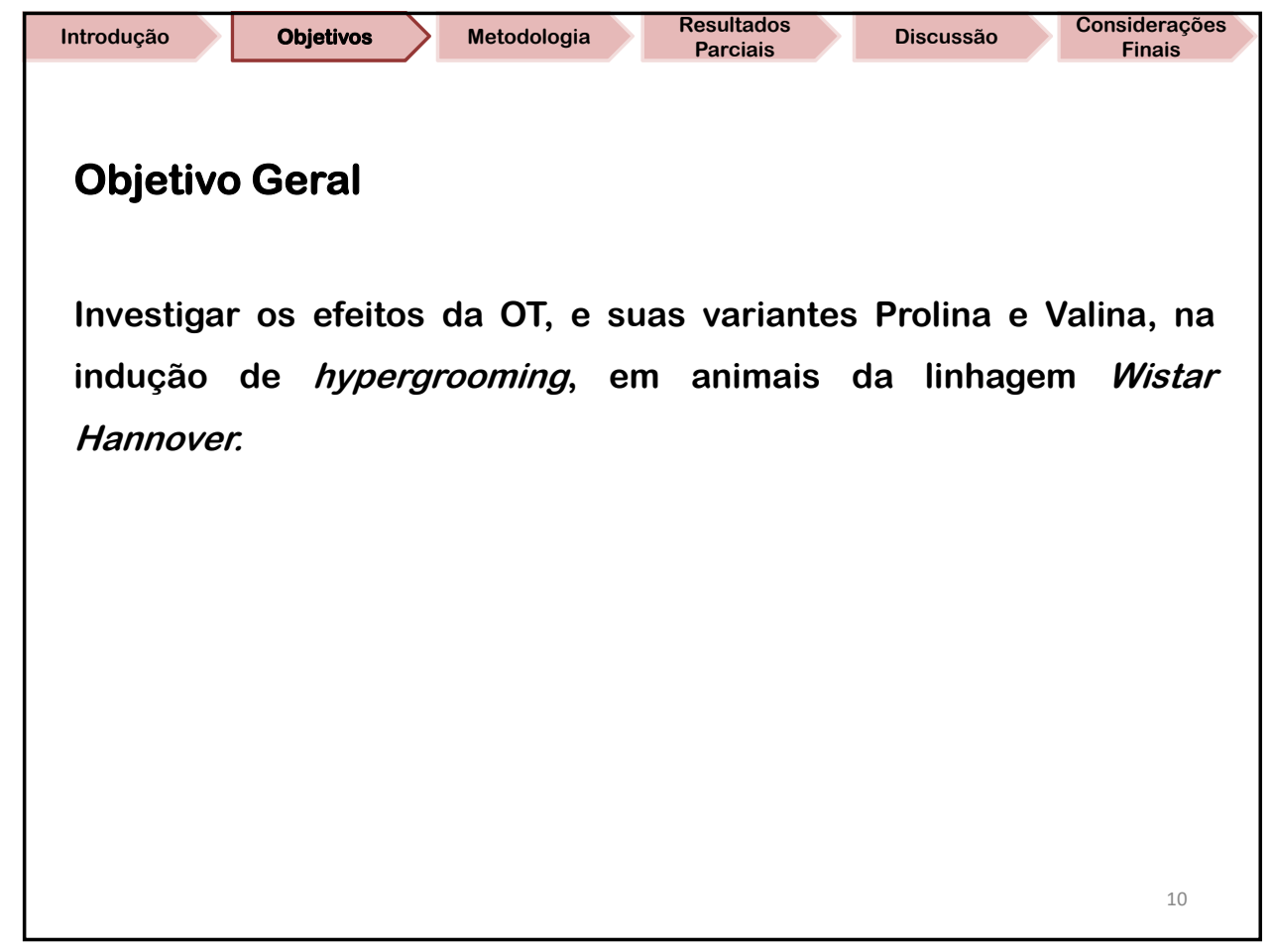




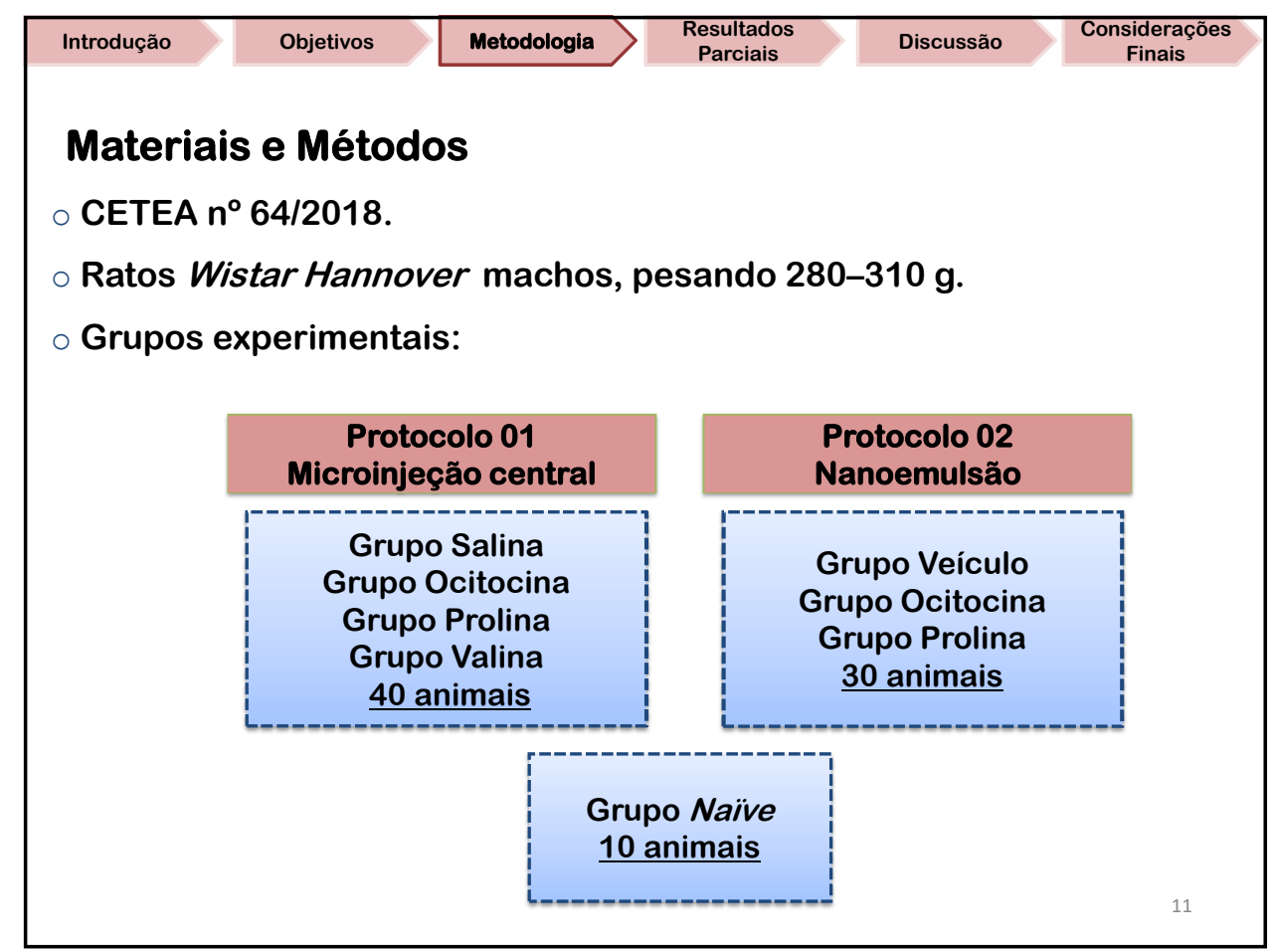

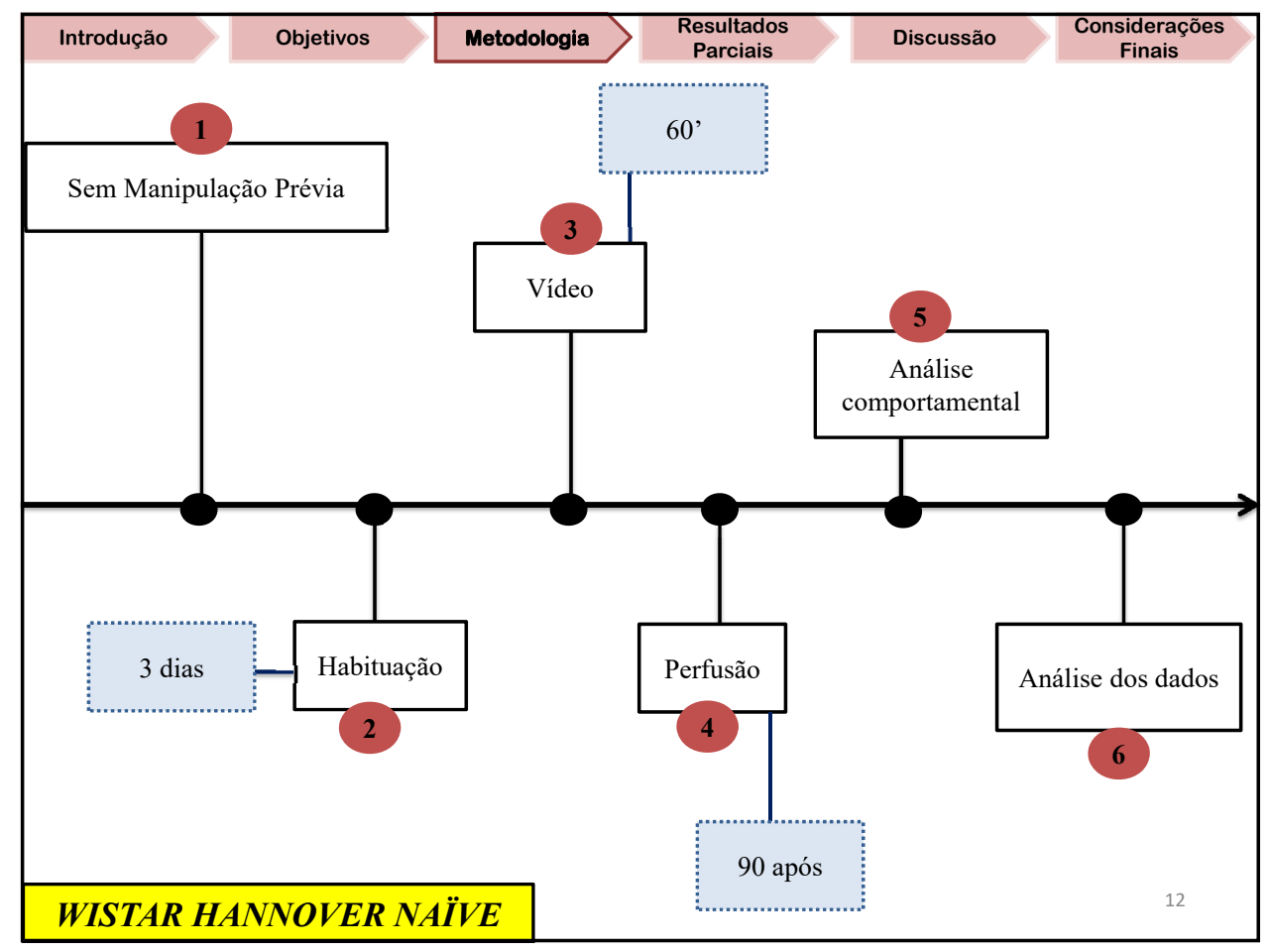




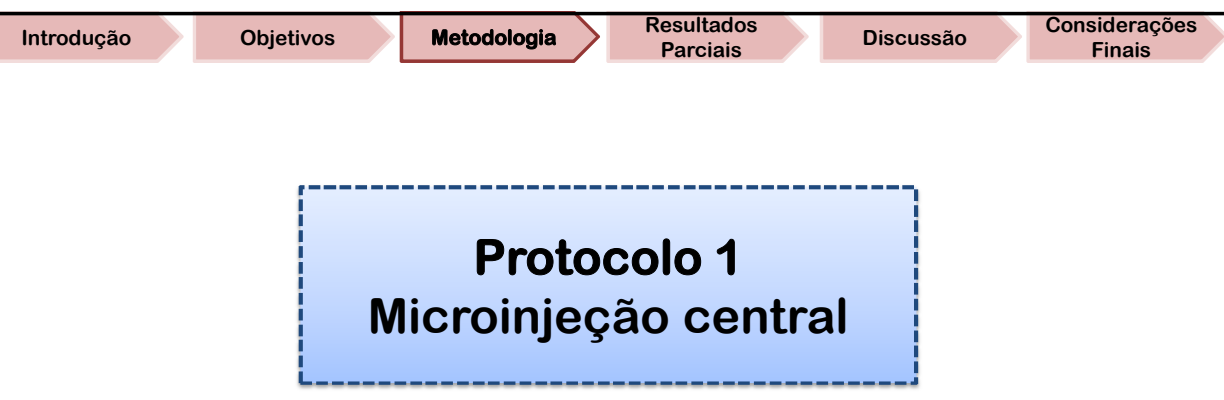

1. Induzir o comportamento de hypergrooming em ratos Wistar Hannover através da microinjeção de OT no CeA.

2. Relacionar o efeito da microinjeção bilateral de OT no CeA com as suas variantes: Prolina e Valina.

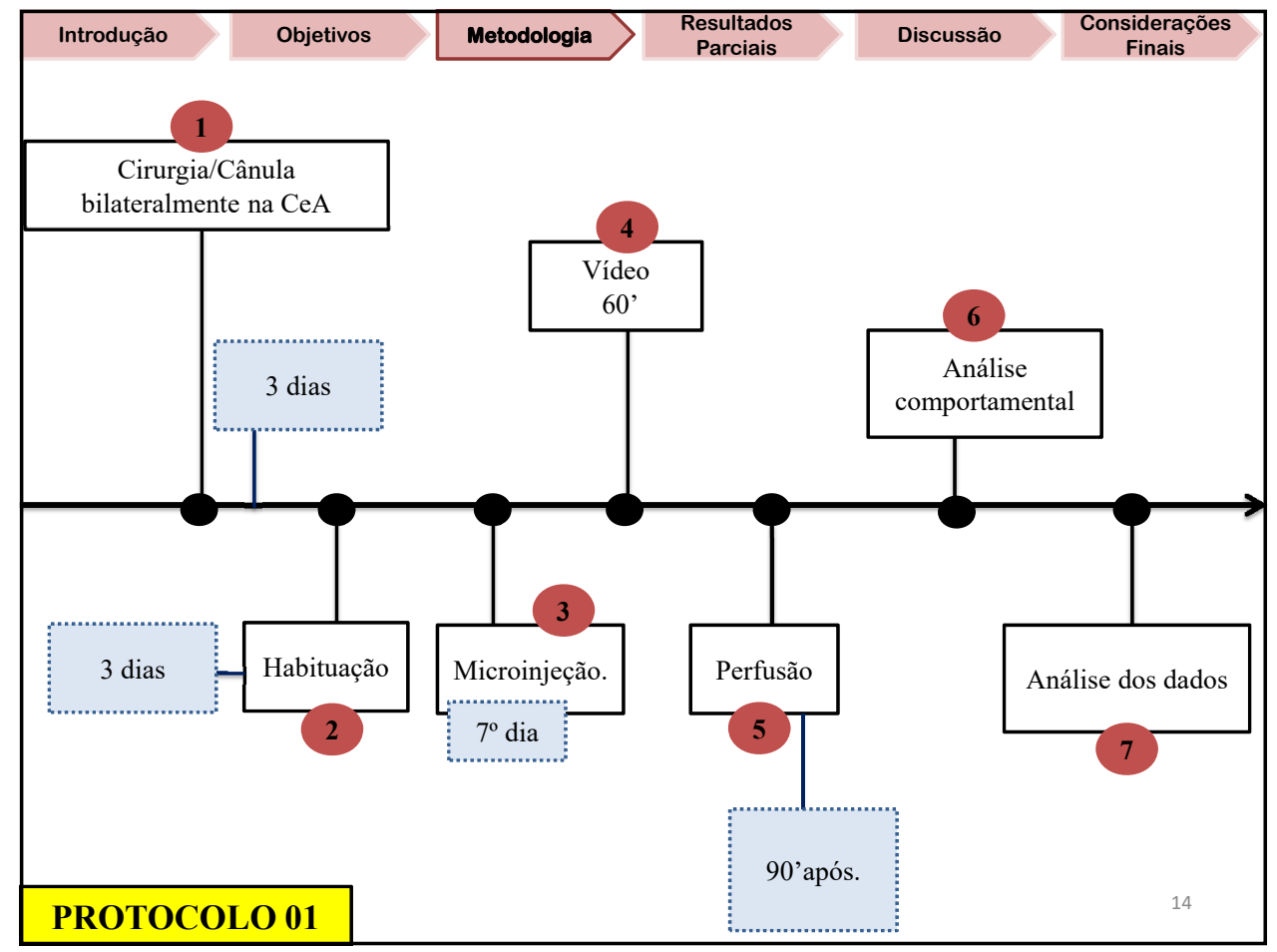




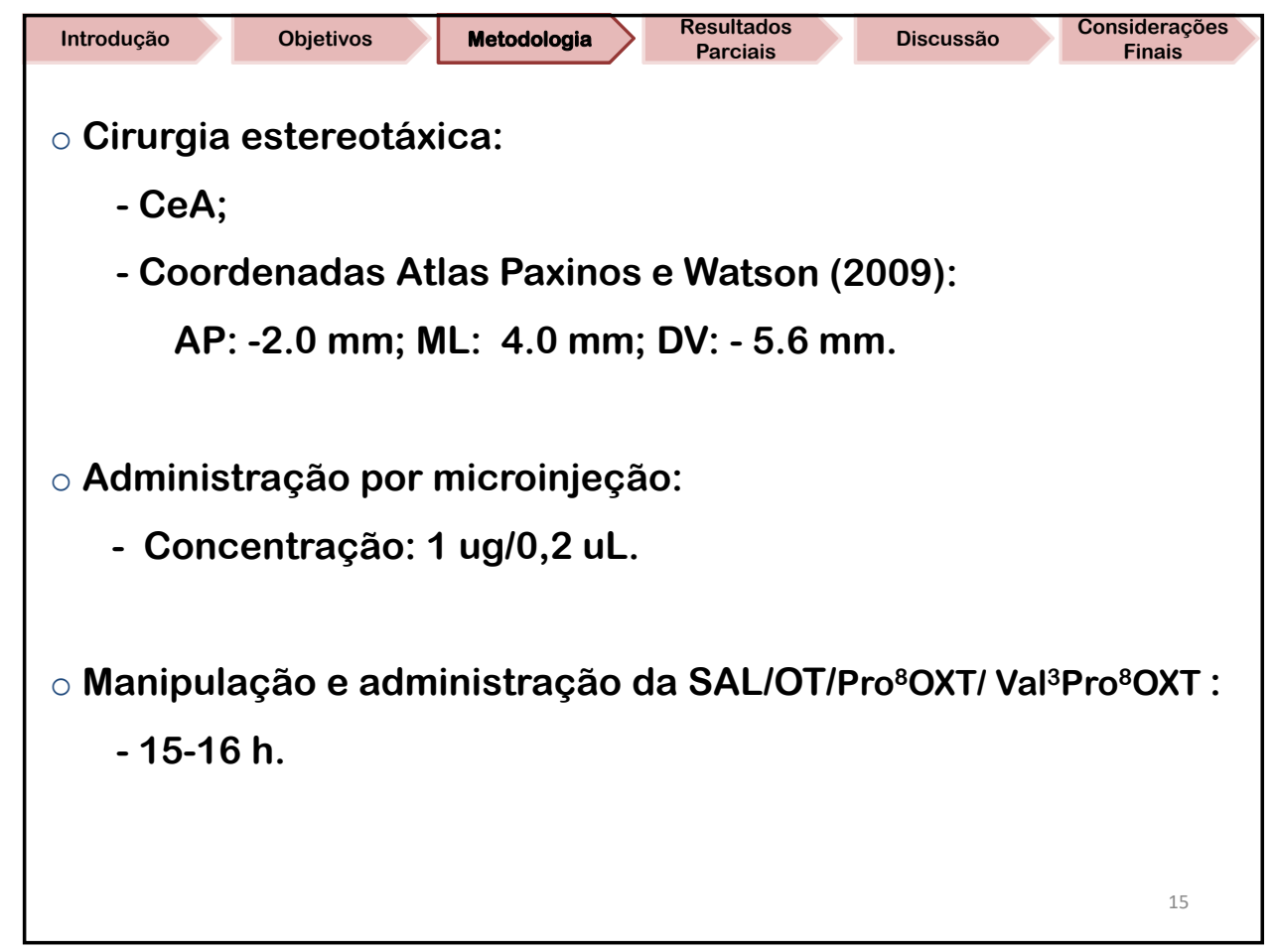

\begin{tabular}{|c|c|c|c|c|c|}
\hline Introdução & Objetivos & Metodologia & $\begin{array}{l}\text { Resultados } \\
\text { Parciais }\end{array}$ & Discussão & $\begin{array}{c}\text { Consideraçöes } \\
\text { Finais }\end{array}$ \\
\hline \multicolumn{6}{|c|}{ - Análise Comportamental } \\
\hline \multicolumn{6}{|c|}{ Tabela 1. Índice de Grooming (Escala de Gispen, 1975) } \\
\hline Siglas & & & Descrição do Com & rtamento & \\
\hline AL & & & Autolimpeza & & \\
\hline ALD & & & Autolimpeza à & reita & \\
\hline ALE & & & Autolimpeza à e & uerda & \\
\hline ALG & & & Autolimpeza de & nitais & \\
\hline CCD & & & Coçar a dir & & \\
\hline CCE & & & Coçar a esqu & & \\
\hline LCB & & & Limpar a ca & & \\
\hline LG & & & Limpar as garras & teriores & \\
\hline $\mathrm{LGD}_{1}$ & & & Limpar a garra ant & or direita & \\
\hline $\mathrm{LGD}_{2}$ & & & Limpar a garra post & ior direita & \\
\hline $\mathrm{LGE}_{1}$ & & & Limpar a garra anter & esquerda & \\
\hline $\mathrm{LGE}_{2}$ & & & Limpar a garra poste & r esquerda & \\
\hline LVF & & & Limpar foci & & \\
\hline LVCA & & & Limpeza de c & & \\
\hline
\end{tabular}



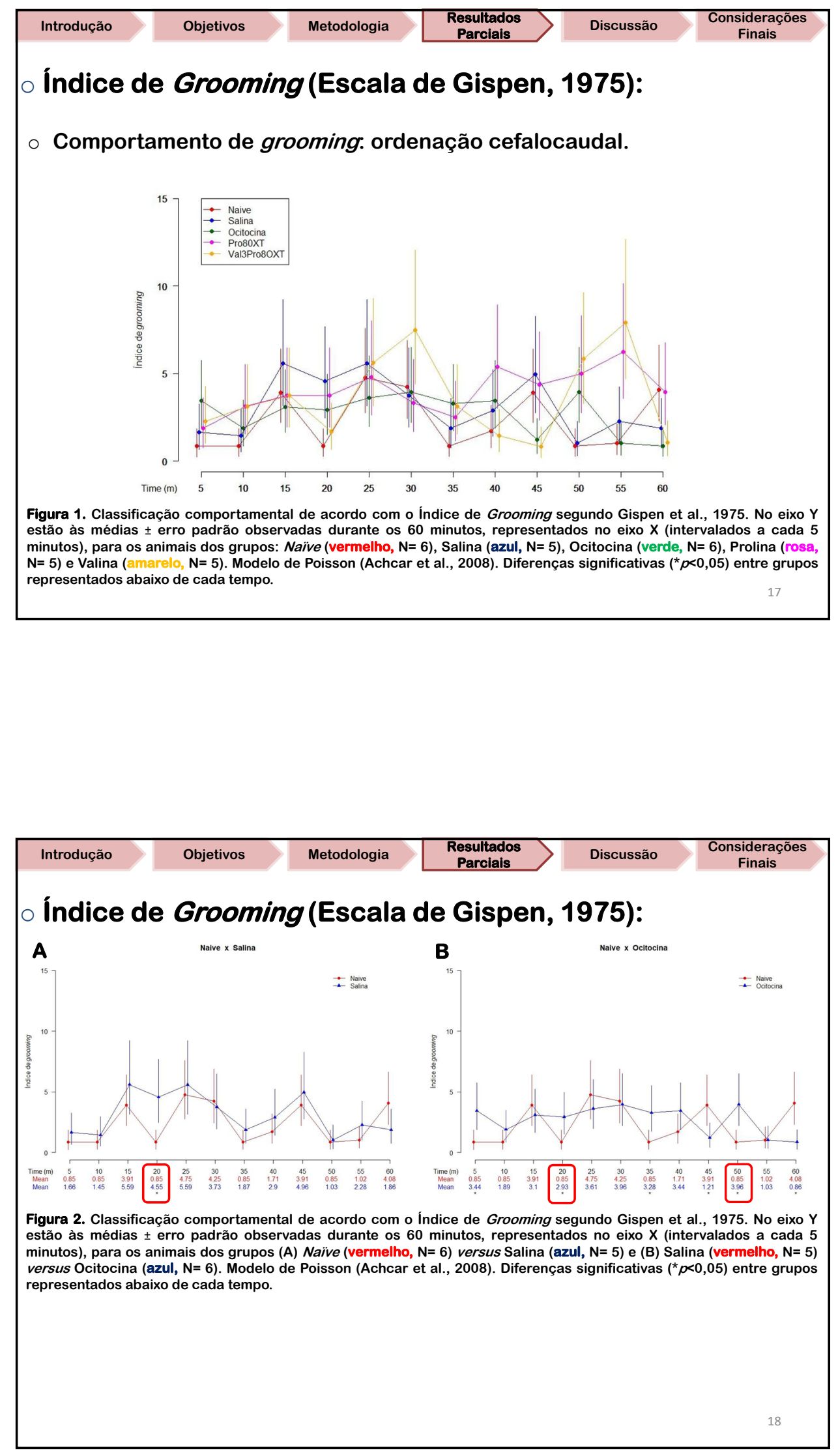


\begin{tabular}{llll|l}
\hline Introdução & Objetivos & Metodologia & $\begin{array}{c}\text { Resultados } \\
\text { Parciais }\end{array}$ & Discussão $>\begin{array}{c}\text { Considerações } \\
\text { Finais }\end{array}$
\end{tabular}

- A Figura 2 (A) acima compara os animais dos grupos Wistar Hannover Naive $(p<0,05)$ e do grupo controle $(S A L)(p<0,05)$, indicando que não houve diferença significativa para o score de grooming dos animais Naive. $\mathrm{O}$ grupo controle apresentou comportamento de hypergrooming em uma janela temporal (20 $\mathrm{min}$ ), indicando que na maior parte do tempo a expressão de hypergrooming não foi observada.

- A Figura 2 (B) compara os grupos Naive $(p)$ e OT $(p<0,05)$, demonstrando que a injeção de OT induziu o comportamento de hypergrooming nos primeiros $5 \mathrm{~min}$, e depois com $20 \mathrm{~min}, 35 \mathrm{~min}, 50 \mathrm{~min}$ e $60 \mathrm{~min}$. Ainda nesta figura, é possível observar que o comportamento de hypergrooming apresentou maior diferença significativa em relação aos animais Naive.

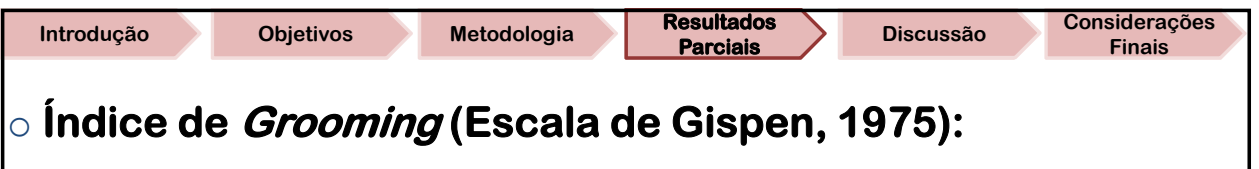

A

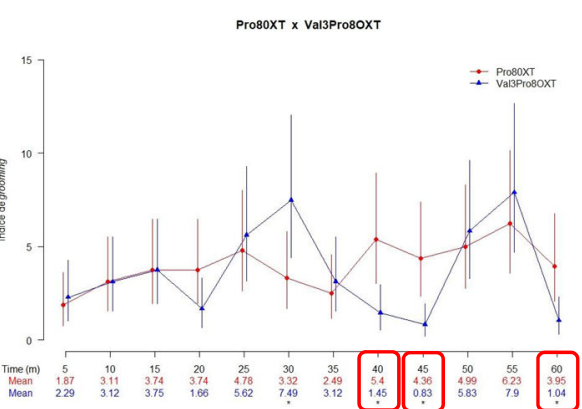

B

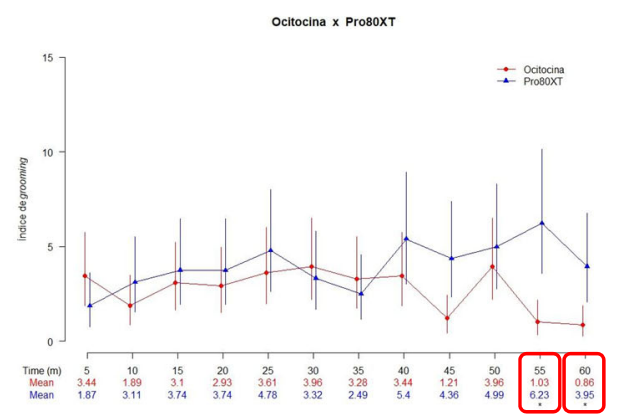

Figura 3. Classificação comportamental de acordo com o Índice de Grooming segundo Gispen et al., 1975. No eixo $Y$ estão às médias \pm erro padrão observadas durante os 60 minutos, representados no eixo $X$ (intervalados a cada 5 minutos), para os animais dos grupos ( $A$ ) Prolina (vermelho, $N=5$ ) versus Valina (azul, $N=5$ ) e $(B)$ Ocitocina (vermelho, $\mathrm{N}=5$ ) versus Prolina (azul, $\mathrm{N}=5$ ). Modelo de Poisson (Achcar et al., 2008). Diferenças significativas $\left({ }^{\star} p<0,05\right)$ entre grupos representados abaixo de cada tempo. 


\begin{tabular}{|c|c|c|c|c|c|}
\hline Introdução & Objetivos & Metodologia & Resultados & & Considerações \\
\hline
\end{tabular}

A Figura 3 (A) compara os grupos Pro ${ }^{8} \mathrm{OXT}(\mathrm{p}<0,05)$ e $\mathrm{Val}^{3} \mathrm{Pro}^{8} \mathrm{OXT}$ $(p<0,05)$, mostrando que as microinjeções apresentam diferenças estatísticas para as janelas temporais de $30 \mathrm{~min}, 40 \mathrm{~min}, 45 \mathrm{~min}$ e $60 \mathrm{~min}$, sendo que a Prolina apresentou diferença em três dessas janelas temporais (40-45 $\mathrm{min}$, e $60 \mathrm{~min}$ ). Evidenciando que a Valina não parece ter um efeito linear ou sustentando ao longo dos $60 \mathrm{~min}$.

- A Figura 3 (B) compara o efeito das microinjeções de OT $(p<0,05)$ e Pro80XT $(p<0,05)$ ao longo do curso temporal do comportamento de grooming. Observamos que a Prolina apresentou diferença estatística quando comparada com a OT nos cinco minutos finais (55-60 min). Indicando um efeito tardio da Prolina.

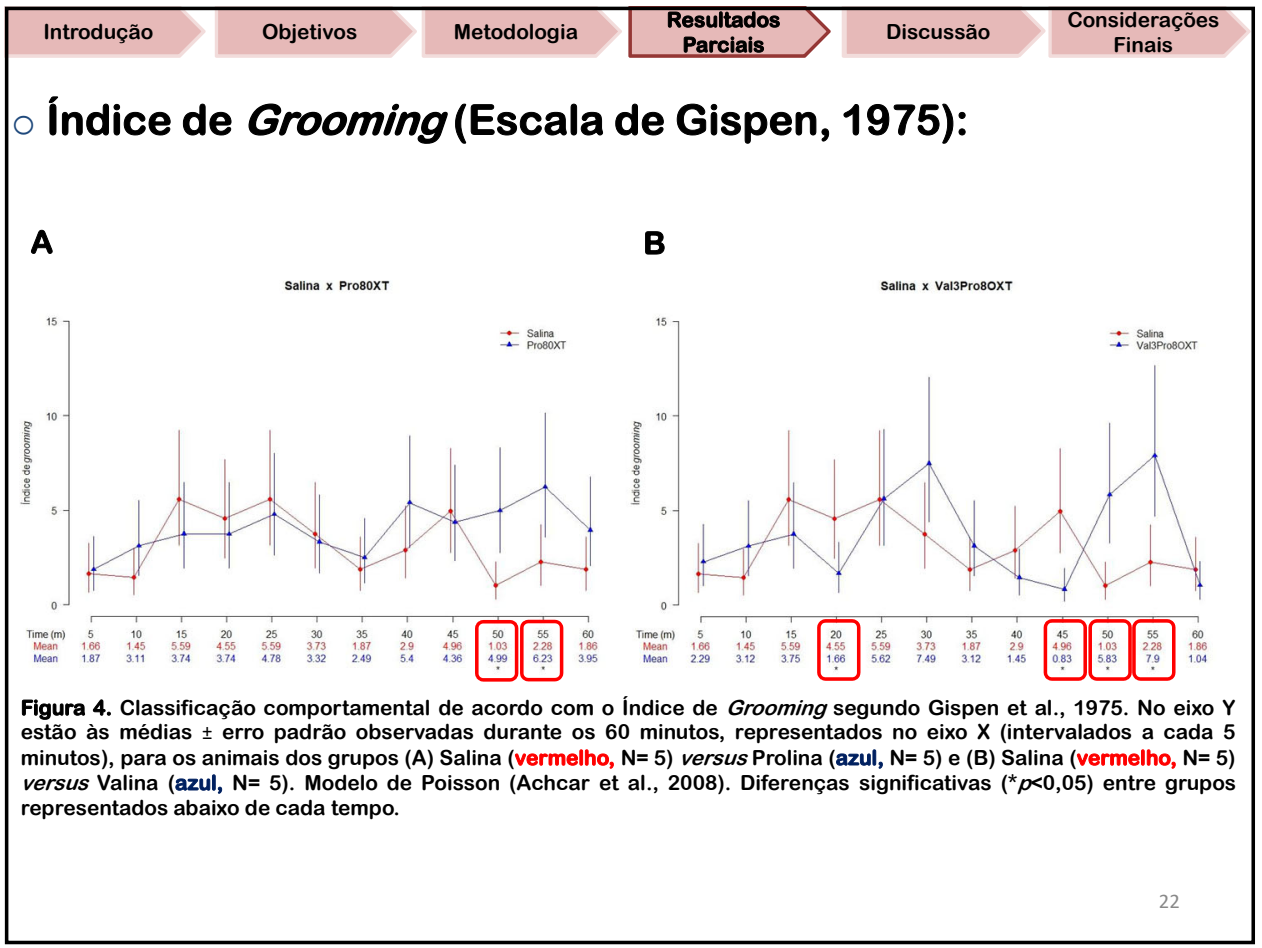




\begin{tabular}{llll|l} 
Introdução & Objetivos & Metodologia & $\begin{array}{c}\text { Resultados } \\
\text { Parciais }\end{array}$ & Discussão $>\begin{array}{c}\text { Considerações } \\
\text { Finais }\end{array}$
\end{tabular}

- A Figura 4 (A) analisa o decurso temporal do comportamento de grooming ao longo de 60 min e compara os grupos Sal $(p<0,05)$ e Pro ${ }^{8} \mathrm{OXT}(p<0,05)$, evidenciando que a Prolina apresentou diferença estatística na janela temporal de 50-55 min, ou seja, a Prolina nesta comparação também apresentou efeito tardio.

- A Figura 4 (B) compara os grupos Sal $(p<0,05)$ e Val $^{3} \mathrm{Pro}^{8} \mathrm{OXT}(p<0,05)$, indicando que houve diferenças estatísticas para o grupo Sal nas janelas temporais de $20 \mathrm{~min}$ e $\mathbf{4 5} \mathrm{min}$, comparado as diferenças estatísticas para o grupo $\mathrm{Val}^{3} \mathrm{Pro}^{8} \mathrm{OXT}$ que foram nas janelas temporais de 50-55 min. Indicando novamente a alternância das médias para o grupo Valina.

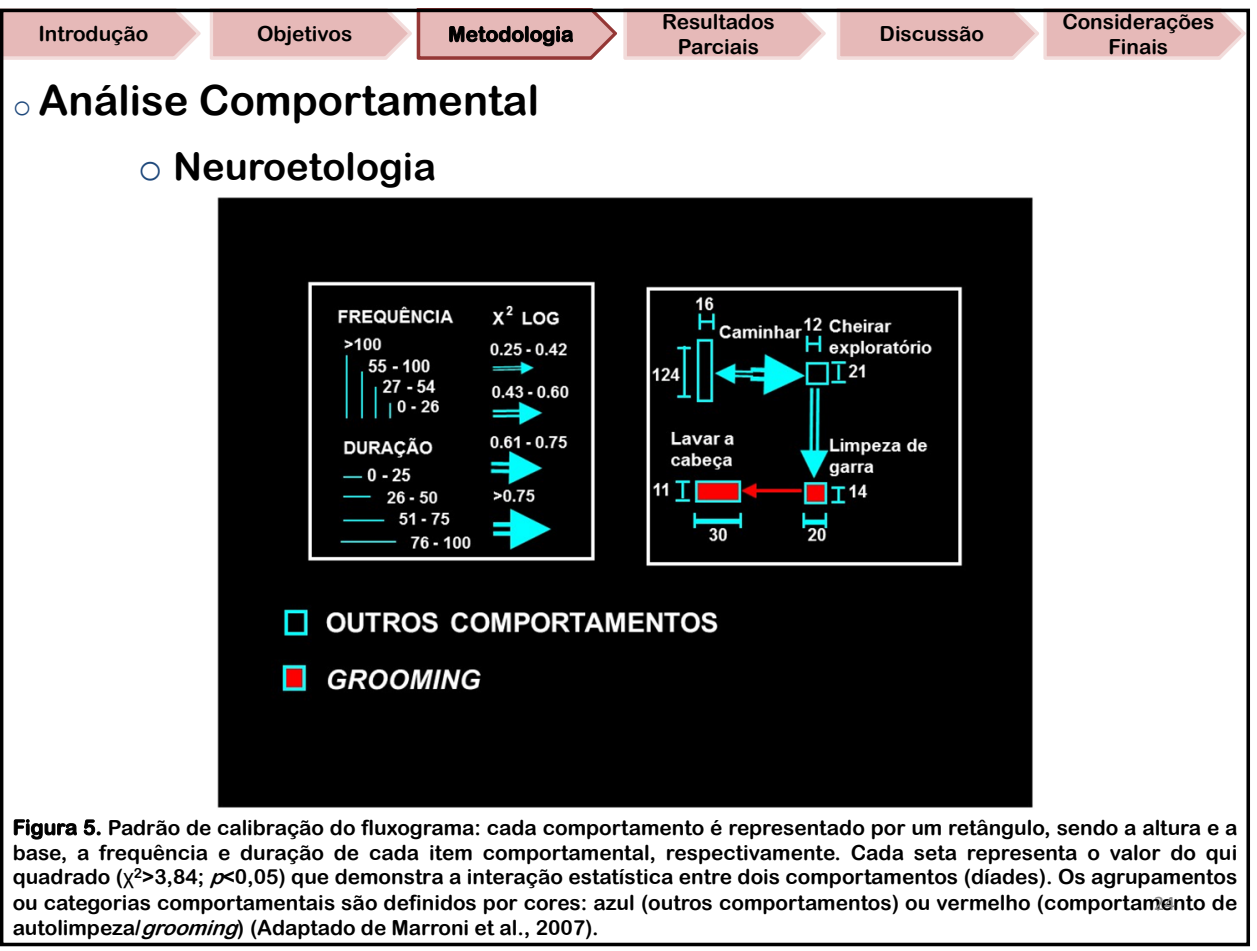




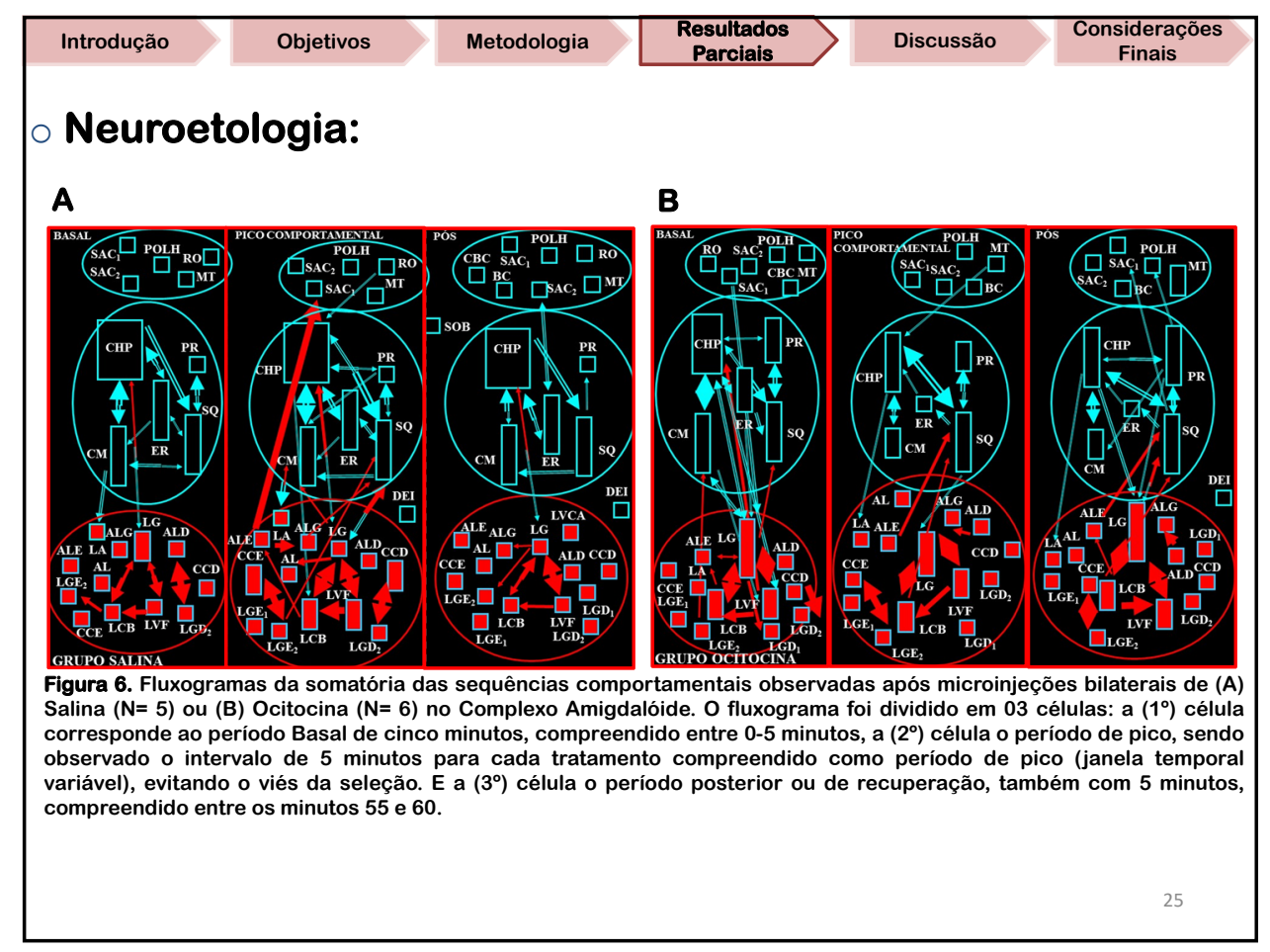

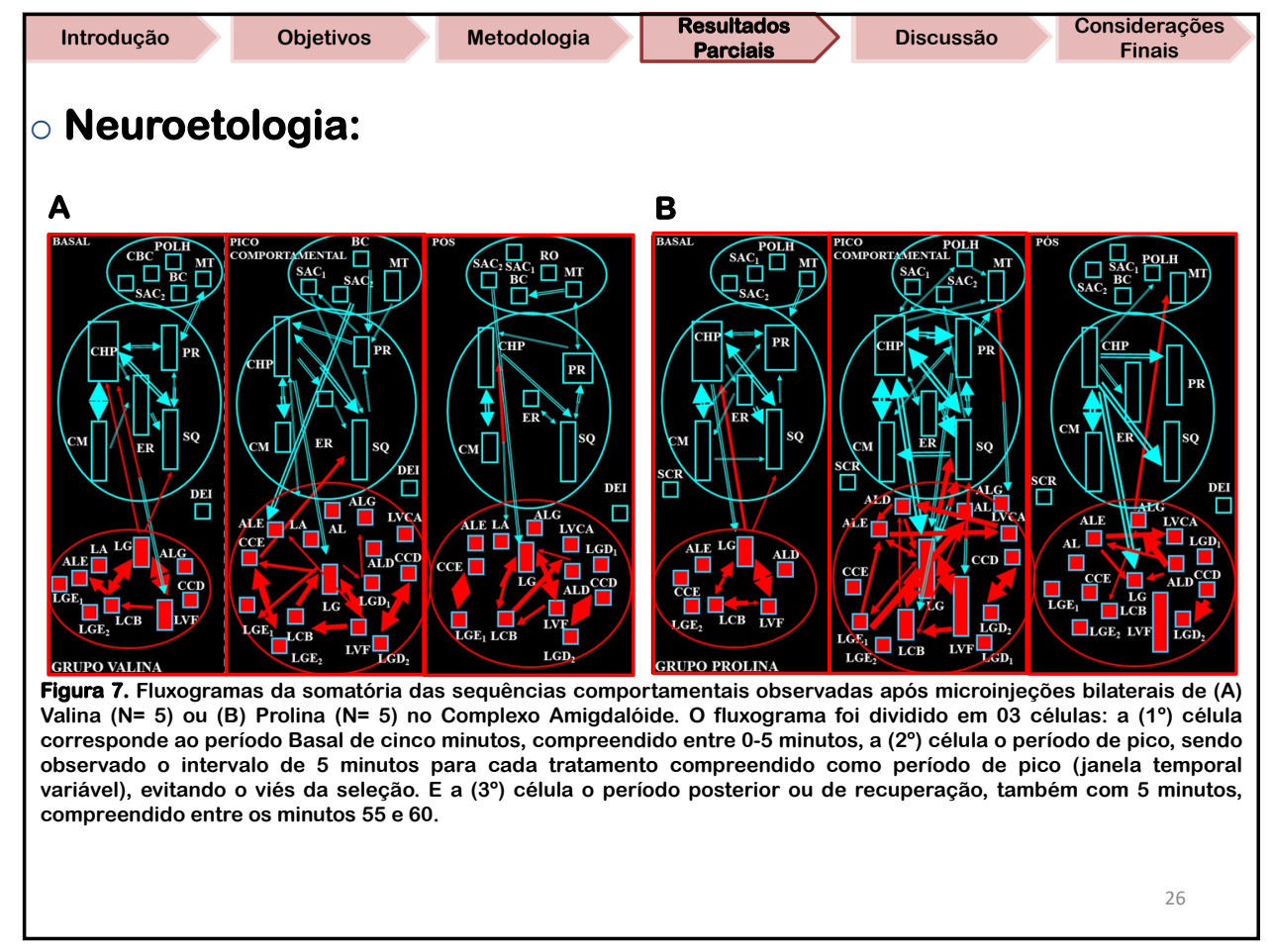




\begin{tabular}{|c|c|c|c|c|c|}
\hline Introdução & Objetivos & Metodologia & $\begin{array}{c}\text { Resultados } \\
\text { Parciais }\end{array}$ & Discussão & $\begin{array}{l}\text { Consideraçōes } \\
\text { Finais }\end{array}$ \\
\hline \multicolumn{6}{|c|}{ o Corte dos Cérebros: } \\
\hline & Áreas & \begin{tabular}{|} 
Córtex \\
Núcleo \\
Subst \\
Área Teg
\end{tabular} & $\begin{array}{l}\text { ré-Frontal } \\
\text { ccumbens } \\
\text { CeA } \\
\text { PVN } \\
\text { SO } \\
\text { cia Nigra ( } \\
\text { ntal Ventr }\end{array}$ & $\begin{array}{l}\text { 'F) } \\
\text { lac) } \\
\text { V) } \\
\text { (VTA) }\end{array}$ & \\
\hline \multicolumn{6}{|c|}{$\circ$ Histoquímica com Azul de Toluidina. } \\
\hline \multicolumn{6}{|c|}{ o Imunoistoquímica para c-Fos. } \\
\hline & & & & & 27 \\
\hline
\end{tabular}

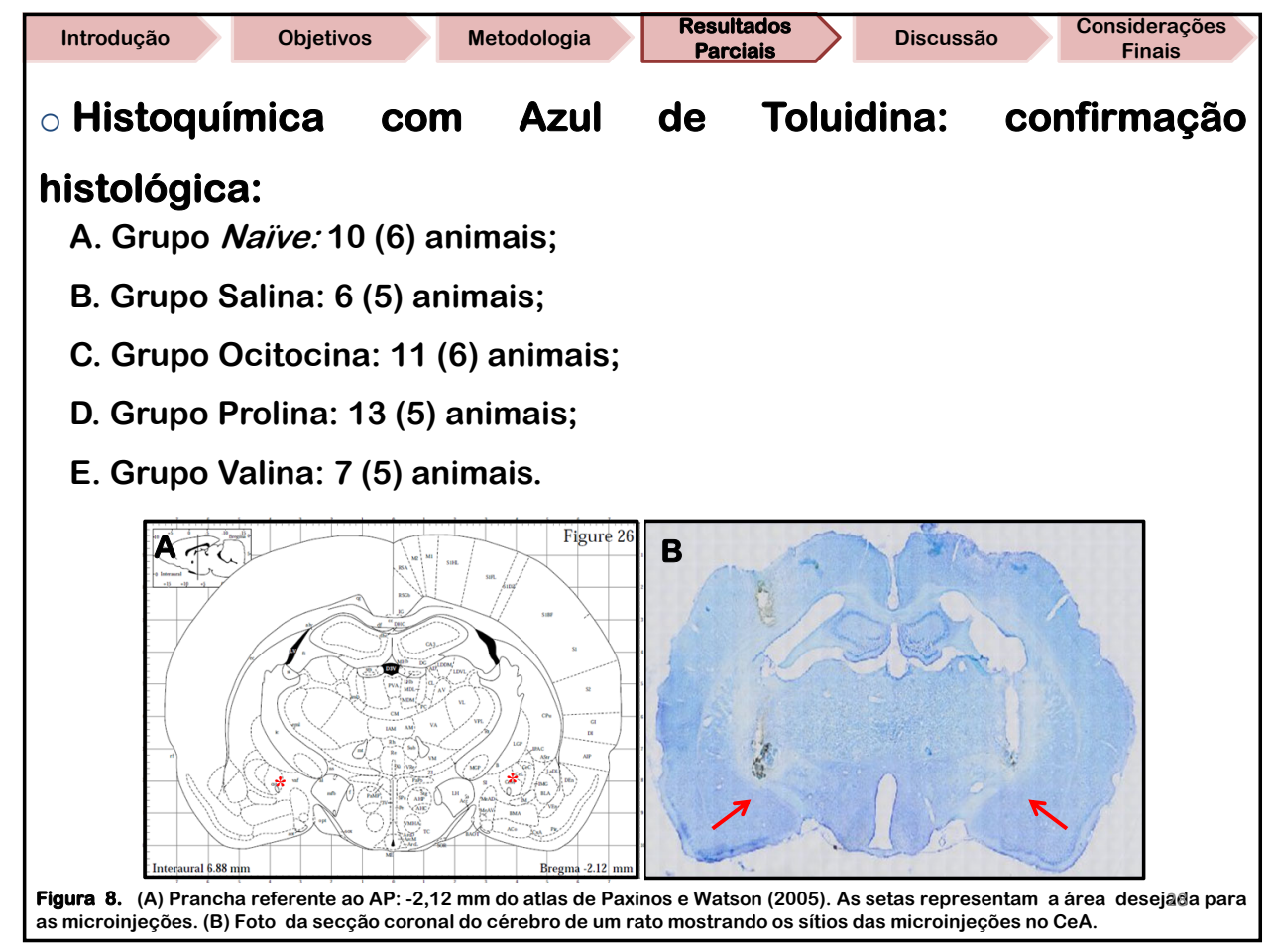



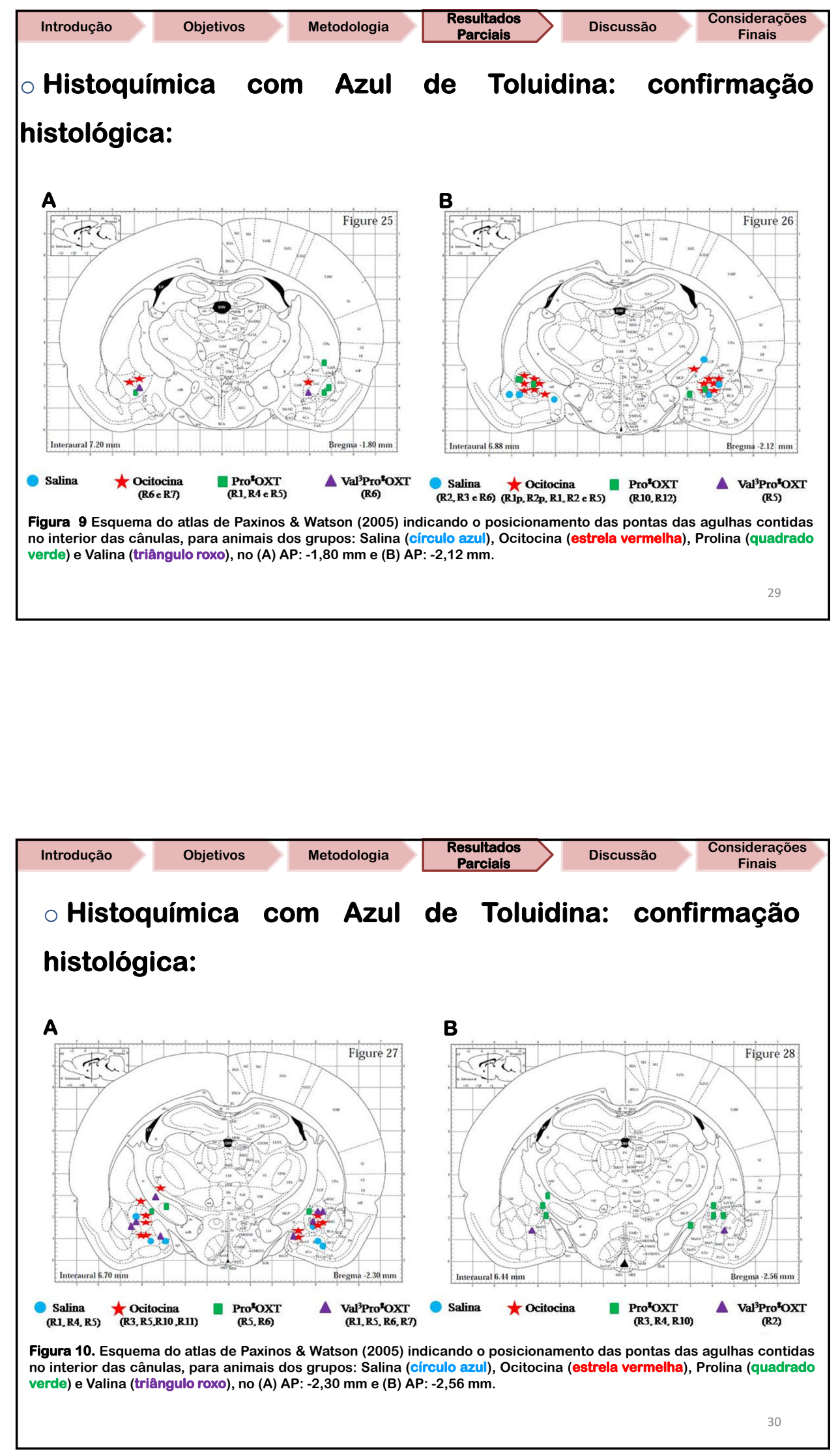

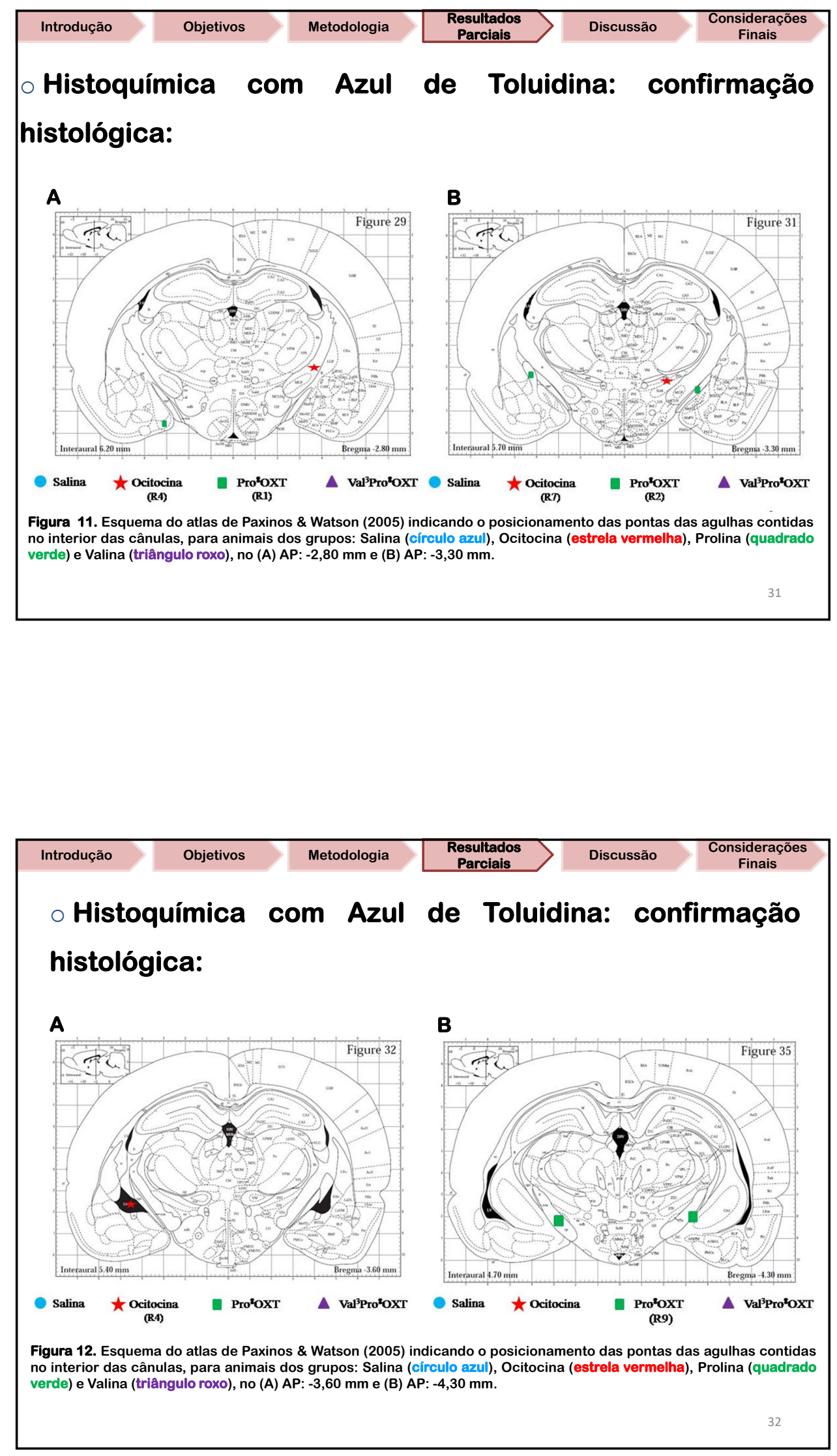


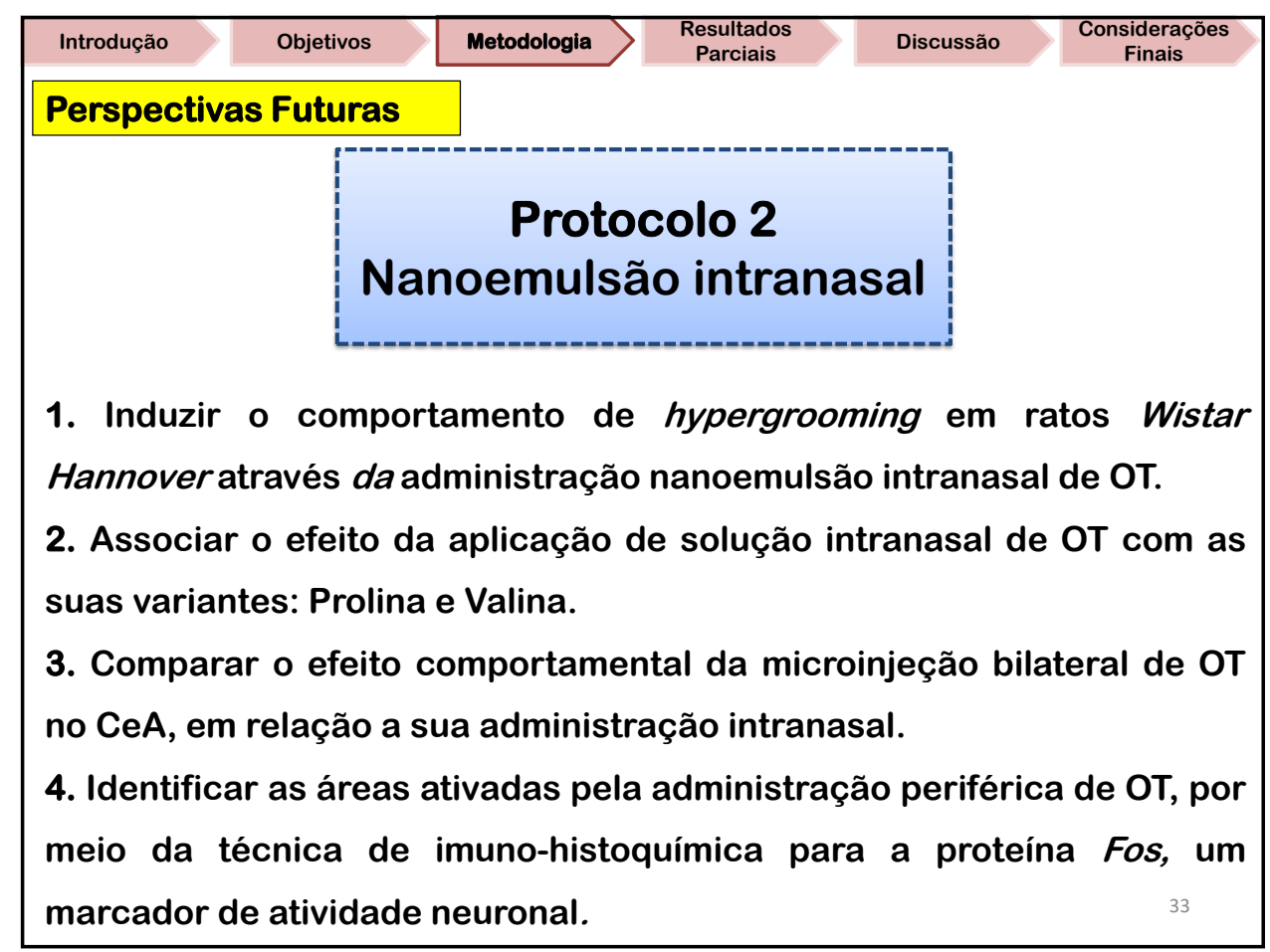

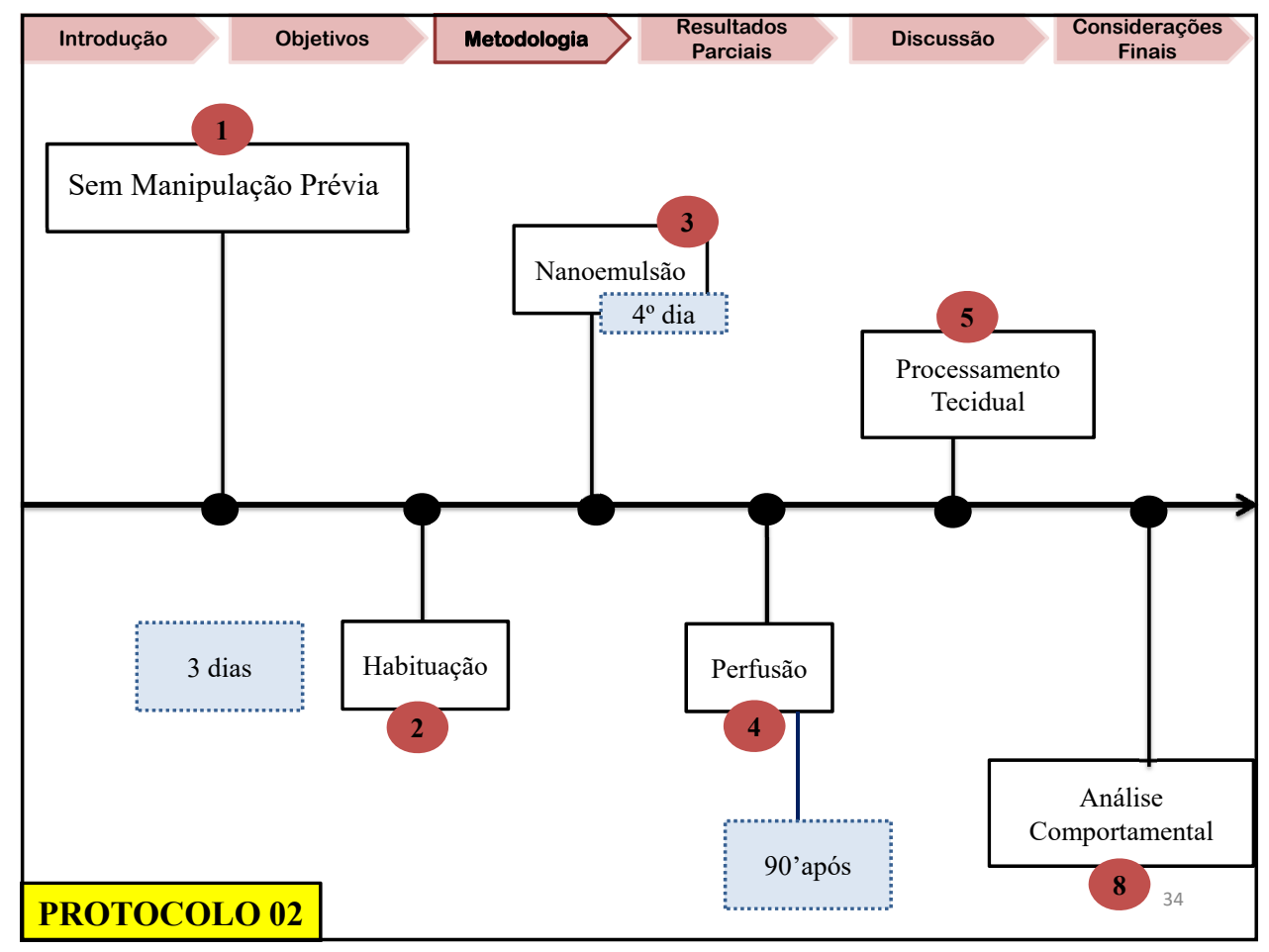




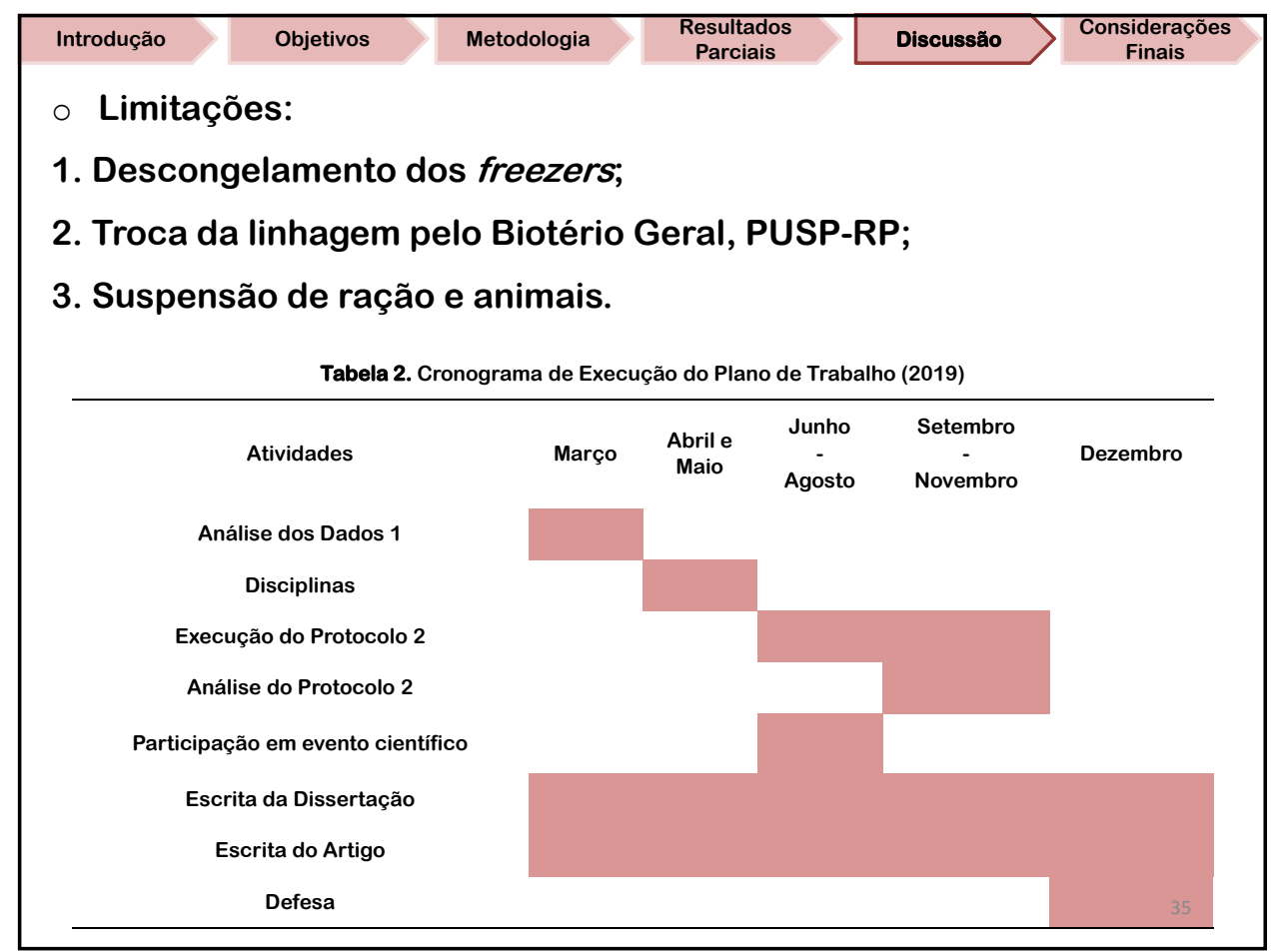

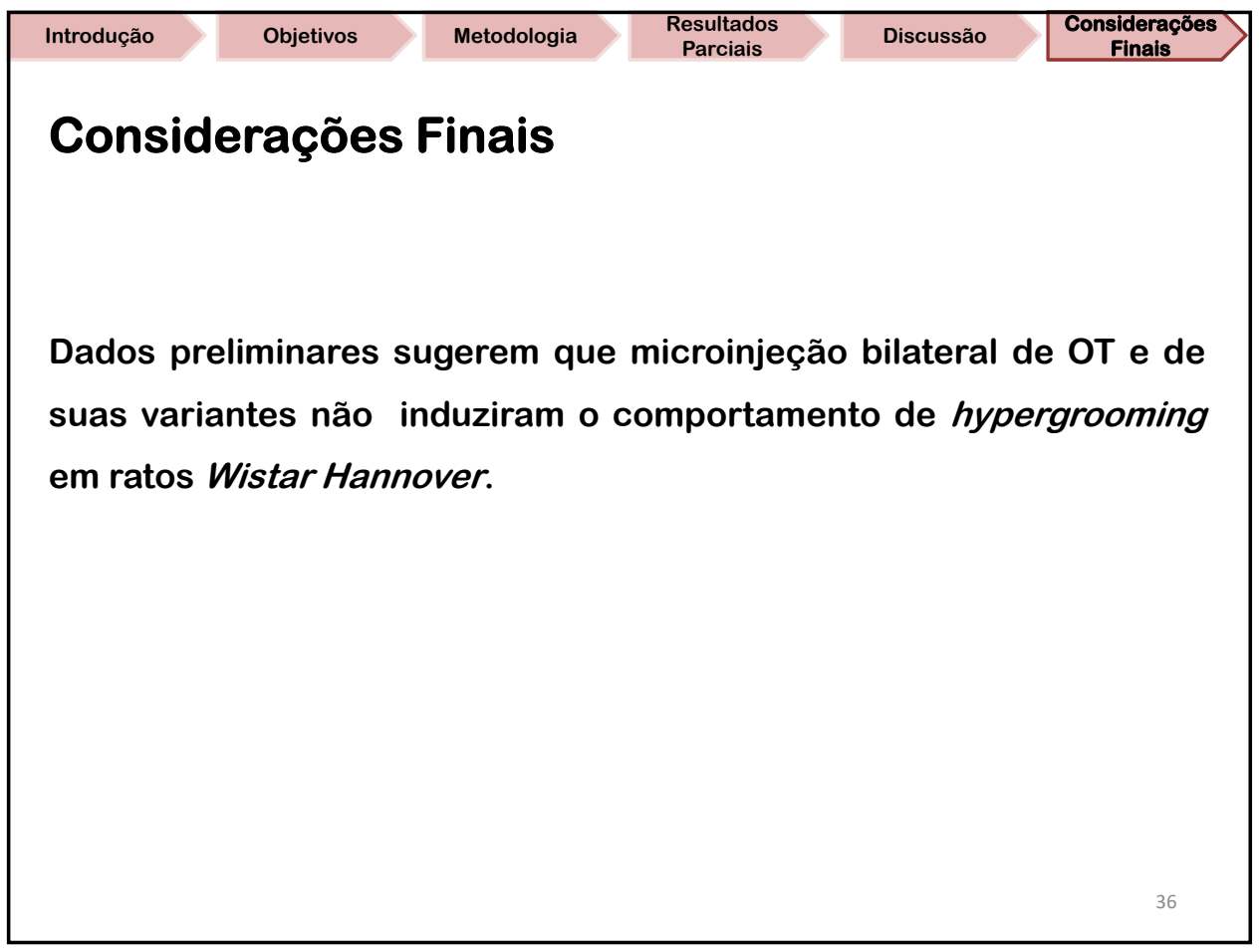




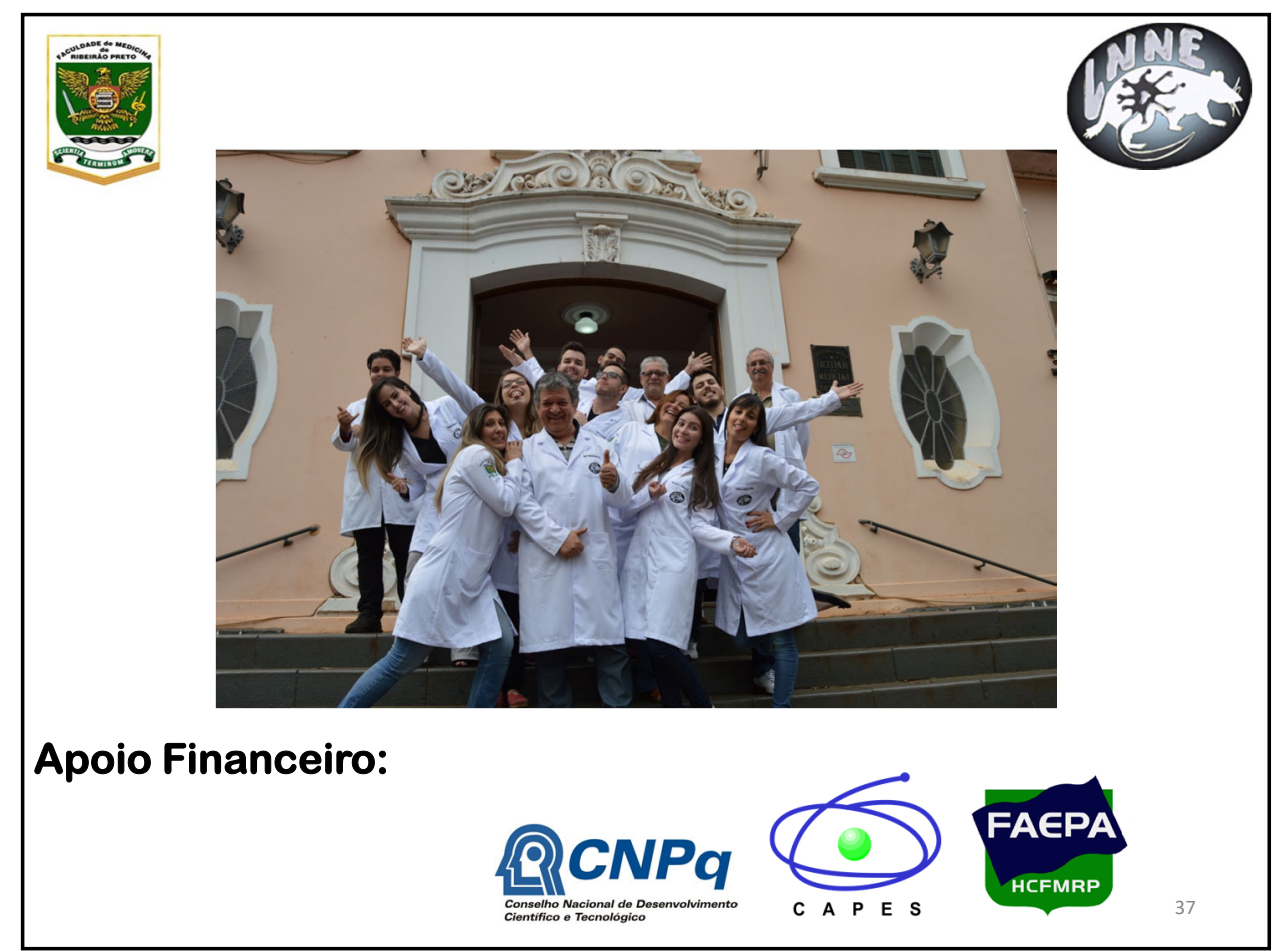

